\title{
Doubling Rice Productivity in Bangladesh: A Way to Achieving SDG 2 and Moving Forward
}

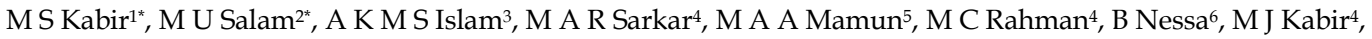 \\ H B Shozib7, M B Hossain ${ }^{8}$, A Chowdhury ${ }^{4}$, M Nasim $^{9}, \mathrm{~K}$ M Iftekharuddaula ${ }^{10}$, M S Hossain ${ }^{11}$, \\ M K A Bhuiyan ${ }^{12}$, B Karmakar13, M S Rahman ${ }^{14}$, M M Haque ${ }^{15}$, M T Khatun ${ }^{6}$, M P Ali16, \\ S M H A Rabbi ${ }^{17}$, P L Biswas ${ }^{18}$, E S M H Rashid ${ }^{19}$ and N M F Rahman ${ }^{5}$
}

\begin{abstract}
Built on deep-rooted political and cultural heritage, 'rice security' is the foundation of 'food security' in Bangladesh. The country has been in production-surplus of rice in the current decade feeding over 165 million people. This on-going 'selfsufficiency momentum' would require to maintain to meet increased demand from growing future population. On developmental side, Bangladesh is placed among the three of the world's fastest growing economies in the years through to 2050. Rice sector would need to match with the pace of this growth. In addition, agriculture sector, that includes rice, is to double the productivity as the government commits to meet the SDG goal 2.3.1. This study addresses those issues through scoping increased rice production and productivity in Bangladesh, developing a plan of work (POW) on translating the scope and designing implementation plans and actions, incorporating efficiency, resilience, stability and sustainability issues, to achieve the POW. The study has used brainstorming, and rigorous analysis to achieve the objectives. The productivity has been explained in terms of yield- and labour-productivity. The developed three-winged 'doubling rice productivity (DRP)' framework directs yield enhancement and production accumulation in unexplored spaces (Wing-1); increased adoption of mechanization to impact on labour productivity (Wing-2), and improvements in nutritional quality and rice-based product diversity, and stabilizing the farmgate price (Wing-3). Analyses show, from the baseline figure of 35.29 MT in 2015, rice production in the country can be raised to 46.90 MT in 2030, 54.09 MT in 2040 and 60.85 MT in 2050 with combined contributions of three pillars - yield improvements by enhanced varietal potential (Pillar 1), reduction in existing yield gap (Pillar 2) and production increase by exploring unexplored spaces for rice (Pillar 3) of Wing-1 of the DRP. This production will produce a surplus of 6.50, 10.29 and 13.65 MT in 2030, 2040 and 2050, respectively, over the production target (40.40, 43.80 and 47.20 MT in 2030 and 2050, respectively). Results further reveal that through scale-appropriate mechanization backed up by estimated fair price, labour productivity in rice will be doubled by 2029, meeting the SDG 2.3.1. Good number of released varieties have been identified to have specific nutritional trait, and value adding quality. We have emphasized on much needed actions on demand-driven research for varietal development and field-adoptable management, mechanization for transplanting and harvesting operations, accommodation of rice in unexplored spaces, farmer-based speedy seed multiplication and dissemination system, establishment of commission for agricultural costs and prices, input buffer stock terminals for managing production risk, long-term storage and export of surplus production, and research-publicity-market development for rice-based products through public-private partnership. It is concluded that efficiency, resilience and sustainability around the three wings of DRP in the rice production systems to be ensured to achieve the rice production, productivity and labour use estimates.
\end{abstract}

Key words: Genetic potential, labour productivity, management potential, mechanization, diffusion-adoption model, space potential, sustainability, yield loss.

${ }^{1}$ Director General, Bangladesh Rice Research Institute (BRRI), Gazipur-1701, Bangladesh; ${ }^{2}$ Freelance Consultant (Agricultural Systems), Bangladesh; ${ }^{3}$ Farm Machinery and Postharvest Technology Division, BRRI, Gazipur-1701, Bangladesh; ${ }^{4} \mathrm{Ag}-$ ricultural Economics Division, BRRI, Gazipur-1701, Bangladesh; ${ }^{5}$ Agricultural Statistics Division, BRRI, Gazipur-1701, Bangladesh; ${ }^{6}$ Plant Pathology Division, BRRI, Gazipur-1701, Bangladesh; ${ }^{7}$ Grain Quality and Nutrition Division, BRRI, Gazipur-1701, Bangladesh; ${ }^{8}$ Irrigation and Water Management Division, BRRI, Gazipur-1701, Bangladesh; ${ }^{9}$ Rice Farming System Division, BRRI, Gazipur-1701, Bangladesh; ${ }^{10}$ Plant Breeding Division, BRRI, Gazipur-1701, Bangladesh; ${ }^{11}$ Training Division, BRRI, Gazipur-1701, Bangladesh; ${ }^{12}$ Agronomy Division, BRRI, Gazipur-1701, Bangladesh; ${ }^{13}$ Adaptive Research Division, BRRI, Gazipur-1701, Bangladesh; ${ }^{14}$ Plant Physiology Division, BRRI, Gazipur-1701, Bangladesh; ${ }^{15}$ Soil Science Division, BRRI, Gazipur-1701, Bangladesh; ${ }^{16}$ Entomology Division, BRRI, Gazipur-1701, Bangladesh; ${ }^{17}$ Biotechnology Division, BRRI, Gazipur-1701, Bangladesh; ${ }^{18} \mathrm{Hybrid}$ Rice Division, BRRI, Gazipur-1701, Bangladesh; ${ }^{19}$ Genetic Resource and Seed Division, BRRI, Gazipur-1701, Bangladesh.

${ }^{*}$ Corresponding Authors' E-mail: kabir.stat@gmail.com (M S Kabir); moinsalam1@gmail.com (M U Salam) 


\section{INTRODUCTION}

Bangladesh will emerge as the $28^{\text {th }}$ largest economy of the world by 2030 and $23^{\text {rd }}$ by 2050, predicts PricewaterhouseCoopers, a leading global accounting firm (PwC, 2017). The firm further projects, the country will be among the three (after Vietnam and India) of the world's fastest growing economies over the period of 20162050. If this happens, and should happen, agriculture will face extra pressure for producing increased food for growing population in the backdrop of diverting resources from this sector to fast-growing non-agriculture sectors. The solution to the challenges is to be the increasing agricultural production efficiency and sustainability.

Bangladesh has been transforming from a traditional agriculture-dominant economy to a modern industrial-based economy (WB, 2007). In such transformation, according to 'structural theory ${ }^{2}$, it is essential that agriculture sector modernizes itself ensuring improved productivity (Adelman, 1984). Productivity is defined here as the output of valued product per unit of resource input (Conway, 1987). There are three basic resource inputs in agriculture - land, labour, and capital. Therefore, measures of productivity could be against any of those resource inputs or their components. For rice, as in other crops, the productivity is usually expressed as yield per hectare (considering landresource input; henceforth we denote it as 'land productivity'); but under circumstances, it can be viewed as yield per labour unit (considering labour-resource input; henceforth we denote it as 'labour productivity').

According to Miah et al. (2020), enhancing labour productivity in agriculture is critical for two aspects: (i) it increases the demand for modern agricultural machinery and tools (sink), and (ii) it releases agricultural labour force to be absorbed in industry (source). The muchneeded industrialization of Bangladesh's developing economy will be highly unlikely without laying a solid foundation of agriculture through increased production and productivity.

Rice is the backbone of Bangladesh's agriculture; here, like in many other countries, 'food security' almost entirely depends on 'rice security' (Brolley, 2015); it alone contributes about $4.5 \%$ to the GDP (BBS, 2020). The crop, both politically- and culturally-sensitive, occupies about $78 \%$ of annual agricultural land (gross cropped area), and currently in production-surplus feeding $\sim 165$ million people (Kabir et al., 2015). The increasing population will demand more rice production in future (although per capita rice consumption is gradually declining), while the continuity of the on-going 'selfsufficiency momentum' will depend on the outcome of land-, labour- and system- productivity. The country will need to increase land productivity because the current production environment will change in future encountering decreasing crop land and labour resources, and increasing climate vulnerability. Side by side, it will also be needed to double the labour productivity as a requirement to meet the SDG 2.3.1, where scale-appropriate mechanization backed up by fair price is to play a crucial role. It may be noted that the government of Bangladesh is fully committed in meeting sustainable development agenda to be a part of 'leave no one behind'.

Stability and sustainability are the two components of production systems that needed to address into productivity in order to ensure

\footnotetext{
${ }^{2}$ Relative weight of significant components of the aggregative indicators of the economy, such as GDP and labour force, by which growth brings about in the economy, which is brought about by resources being transferred between sectors in the economy in response to the changing pattern of consumer demand, technological development and differential rates of productivity growth (more details in Gali et al., 2000).
} 
resilience. As described by Conway (1987), stability is the constancy of productivity in the face of small disturbing forces arising from the normal fluctuations and cycles in the surrounding physical, biological, social and economic environments, such as fluctuations in the climate or in the market demand. Sustainability, on the other hand, is the ability of an agroecosystem to maintain productivity at least equal to or higher compared to long term (3-5 years or even 10-20 years) average yield (Lynam and Herdt, 1989) when subjected to a major disturbing force, such as salinity, erosion, indebtedness, declining market demand, rare drought or flood or what the world is facing now, the zoonotic disease COVID-19.

Considering the food habit of the people of Bangladesh, 'rice security' should also address the 'nutrition security'. In this country, rice is not only the carbohydrate-supplying food, but also the major provider of protein, micronutrients, and health benefits. Antioxidants supplied by rice contribute to relieving oxidative stress, and preventing cancer, cardiovascular problems and complications of diabetes (Shozib et $a l ., 2020)$. In addition to contribution to nutrition security, rice as a commodity could be attractive to consumers beyond its traditional use of 'cooked rice'. Emphasizing research and marketing on rice-based products would boost the morale of stakeholders in increasing rice production and productivity of Bangladesh.

With the above background, this paper aims to present the:

- scope of increasing land- and labourproductivity in the rice sector in Bangladesh to meet the SDG 2.3.1 and taking the momentum further beyond;

- plan of work (POW), translating the scope; and,

- implementation plans and actions to achieve the POW for improving efficiency and sustainability of rice farming.

\section{METHODOLOGY}

\section{Study Approach}

Analysis and synthesis underlying historical, current and future production and/or productivity of rice accounted for this study followed in three dimensions: vertical, horizontal and cross-dimensional. The vertical dimension included yield improvements by enhanced genetic potential (GenPot), and reduction in existing yield loss through every aspect of crop management (ManPot). The horizontal dimension addressed production increase by exploring unexplored spaces for rice (SpacePot), and speeding up the adoption cycle of promising varieties. The farm mechanization, and rice market price risk were analyzed across cross-dimensional aspects. In addition, the study addressed the issues of nutritional improvements, future production and productivity challenges, and highlighted evidence-based successes encountering production environments including those caused by climate change.

\section{The Concept of Doubling Rice Productivity (DRP) Framework}

Ten brainstorming sessions were conducted with the participation of 25 professionals representing national and international rice scientists and senior rice research managers. The first session accumulated all the possible components and sub-components of the concept of the Doubling Rice Productivity (DRP) framework, including the terminologies to be used in the study. Further, discussion included the right definitions of terminologies to be used for the DRP framework. In the second session, a draft of the DRP framework was developed through group discussion. The draft was sent to each of the participants for thorough scrutiny and comments. In the third and final session, the draft DRP framework was finalized by addressing the comments. Each session lasted for about three hours. 
There is a general perception that 'doubling productivity' denotes for 'double the production'. According to the meta data definition of SDG (https://www.sdg.gov.bd/public/files /upload/IndicatorMetadataFiles/5e686b8e024 5e_320_Metadata-02-03-01.pdf), the 'doubling productivity' is expressed as 'doubling labour productivity', which can be achieved through increased production and reduced labour use. In this study, we have adopted 'Doubling Rice Productivity (DRP)' as a concept for sustaining rice production against all the odds. We define DRP as systematic approach for the improvements of rice production system, which will result in incremental progression of yield, expansion of rice area in unexplored lands, widespread adoption of mechanization, enrichment of product quality, ensured fair price, and minimizing risks. Taken all together, DRP inherently will double the rice labour productivity. Here, rice labour productivity is expressed as 'rice labour productivity index', which is an output of DRP.

\section{Measurement of Rice Productivity, Produc- tion and Sensitivity}

Annual rice productivity and production were calculated for the period of 2015 through 2050.

\section{Estimation of varietal yield potential}

$$
\mathrm{VYP}_{\mathrm{a}}=\mathrm{RPTCYL}_{\mathrm{a}} \times \mathrm{RA}_{\mathrm{a}}{ }^{-1} \ldots . \text { Eq. } 1
$$

Where $\mathrm{VYP}_{\mathrm{a}}$ is variety yield potential ( $\mathrm{t} \mathrm{ha}^{-1}$ ), annualized across the varieties and rice growing seasons; $\mathrm{RA}_{\mathrm{a}}$ is the total area under rice in a given year considering all rice growing seasons (million hectare); and RPTCYL $\mathrm{L}_{\mathrm{a}}$ is the annual rice production target (million ton) assuming yield loss will remain at the same percentage in future as of the current level. Data for $\mathrm{RA}_{\mathrm{a}}$ were sourced from published document which accounted for declining rice area (Kabir et al., 2015). RPTCYLa was calculated as follows:

$$
\mathrm{RPTCYL}_{\mathrm{a}}=\mathrm{RPT}_{\mathrm{a}} \times(1-\mathrm{YL})^{-1} \ldots . . \text { Eq. } 2
$$

Where, $\mathrm{RPT}_{\mathrm{a}}$ is the annual rice production target (million ton); YL is the annualized yield loss (expressed as fraction). Data for $\mathrm{RPT}_{\mathrm{a}}$ were sourced from published document (Kabir et al., 2015). YL was calculated in the following section 'Estimation of yield loss and creation of yield loss minimization scenario'.

\section{Estimation of yield loss and creation of yield loss minimization scenario}

The term 'yield loss' is defined here as the 'gap' between potential farm yield and actual farm yield, expressed as percentage of potential farm yield. The loss was previously estimated for rice by the Bangladesh Rice Research Institute (BRRI) as $20.7 \%$ considering yields of major varieties in the research fields and national yields during 2009-2013 (Kabir et al., 2015). This loss is related to crop management. BRRI in its earlier study, did not partition the yield loss by management components. For the requirement of this study, the overall yield loss estimated by BRRI $(20.70 \%)$ partitioned into 14 components using three tools - literature search, brainstorming and expert consultation. The management component specific collated yield loss figures from literature were discussed, debated and compiled in 12 brainstorming sessions participated by 25 multidisciplinary rice experts of national and international repute. The management component-wise yield loss table was sent to senior scientists of respective disciplines for their comments and observations. Finally, the management component-wise yield loss figures were finalized by rigorous discussion on the comments and observations with selected 25 multidisciplinary rice scientists.

The yield loss minimization scenario was analyzed using the following equation:

$$
\mathrm{YL}_{\mathrm{cy}}=\mathrm{YL}_{\mathrm{py}}-\left(\mathrm{YL}_{\mathrm{py}} \times\left(\mathrm{YL}_{\mathrm{mc}} / 100\right)\right) \ldots . . \mathrm{Eq} \cdot 3
$$


Where, $\mathrm{YL}_{\mathrm{cy}}$ is the yield loss in current year (\%), $\mathrm{YL}_{\mathrm{py}}$ is the yield loss in previous year (\%) and $\mathrm{YL}_{\mathrm{mc}}$ is the yield loss minimization constant; this constant was assumed as 3 (\% per year) aiming the yield loss reduced to around $7 \%$ in 2050 from the baseline figure of $20.61 \%$.

\section{Estimation of production in the unexplored spaces}

Based on current land utilization status and rice cropping suitability, five spaces were identified through 'expert consultation'. They are: (i) Space 1: Greater Barishal region; (ii) Space 2: North-eastern Bangladesh predominantly greater Sylhet region; (iii) Space 3: South-west and greater Jashore region; (iv) Space 4: Coastal charland in greater Barishal region and Noakhali district; and (v) Space 5: Chattogram hill tracts especially Kaptai lake areas.

On a five-year time-step (beginning at 2020 through to 2050), rice area and yield for each space were estimated by 'expert consultation'. Space-wise rice production (million ton) for each time-step was calculated by multiplying yield by area.

The production was estimated by regressing the rate of total production (million ton) of the five unexplored spaces over seven timesteps, as depicted in the following equation:

$$
\mathrm{Y}=\alpha+\beta \mathrm{t} \ldots . . \text { Eq. } 4
$$

Where, $\mathrm{Y}$ is the total production (million ton) of the five unexplored spaces (SpacePot) and $t$ is the year from 2020 to 2050 . The estimated coefficient for $\alpha$ and $\beta$ was -25.2706 and 0.012841, respectively.

\section{Estimation of production flow and production targets}

The total production of rice (million ton) in a given year was calculated as the sum of production contribution improved genetic potential, yield gap minimization, and cropping in the unexplored area (described in Section 'Estimation of production in the unexplored spaces').

The production contribution improved genetic potential was estimated using the following equation:

$$
\mathrm{PC}_{\mathrm{igp}}=\mathrm{RPTCYL}_{\mathrm{a}}-\mathrm{PL}_{\mathrm{yl}} \ldots \text {...Eq. } 5
$$

Where, $\mathrm{PC}_{\text {igp }}$ is the production contribution from improved genetic potential; and RPTCYLa is the annual rice production target (million ton) assuming yield loss will remain at the same percentage in future as of the current level [Eq. 2]; and PLyl is the production loss due to yield loss (million ton), calculated as follows:

$$
\mathrm{PL}_{\mathrm{yl}}=\mathrm{RPTCYL}_{\mathrm{a}} \times(\mathrm{YL} / 100) \ldots . . \text { Eq. } 6
$$

Where, RPTCYL $\mathrm{L}_{\mathrm{a}}$ is the annual rice production target (million ton) assuming yield loss will remain at the same percentage in future as of the current level [Eq. 2]; and YL is the annualized yield loss (expressed as fraction), the value estimated in the study (Section 'Estimation of yield loss and creation of yield loss minimization scenario').

The production contribution from yield loss minimization $\left(\mathrm{PC}_{\mathrm{ylm}}\right)$ was estimated using the following equation:

$$
\mathrm{PC}_{\mathrm{ylm}}=\mathrm{PL}_{\mathrm{yl}}-\mathrm{RPTCYL}_{\mathrm{a}} \times\left(\mathrm{YG}_{\mathrm{cy}} / 100\right) \ldots . . \text { Eq. } 7
$$

Where, $P L_{y l}$ derived from Eq. 6; RPTCY $L_{a}$ from Eq. 2 and $\mathrm{YL}_{\mathrm{cy}}$ from Eq. 3.

The production contribution from production gain from unexplored space ( $\left.\mathrm{PC}_{\text {gua }}\right)$ was estimated by regressing total production (million ton) of the five unexplored spaces (Section 'Estimation of production in the unexplored spaces') over seven time-steps $(2020,2025,2030$, 2035, 2040, 2045 and 2050), as depicted in the following best-fitted third-order polynomial equation:

$$
\left.\mathrm{PC}_{\text {gua }}=\alpha+\beta_{1} \mathrm{t}+\beta_{2} t^{2}+\beta_{3} t^{3}\right) \ldots . \text { Eq. } 8
$$


Where, the estimated coefficient for $\alpha, \beta_{1}, \beta_{2}$ and $\beta_{3}$ was $0,2.074274737,-0.002122457$ and 0.00000054 , respectively.

Two target production was set based on assumptions: (i) production will be driven by improved genetic potential, while no contribution from yield loss minimization and gain from unexplored space; and (ii) production will be driven simultaneously by improved genetic potential, yield loss minimization and gain from unexplored space.

\section{Demand domain of production flow}

The total rice demand was estimated by accounting human and non-human consumption requirements per annum in Bangladesh. The human consumption demand is the sum of per capita annual requirement of the total population of the country. The non-human consumption demand is the sum of the need for seed, feed, industrial use, and wastage for harvest operation, post-harvest losses, and processing losses per annum. The total rice demand was estimated based on the equations below:

$$
\begin{array}{r}
T_{R D_{i}}=H C_{i}+N H C_{i} \ldots . . \text { Eq. } 9 \\
\mathrm{HC}_{\mathrm{i}}=\mathrm{PoP}_{\mathrm{i}} \times(\mathrm{CR}+\mathrm{PR}+\mathrm{FR}+\mathrm{PoR}+\mathrm{RC}) \ldots \ldots \text { Eq. } 10 \\
N H C_{i}=S_{i}+F_{i}+\mathrm{IU}_{i}+\mathrm{HL}_{i}+\mathrm{PHL}_{i}+\mathrm{PL}_{i} \ldots . . \text { Eq. } 11
\end{array}
$$

Where, $T R D_{i}$ is the total rice demand for $\mathrm{i}^{\text {th }}$ year; $\mathrm{HC}_{\mathrm{i}}$ is the human consumption for $\mathrm{i}^{\text {th }}$ year; $\mathrm{NHC}_{\mathrm{i}}$ is the non-human consumption for $\mathrm{i}^{\text {th }}$ year; $\mathrm{PoP}_{\mathrm{i}}$ is population for $\mathrm{i}^{\text {th }}$ year; $\mathrm{CR}_{\mathrm{i}}$ is per capita clean rice consumption for $i^{\text {th }}$ year; $P R_{i}$ is per capita puffed rice consumption for $\mathrm{i}^{\text {th }}$ year; $\mathrm{FR}_{\mathrm{i}}$ is per capita flattened rice consumption for $\mathrm{i}^{\text {th }}$ year; $\mathrm{PoR}_{\mathrm{i}}$ is per capita popped rice consumption for $i^{\text {th }}$ year; $R C_{i}$ is per capita rice cake consumption for $\mathrm{i}^{\text {th }}$ year; $S_{i}$ is seed requirement for $i^{\text {th }}$ year; $F_{i}$ is feed demand for $i^{\text {th }}$ year; $I U_{i}$ is industrial use for $i^{\text {th }}$ year; $\mathrm{HL}_{\mathrm{i}}$ is wastage for harvest operation for $i^{\text {th }}$ year; $\mathrm{PHL}_{\mathrm{i}}$ is post-harvest losses for $\mathrm{i}^{\text {th }}$ year and, $P L_{\mathrm{i}}$ is processing losses for $i^{\text {th }}$ year; where, $i=1,2,3 \ldots n^{\text {th }}$ year.
Data, which included decreasing trend in per capita rice consumption, were sourced from Kabir et al. (2015) and, estimated through to 2050 using the linear equation model.

\section{Estimation of labour productivity}

A rice labour productivity framework was developed accounting for area, production, price, and farm power (Fig. 1). The estimation of labour productivity in rice cropping considered five parameters on an annual-step: (i) country's total labour force, (ii) proportion of agricultural labour, (iii) proportion of rice labour, (iv) rice production target including safety net, and (v) rice market price. Data of total labour force sourced from literature and, as required, estimated through to 2050 using standard statistical procedures (Eq. 15). When data were not available, assumptions were made based on 'expert opinion'.

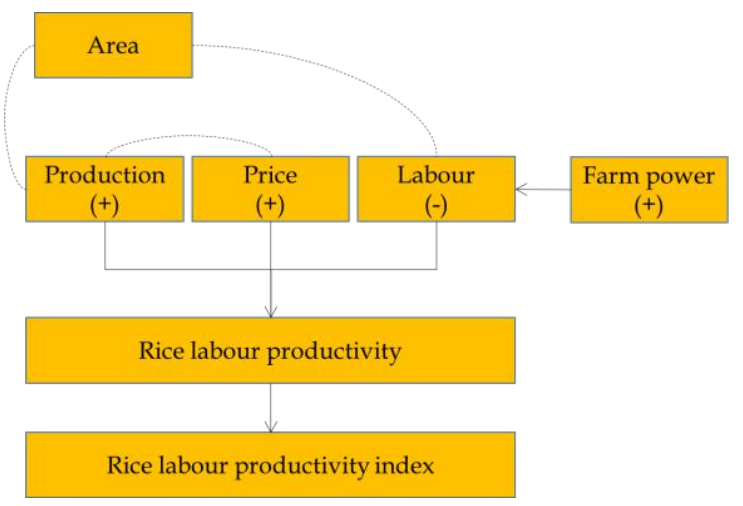

Fig. 1. A framework for increasing rice labour productivity in Bangladesh. The signs ' + ' and ' - ' denotes for the factors contributing positively and negatively, respectively, to the productivity. The solid and dotted lines represent direct and indirect effect in the system, respectively.

The labour productivity was estimated using the following equation:

$$
\mathrm{RLP}_{\mathrm{d}}=\operatorname{ReRLP}_{\mathrm{d}} \times \mathrm{RP} \times \mathrm{DWH} \ldots . . \text { Eq. } 12
$$

Where, $R P_{d}$ is rice labour productivity as BDT labour ${ }^{-1}$ day $^{-1} ;$ ReRLP $_{d}$ is the rice equivalent RLP as $\mathrm{kg}$ labour $^{-1}$ day $^{-1}$; RP is price of rice as BDT 
$\mathrm{kg}^{-1}$; and DWH is the daily work hour. The value of DWH was set as 8 in the line of daily standard work hours. The base value of RP was

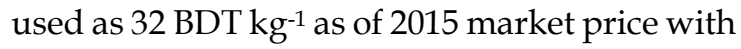
incremental increase @3\% year ${ }^{-1}$ in the subsequent years by adjusting inflation. The incremental values were estimated using data from 1991-2017 (FAOSTAT: http:/ / www.fao.org/fa ostat/en/\#data/PP). The ReRLP d $_{\mathrm{d}}$ was calculated using the following equation:

$$
\operatorname{ReRLP}_{\mathrm{d}}=\left(\mathrm{RPT}_{\mathrm{aasn}} / \mathrm{RL}_{\mathrm{av}}\right) \times \mathrm{CF} \ldots . . \text { Eq. } 13
$$

Where, $\mathrm{RPT}_{\text {aasn }}$ is the $\mathrm{RPT}_{\mathrm{a}}$ (the annual rice production target in million ton; sourced from Kabir et al., 2015, see Eq. 2) adjusted by adding 0.6 MT year ${ }^{-1}$ as safety net; $R L_{a v}$ is the annual available rice labour (million by number); and CF is the conversion factor for adjusting ton to kilogram and year to day. The $\mathrm{RL}_{\mathrm{av}}$ was calculated using the following equation:

$$
\mathrm{RL}_{\mathrm{av}}=\mathrm{TaLF} \times \operatorname{PrALF} \times \operatorname{PrRLF} \ldots . . . \text { Eq. } 14
$$

Where, TaLF is the total annual labour force (million by number); PrALF is the proportion of TaLF available for agricultural production; and PrRLF is the proportion of PrALF available for rice production, assumed as $60 \%$ (expert opinion). The TaLF was estimated using ILO data for the period of 2000 - 2017 (ILO, 2020) and projecting through to 2050 using the following linear equation for the years 2018 - 2050:

$$
\mathrm{TaLF}=\alpha+\beta \mathrm{t} \ldots . . \text { Eq. } 15
$$

Where, ' $t$ ' is the time expressed as year. The estimated coefficient for $\alpha$ and $\beta$ was -2105.16698 and 1.076708911, respectively.

The productivity index was expressed as the ratio of $\mathrm{RLP}_{\mathrm{d}}$ of the base year (2015) to the RLP $_{\mathrm{d}}$ of the forwarding years through to 2020. The clean rice price and farm power availability were regressed on the years of the study period (2015 - 2050). The data of farm power availabil- ity were analyzed through an exponential equation using data from the literature (Mottaleb and Krupnik, 2015; MOA, 2016; Ahmmed, 2017; Islam, 2018; Alam, 2019).

\section{Sensitivity analysis - the approach and execution}

The composition of future rice production in Bangladesh is presented in the study by accounting for three pillars of Wing-1 (incremental volume of production) of DRP Framework: yield improvements by enhanced genetic potential (GenPot, Pillar 1), reduction in existing yield loss through improved management (ManPot, Pillar 2) and production increase by exploring unexplored spaces for rice (SpacePot, Pillar 3). Two targets of future rice production were set: (i) reference minimum production to achieve (Ref-MinPro) and (ii) the reference maximum production potential (Ref-MaxPro).

Sensitivity of future rice production was studied under four scenarios: (i) zero success $(0 \%)$ in the interventions as planned in relation to the three pillars, or in other words, progress will remain halted as it is as of now; (ii) $25 \%$, (iii) $50 \%$ and (iv) $75 \%$ success in the interventions across the three pillars. The analysis undertook quantifying the impact four sensitivity circumstances on the production targets. The outputs of the four scenarios were compared with the set of annual rice production target (RPTa) and expressed as percent change. In the same way, the sensitivity of the labour productivity was analyzed and compared.

\section{Mechanisms for speeding up adoption-cycle}

A new 'Generic rice variety adoption' (GRVA) model was developed by using cumulative Beta distribution function (Salam et al., 2003), and parameterizing with data of variety adoption rate. For this purpose, long-term (1991-2018) data of 
nine varieties were sourced from the Agricultural Economics Division of BRRI (Rice Database, BRRI website: www.brri.gov.bd).

The accelerated diffusion for newly released rice varieties (AD4NRV) model was newly developed based on a blueprint. The blueprint was constructed through a small group discussion.

An experimental sensitivity was conducted in a four-by-four matrix of two factors (auxiliary variables): amount of base seed available from research institute $(500,600,700$ and $800 \mathrm{~kg}$ ) and farmers seed retention $(20 \%, 25 \%, 30 \%$ and $35 \%$ of produced seeds). Two outputs - number of demos to be need and adoption in percent area were compared with three reference of points (current adoption peak of 16 years (LAP16), the peak cut by 3 (LAP13), and 6 (LAP10) years.

\section{Approaches of Adding Value to Rice}

A profile of nutritional status and potential product diversity of BRRI-released varieties were developed based on nutraceutical properties with reference to BRRI threshold. The nutraceutical properties, including grain quality, were assessed following standard methods referenced in the Table 1.

\section{Identification of Rice Production Challenges, and Measuring Successes in Productivity}

An outline of current rice production environment of Bangladesh was composed using perception, idea and information from literature and expert consultation.

\section{Estimation of yield trend of clean rice}

The trend in clean rice yield was estimated by fitting the five-year averaged data using an exponential growth model during the period of 1960 to 2015. The national data was sourced from FAOSTAT (http:/ / www.fao.org/faostat/ en/\#data/QC). The trend line was forwarded to 35 years through to 2050 .

\section{Relationship between climate variables and rice yield}

The potential evapotranspiration $\left(\mathrm{ET}_{0}\right)$ was calculated for Boro rice season using monthly average historical weather data for the period of 1981 to 2016 sourced from the Bangladesh Meteorological Department (BMD). The weather variables, included minimum temperature, maximum temperature, relative humidity, wind speed and bright sunshine hours, used as inputs of the FAO developed Cropwat8.0 model (Allen et al., 1998) to obtain $\mathrm{ET}_{0}$. Sen's slope estimator (Sen, 1968) was applied in the model for estimating long-term changes in the $\mathrm{ET}_{0}$. To relate the estimated changes in $\mathrm{ET}_{0}$ to Boro rice, the yield data were obtained from the Bangladesh Bureau of Statistics (BBS, 2018). We used the yield data for four Department of Agricultural Extension (DAE) designated regions Faridpur, Khulna, Mymensingh, and Rajshahi. We purposely selected the four regions because the estimated $\mathrm{ET}_{0}$ of the regions had shown marked decline in $\mathrm{ET}_{0}$ over the years.

The relationship between country-averaged annual temperature and national rice yield for the period 1961 to 2016 was estimated. For this, rice yield data were obtained from Bangladesh Bureau of Statistics (BBS 2018), and the temperature data from the International Rice Research Institute (IRRI) (http://ricestat.irri.org:8080/wrs). The IRRI-sourced temperature data were the anomalies in the weather variable using the base period of 1965 to 1980 . In the same line of temperature anomaly, the rice yield anomaly was calculated for the purpose of comparison.

\section{Sustainability}

A framework for rice sustainability was conceptualized and developed by following the SDG indicator no. 2.4.1 (http:/ / www.fao.org/3/ca7 154en/ca7154en.pdf). 
Table 1. List of nutraceutical properties and developed rice-based products together with the reference(s) followed for their estimation, and reference value of their categorization.

\begin{tabular}{|c|c|}
\hline Parameter [reference followed for estimation] & Threshold $^{*}$ \\
\hline Protein [Ma and Zuazaga, (1942)] & High protein: $\geq 10 \%$ \\
\hline Glycaemic index (GI) [Haffner (1986); Psyrogiannis (2003); Keh (2004)] & $\begin{array}{l}\text { GI low: } \leq 55.0 \text {; intermediate: }>55.0-69 \text {, and } \\
\text { high: } \geq 70\end{array}$ \\
\hline Zinc (Zn), Iron (Fe) and Calcium (Ca) [AOAC (1995)] & $\mathrm{Zn}: \geq 19.0$ ppm; Fe: $\geq 10.0$ ppm; Ca: 80.0 ppm \\
\hline Phosphorus (P) [Yoshida et al., (1976)] & $\mathrm{P}: \geq 3.0 \mathrm{~g} \mathrm{~kg}^{-1}$ \\
\hline $\begin{array}{l}\text { Antioxidants - Phenolic compound, total antioxidant capacity, DPPH, } \\
\text { Ferric reducing antioxidant power [Oktay et al., (2003); Banerjee et al., } \\
\text { (2005); Turkmen et al., (2007); QiuY et al., (2010)] }\end{array}$ & - \\
\hline Water-soluble vitamin - thiamin [Shozib et al., (2018b)] & Thiamin: $\geq 1.0 \mathrm{mg} 100 \mathrm{~g}^{-1}$ \\
\hline Fat-soluble vitamin A for 'Golden rice' [Tang et al., (2009)] & VitA: $\geq 8.64^{* *} \mathrm{ppm}$ \\
\hline $\begin{array}{l}\text { Gamma amino butyric acid of pre-germinated rice [Siddiquee et al., } \\
(2017) \text { ] }\end{array}$ & GABA: $\geq 12.0 \mathrm{mg} 100 \mathrm{~g}^{-1}$ \\
\hline Premium quality rice [Custodio et al., (2019)] & Export oriented traits ${ }^{* * *}$ \\
\hline Saturated fatty acid of rice bran [Gunawan et al., (2006)] & Saturated fatty acid: $\leq 21.0 \%$ \\
\hline Gamma oryzanol in $\mathrm{RBO}^{* * *}$ [Srisaipet et al., (2013)] & Gamma oryzanol: $\geq 1200$ mg $100 \mathrm{~g}^{-1}$ \\
\hline Rice-based bakery products (Rice biscuit, energy dense rice biscuit, & Energy density in energy dense rice biscuit: \\
\hline cake, bread and noodles) [Shozib et al., (2018a); Shozib et al., (2018b)] & $\geq 5.0$ ) indicating $500 \mathrm{kcal}$ per $100 \mathrm{~g}$ serving \\
\hline Indigenous rice-based products (Popped, puffed and flattened rice) & Change in rice shape due to form utility \\
\hline \multicolumn{2}{|c|}{$\begin{array}{l}\text { *Adopted by the Grain Quality and Nutrition (GQN) Division of the Bangladesh Rice Research Institute (BRRI) for in- } \\
\text { breds. } \\
{ }^{* *} \text { For GR2E Golden rice (Donald MacKenzie, Personal Communication). } \\
{ }_{* * *} \text { RBO denote rice bran oil. }\end{array}$} \\
\hline
\end{tabular}

\section{Food Security}

Food self-sufficiency ratio (SSR) is commonly used as an indicator for measuring national food security (Clapp, 2017). This ratio focuses supply side of food availability. To account for the demand side, Chen and $\mathrm{Lu}$ (2018) used food security index (FSI); however, ignored some important component of supply side, such as import, export and previous year's carryover. We modified the equation of Chen and $\mathrm{Lu}$ (2018) by accounting for those ignored components.

Food security is equivalent to rice security in Bangladesh. In this study, rice security is expressed as rice self-sufficiency ratio (RSSR) in percentage and estimated using the following equation:

$$
\operatorname{RSSR}_{\mathrm{t}}=\left(\frac{\mathrm{P}_{\mathrm{t}}+\mathrm{I}_{\mathrm{t}}-\mathrm{X}_{\mathrm{t}}+\mathrm{COP}_{\mathrm{t}}}{\mathrm{HC}_{\mathrm{t}}+\mathrm{NHC}_{\mathrm{t}}}\right) \times 100 \ldots . . \text { Eq. } 16
$$

Where, ' $P_{t}{ }^{\prime}$ is the domestic production; ' $I_{t}$ ' is the import, ' $X_{t}$ ' is the export, ' $C O P_{t}^{\prime}$ ' is the previous year's carryover, ' $H C_{t}$ ' is the human consumption, and ' $N H C_{t}$ ' is the non-human consumption of rice in th year. A similar unit to be used for all parameter of the Eq. 16. The value of RSSR in a particular year is (i) equal to 100 , indicates self-sufficient; (ii) less than 100, indicates deficit; and (iii) greater than 100, indicates a surplus. The annual national rice production data was accessed from various issues of BBS, whereas import and export data from 'IndexMundi' (https://www.indexmundi.com/a griculture $/$ ? country $=$ bd\&commodity $=$ milledri ce\&graph, accessed on 17 October 2020). Section 'Demand domain of production flow' presented the procedure of data generation for human consumption and non-human consumption. The $\mathrm{COP}_{t}$ was calculated as:

$$
\mathrm{COP}_{\mathrm{t}}=\left(\mathrm{P}_{\mathrm{t}-1}+\mathrm{I}_{\mathrm{t}-1}\right)-\left(\mathrm{X}_{\mathrm{t}-1}+\mathrm{HC}_{\mathrm{t}-1}+\mathrm{NHC}_{\mathrm{t}-1}\right) \ldots . . \text { Eq. } 17
$$

where ' $t-1$ ' is the lag period of $t^{\text {th }}$ year. 


\section{Concept Development for Rice Price Stability}

A policy concept for market price stability was developed based on (i) literature review, and (ii) suggestions of key informants of stakeholders including farmers, traders, researchers and extension personnel.

\section{RESULTS AND DISCUSSION}

\section{Rice Productivity, Production and Sensitivity \\ The concept of doubling rice productivity (DRP) framework}

Figure 2 depicts the concept of doubling rice productivity (DRP) framework, consists of three wings - increase in the volume of production (Wing-1), decrease in per unit area of labour use in the production systems (Wing-2), and adding value to production (Wing-3). Yield enhancement and rice area expansion are the two avenues designated for achieving the goal of Wing-1. For Wing-2, increasing adoption of mechanization has been pointed out which would ultimately impact on labour productivity. Another wing is included in the framework in relation to uplifting the value of production which would potentially contribute to the production increase (Wing-3). Improvements in the nutritional quality of rice, and ensuring access to a stable market are the two areas identified as action pathways for Wing-3.

Potential interventions under Wing-1 include enhancement of genetic potential (GenPot, Pillar 1) of rice varieties, minimization of yield loss (ManPot, Pillar 2) and exploration of unexplored spaces (SpacePot, Pillar 3) for rice cultivation. Advancement in conventional breeding, emphasizing hybridization and application of biotechnology are the suggested tools for enhancing and sustaining GenPot. The yield loss due to improper management remains a barrier to enhanced productivity in rice sector in Bangladesh (Ran et al., 2018). The improvements in genetic potentials cannot automatically ensure increased productivity unless those are utilized in farmers' fields. Evidence showed, even for extremely successful varieties, also known as mega-varieties ${ }^{3}$,

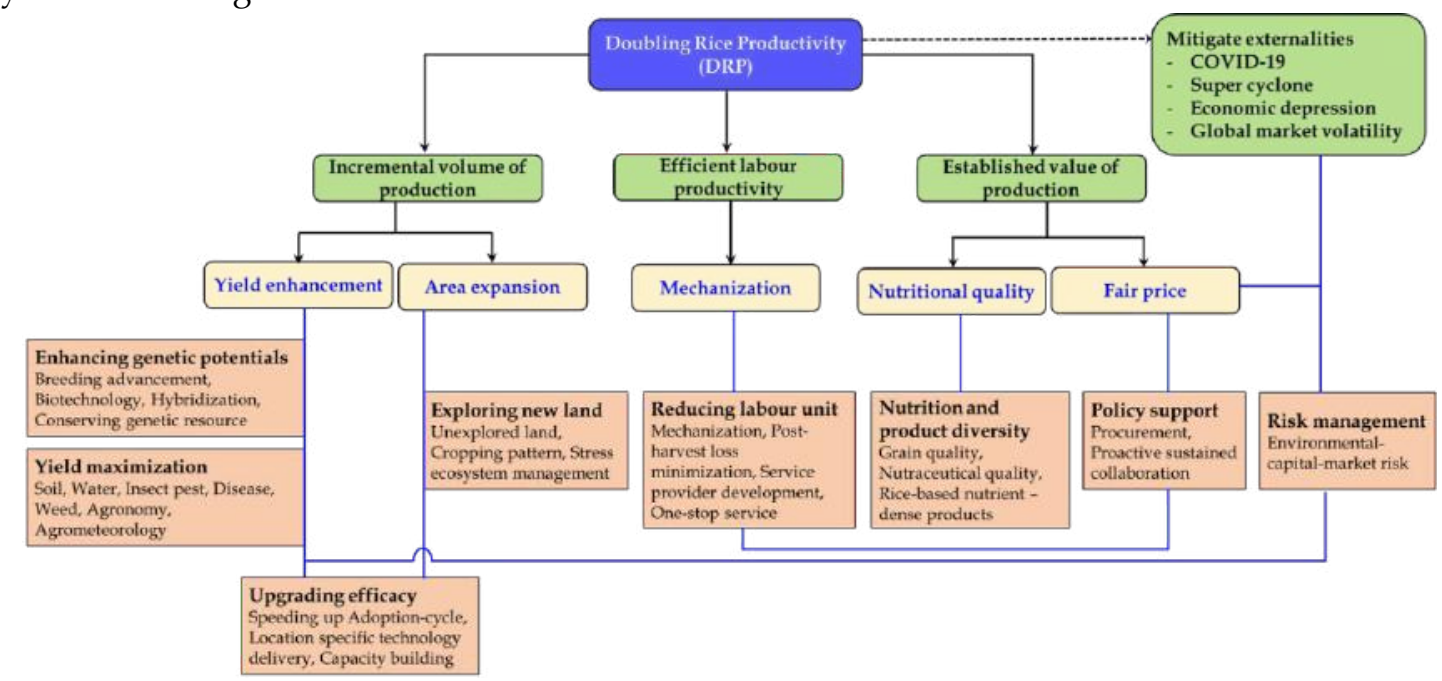

Fig. 2. The proposed concept of doubling rice productivity (DRP) framework of Bangladesh towards meeting the SDG 2.3.1 and moving forward.

\footnotetext{
${ }^{3} \mathrm{~A}$ variety is designated as a 'mega-variety' which, within its adoption cycle, receives significant area coverage (perceived as at least $25 \%$ ) in a growing season.
} 
the adoption lag had been very high. For example, BR11 took 13 years, BRRI dhan28 took 19 years and BRRI dhan29 took 13 years to reach their adoption peak (Kabir et al., 2015). This framework has emphasized on finding interventions on speeding up the adoption-cycle for promising rice varieties.

The DRP framework highlights annualized yield loss scenarios for each management component of rice - agronomy, soil, water, biotic and abiotic agents, harvesting and post-harvesting, and unpredicted weather-related stresses. Besides, the arable land in the country has been shrinking (@ 0.4\% annually, The Daily Prothom Alo, 2015) over time that also aggravated the rice security challenges (Hasan et al., 2013; Alam et al., 2015). However, there is a considerable volume of culturable waste land that has the potential to contribute to the national rice basket subject to undertaking situation-specific interventions.

Doubling productivity, concerning rice is a target for meeting SDG 2.3.1. Rice is a staple food in the country that has immense significance in the economy and politics that pointed out the gravity of the goal. Farm mechanization is a key to transforming subsistence agriculture into commercial agriculture in Bangladesh (Van Loon et al., 2020). The framework (Fig. 2) has categorically directed to explore the actionpoints of how the on-going momentum of mechanization can be translated into reality in meeting the SDG.

The framework (Fig. 2) has also figured out that for sustaining rice productivity and production in Bangladesh, it would need to add value to rice commodities (Singh et al., 2002), such as nutritional improvements, product diversity, and safety. It has further added market risk management and rice procurement policy support to ensure that rice becomes a profitable crop to farmers. All the wings and underlying intervention will contribute to increased rice productivity and production to remain Bangladesh as a rice surplus country and become an influential actor in the rice world.

Another component, the externalities (termed as 'perturbation' by Conway, 1987), can suddenly and strongly disrupt the existing rice production system, such as COVID-19, that would affect sustainability. The proposed framework has specified the pathway to mitigate those externalities.

\section{Improving genetic potential}

The GenPot has been set in such a way that the minimum requirement of rice production (RefMinPro) for the country could entirely be met through to 2050 by this pillar alone, one of the major incremental rice production and productivity pillars. According to the estimation, to achieve the Ref-MinPro for the year 2030, the GenPot has set as $4.79 \mathrm{t} \mathrm{ha}^{-1}$ as clean rice $(7.15 \mathrm{t}$ $\mathrm{ha}^{-1}$ as rough rice) from $3.94 \mathrm{t} \mathrm{ha}^{-1}$ as of 2015 productivity. For 2050, this GenPot is set as 6.06 $\mathrm{t} \mathrm{ha}^{-1}$ (9.05 $\mathrm{t} \mathrm{ha}^{-1}$ as rough rice) (Fig. 3). The improvements in GenPot will be made possible by using modern biotechnological methods and tools such marker assisted selection (MAS), genome editing, speed breeding, etc (details in Rabbi et al., 2020). This estimation has been made with the assumption that the current yield loss status (20.61\%) will remain unchanged during the study period, as if the variety will perform in full potential without encountering any yield loss.

\section{Minimizing yield loss}

\section{Determinants and partitioning of yield loss}

The rice cultivars are unable to perform to their full potential due to yield loss (YL) because of stress and/or improper management at any of the 17 stages of the rice crop life-cycle. The yield detrimental factors included agronomic, soil and water mismanagement issues, biotic and 


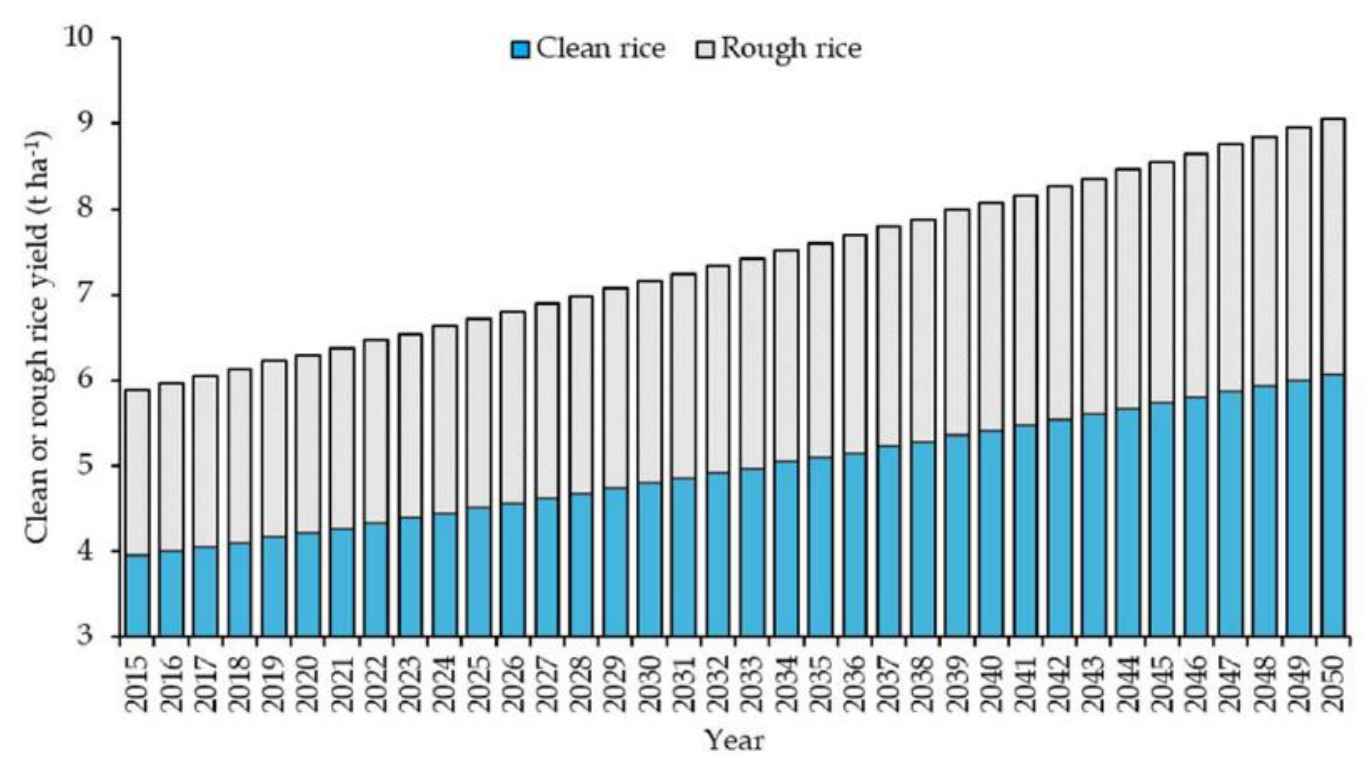

Fig. 3. Estimated genetic potential of clean and rough rice in Bangladesh with the assumption that current yield loss status will remain unchanged during 2015-2050.

abiotic threats, harvesting and post-harvesting mishandling and unanticipated climate hazards. These factors were accounted for as determinants of YL. Conventionally, YL is estimated comparing treatment (i.e., full interventions) with control (i.e., without interventions) for individual YL-determinants. For example, indirect wet seeded rice about $82 \%$ YL has been reported if not weeded (Bhuiyan, 2016). The YL due to improper weeding in the farmer's field in Bangladesh has been found in the range of $4.25 \%$ to $20.00 \%$ depending on different rice ecosystems (Bhuiyan et al., 2018). The YL from rice hispa was reported as high as 32.85\% (Bari et al., 2012). Shahjahan et al. (1994) recorded an YL of 31\% when the crop was infested with sheath rot disease at the critical stage. While those losses, may be called management potential (ManPot) losses, can occur in specific onfield circumstances and specific seasons; they do not represent the scenario of all the fields of a country in all the seasons in all the years. To represent the reality, we have estimated the 'annualized YL' which can be treated as recurring year after year.

The total loss from all YL-determinants has been estimated as $20.61 \%$. This figure is very similar to that reported by Kabir et al. (2015). In this study, we have partitioned this loss into 14 YL-determinants through expert elicitation workshops (Fig. 4). For example, agronomic management related analyzed YL has been estimated as $11.35 \%$ arising from seed quality and tillage (SQ\&T, 1.00\%), time of sowing/transplanting (Planting, 4.75\%), seedling age (SIA, $2.50 \%$ ), spacing (Spa, $1.20 \%$ ) and weed management (WdM, 1.90\%); soil and moisture stressrelated losses as $4.50 \%$ for fertilizer management (FM, $4.00 \%$ ) and water management (WM, 0.50\%); abiotic and biotic stresses as $2.50 \%$ for diseases $(\mathrm{D}, 1.00 \%)$, insect-pest $(\mathrm{P}$, $1.00 \%$ ) and all abiotic stresses (A, $0.50 \%$ ); and post-maturity as $2.01 \%$ from harvesting $(\mathrm{H}$, $1.00 \%)$, post-harvesting $(\mathrm{PH}, 1.00 \%)$ and processing $(0.01 \%)$. Besides, annualized YL from natural calamities (NC) is estimated as $0.25 \%$. 


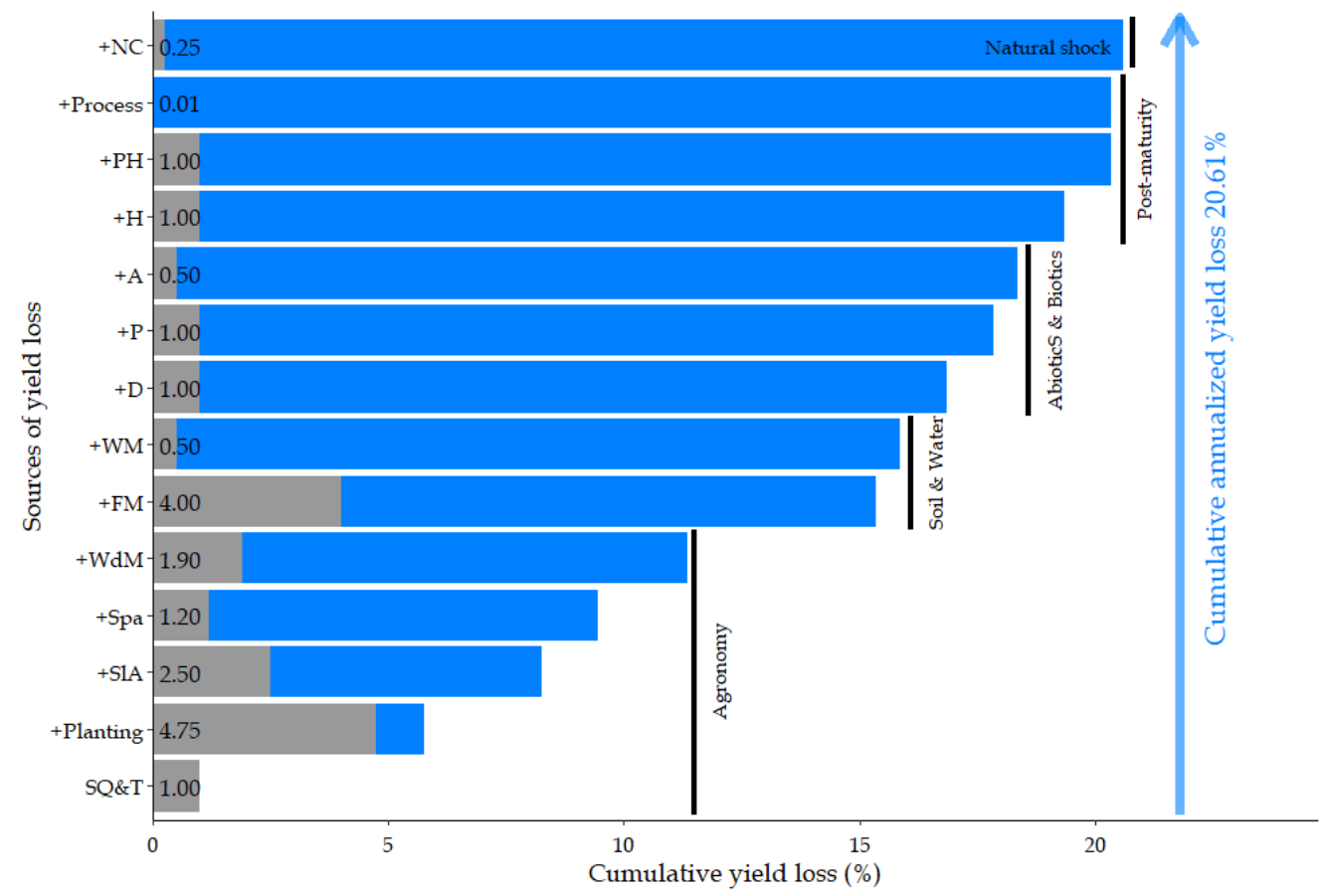

Fig. 4. Cumulative annualized rice yield loss in Bangladesh accounting for 14 yield-loss-determinants at different phases of production systems. 'SQ\&T' denotes for seed quality and tillage, 'Planting' indicates time of sowing / transplanting, 'SIA' for seedling age, 'Spa' for spacing, 'WdM' for weed management, 'FM' for fertilizer management, ' $W M^{\prime}$ for water management, ' $\mathrm{D}$ ' for diseases, ' $\mathrm{P}$ ' for insect-pest, ' $\mathrm{A}$ ' for all abiotic stresses, ' $\mathrm{H}$ ' for harvesting operations, ' $\mathrm{PH}^{\prime}$ for post-harvest management, 'Process' for all sort of processing, and ' $\mathrm{NC}$ ' for natural calamities.

\section{Measures to reduce the yield loss}

Figure 5 presents that the yield loss will be decreased to $13.05 \%$ in 2030 and $7.10 \%$ in 2050 from the baseline (2015) figure of $20.61 \%$, through implementation of means and methods suggested in recent and contemporary research papers (Islam, 2020; Bhuiyan et al., 2020a; Bhuiyan et al., 2020b; Rabbi et al., 2020; Rahman et al., 2020; Shozib et al., 2020; Ali et al., 2020; Khatun et al., 2020; Hossain et al., 2020, Kabir et al., 2020).

Plan and activities have been formulated in order to minimize yield loss in ManPot accounting for each of the 14 designated yield loss determinants (Fig. 6). For example, production gain of 0.79 and 1.97 MT by 2030 and 2050, respectively, will be achieved through managing the time of sowing/transplanting. Proper fertilizer management will ensure $0.68 \mathrm{MT}$ production gain by 2030 and 1.66 MT by 2050 . Similarly, 0.22 and 0.41 MT gain in production will occur in 2030 and 2050, respectively, through managing diseases; a similar gain has been estimated from managing insect-pest (Fig. 6).

A number of cutting-edge technologies will be adopted to address to improve ManPot. For example, the rice yield loss from insect-pest will be reduced following recommendations based on early warning systems (Salam et al., 2019b), smart pest management systems, and implementing precision insecticide application technologies (Ali et al., 2020). 


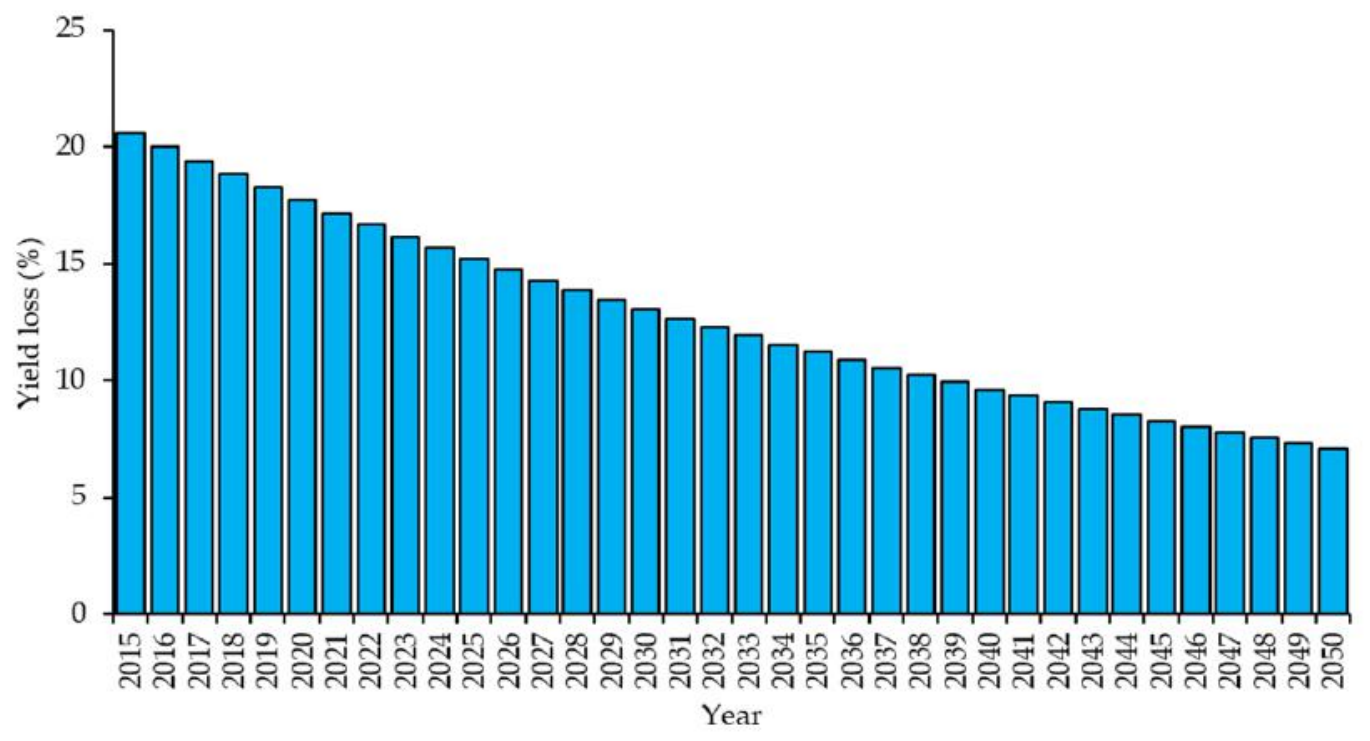

Fig. 5. Planned reduction of yield loss in Bangladesh in annual step during the period of 2015-2050.

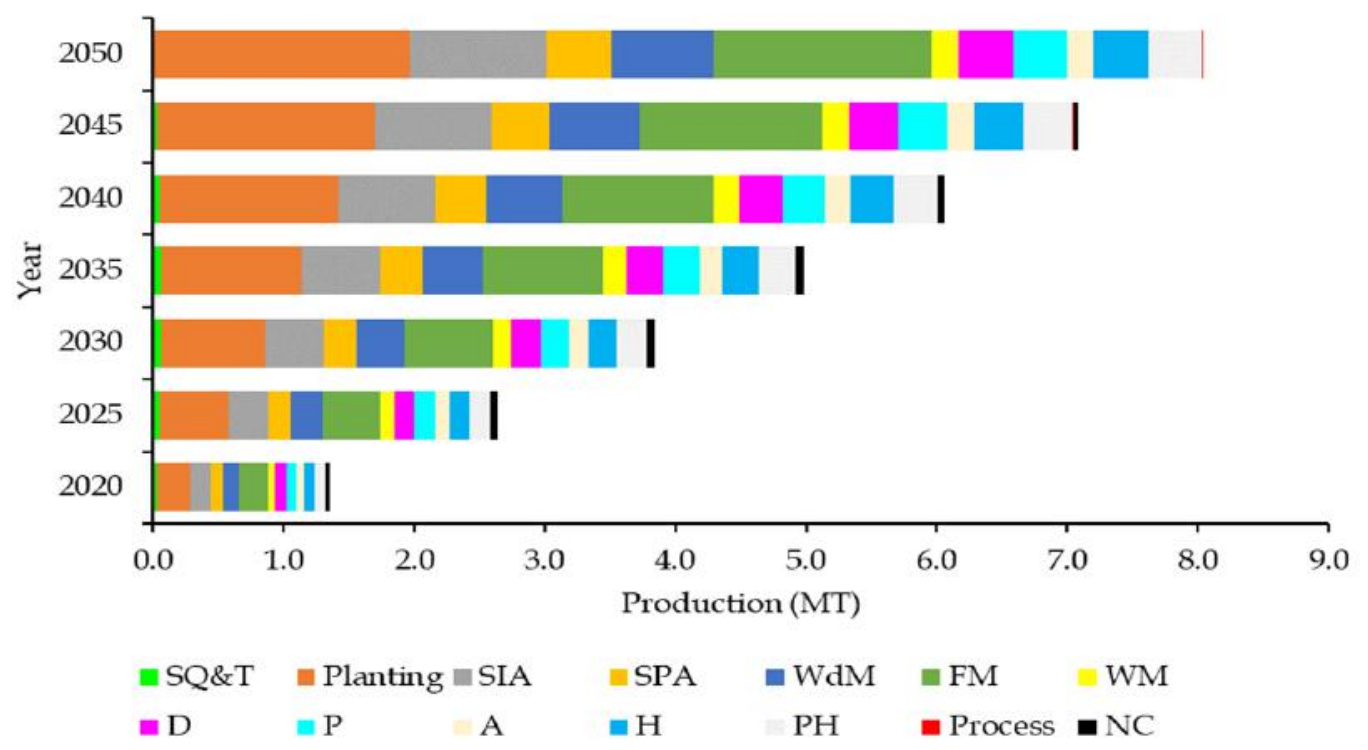

Fig. 6. Estimated clean rice production gain in Bangladesh under 14 yield-loss-determinants (ManPot) at different phases of production systems. 'SQ\&T' denotes for seed quality and tillage, 'planting' indicates time of sowing /transplanting, 'SIA' for seedling age, 'Spa' for spacing, 'WdM' for weed management, 'FM' for fertilizer management, ' $W M^{\prime}$ for water management, ' $\mathrm{D}$ ' for diseases, ' $\mathrm{P}$ ' for insect-pest, ' $\mathrm{A}$ ' for all abiotic stresses, ' $\mathrm{H}^{\prime}$ for harvesting operations, ' $\mathrm{PH}^{\prime}$ for post-harvest management, 'Process' for all sort of processing, and ' $\mathrm{NC}$ ' for natural calamities. 
Moreover, the disease-related yield loss of $1.0 \%$ in 2015 will be reduced to $0.7 \%$ by 2030 through adopting digital tools for data collection, early warning system for supporting decision-making, provision of agro-advisory, effective training for farmers and extension agents at grassroots level, regular field monitoring, and reviving indigenous technologies (such as adjusting crop density, depth of planting, adjusting time of planting, altering of plant and crop architecture, and mulching) (Khatun et al., 2020). Furthermore, yield loss during post-maturity can be minimized through scale-appropriate mechanization such as using reaper, combined harvester, mechanical thresher, and mechanical dryer (Islam, 2020).

\section{Change management easing pressure on tar- get genetic potential}

We compared required genetic potential (GenPot) under two scenarios, where both achieve the minimum production requirements (RefMinPro) of rice: a constant yield loss of $20.61 \%$ as of current management, and incrementally decreasing yield loss coming down to $7.10 \%$ in the year 2050 through improved management. An exponential model was used to fit the data.

We report that the estimated GenPot of 4.8 $\mathrm{t}$ ha $\mathrm{a}^{-1}$ as clean rice $\left(7.1 \mathrm{t} \mathrm{ha}^{-1}\right.$ as rough rice) and $6.1 \mathrm{t} \mathrm{ha}^{-1}$ (9.1 $\mathrm{t} \mathrm{ha}^{-1}$ as rough rice) for 2030 and 2050, respectively, to achieve the Ref-MinPro (Fig. 7). Realizing an annualized clean rice yield of $6.1 \mathrm{t} \mathrm{ha}^{-1}$ (9.1 $\mathrm{t} \mathrm{ha}^{-1}$ as rough rice) in 30 years from now, which will need a continued improvement in GenPot @1.23\% year-1 (equivalent to $61 \mathrm{~kg} \mathrm{ha}^{-1}$ ), could be a mammoth task for the breeders. This pressure would be eased by incrementally decreasing yield loss through to 2050 from 20.61 to $7.10 \%$ (Fig. 5) by adopting improved management. This will result in the requirement of lower GenPot, $4.4 \mathrm{tha}^{-1}$ as clean rice (6.6 tha-1 as rough rice) and $5.2 \mathrm{t} \mathrm{ha}^{-1}(7.7 \mathrm{t}$

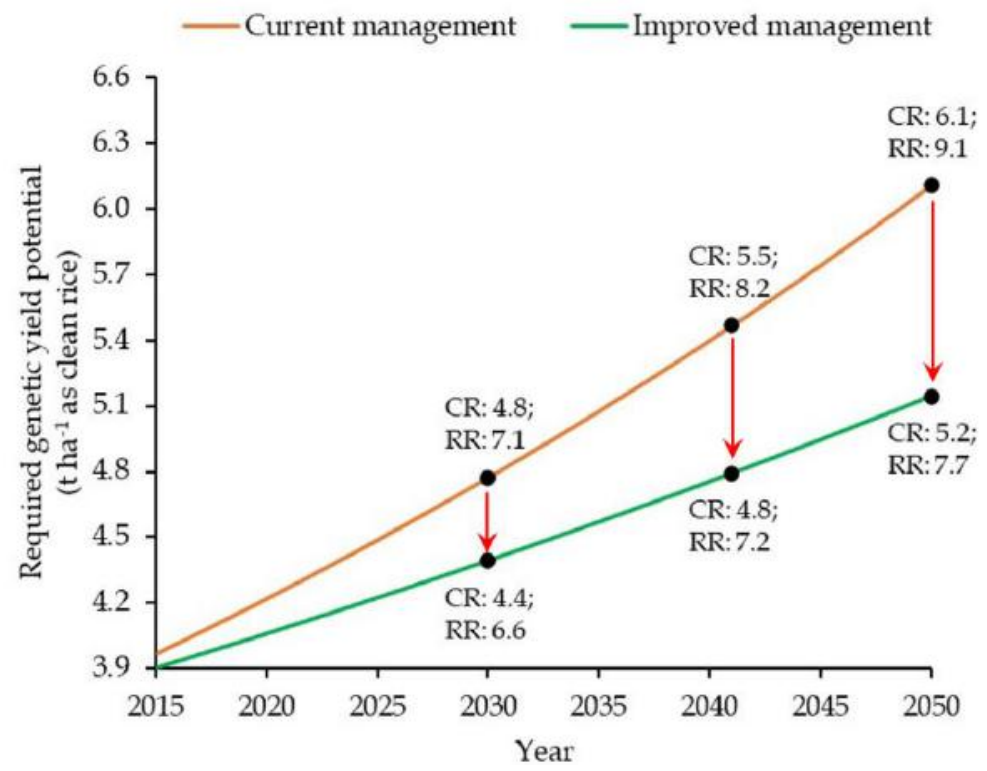

Fig. 7. Required genetic yield potential to meet the minimum rice production target (Ref-MinPro) across 2015 to 2050. Two scenarios are shown: the yield loss will remain unchanged (Current management) and reduction in yield loss @3\% year-1 (Improved management). Red colour arrows indicate the ease of pressure. Filled circles on the lines indicate corresponding yields for 2030, 2041, and 2050. 'CR' and 'RR' denote for clean and rough rice yield, respectively. 
ha-1 $^{-1}$ as rough rice) for 2030 and 2050, respectively, by maintaining genetic improvement @ $0.79 \%$ year $^{-1}$ (equivalent to $36 \mathrm{~kg} \mathrm{ha}^{-1}$ ).

The rate of yearly change of GenPot for current and improved management was calculated. The relative contribution of improved management was estimated as the ratio of the difference in the rate of yearly change between the management to the rate of change under current management. The relative contribution was expressed as percentage. Results show that improved management will reduce the required rate of genetic gain by $\sim 41 \%$ while hitting the target of the Ref-MinPro. In other words, the average co-contribution of improved management will gain $\sim 41 \%$ to rice productivity compared to current management.

It is generally agreed that both breeding and agronomy (i.e. management) have contributed to yield advances although the relative contributions of each have varied according to the crop species and environment (Anderson et al., 2005). Table 2 shows that the desired rice productivity under long-term changing yield loss (YL) scenarios will be achieved in combination of four contributors - genotype $(\mathrm{G})$, management $(\mathrm{M})$, environment $(\mathrm{E})$ and people $(\mathrm{P})$. To estimate historical YL, we developed a model to back calculate the loss based on 2015 2050 estimations; on the other hand, partitioning of yield contributors was undertaken from literature (Salam et al., 2016). With the aimed gradual decrease in $\mathrm{YL}$, the contribution of ' $\mathrm{G}$ ' and ' $\mathrm{M}$ ' will increase, respectively, from $8.00 \%$ and $40.00 \%$ in $1971-75$ to $23.67 \%$ and $48.19 \%$ in 2046-50 (Table 2). During the periods, environmental influence (E) on yield will reduce because of improvements in genotype and management. The technology development will enhance people's (P) efficiency; thus, the relative contribution of this yield-contributor will automatically reduce. It has been reported that about $70 \%$ of yield improvement achieved from improved management and about 30\% from improved cultivars of wheat in Western Australia (Anderson et al., 2005), whereas Abrecht et al. (2008) observed $40 \%, 16 \%$ and $16 \%$ wheat yield variation though management, genotype and environment, respectively. For rice, according to farm survey 2017, genotype contributed to yield variation by $24 \%$, management by $46 \%$, and environment and people combinedly by 30\% (Naris Parvin, unpublished PhD research). Findings show that emphasizing on improved management can considerably ease the increasing pressure on achieving genetic potential for future rice varietal development.

\section{Exploring the unexplored spaces for increased production}

There still remain some areas which can be brought under rice cultivation by creating irrigation facilities. This study has identified five such potential spaces across the country. The potential area coverage, including productivity and production, in those spaces are presented below.

\section{Area and productivity of rice in five unex- plored spaces}

About $0.26 \mathrm{M}$ ha of land with a target clean rice yield of $3.69 \mathrm{t} \mathrm{ha}^{-1}$ has been estimated to bring under Boro rice cultivation by 2030 in Space 1; this estimated area to be raised to $0.50 \mathrm{M}$ ha (with the target clean rice yield $4.49 \mathrm{t} \mathrm{ha}^{-1}$ ) in 2050 (Fig. 8). This would be possible by facilitating irrigation and sourcing water from re-excavation of canals in the greater Barishal region. Strong community motivation would be required to harvest success from this initiative.

In Space 2, the estimated area has been set to about $0.13 \mathrm{M}$ ha (targeting clean rice yield $3.63 \mathrm{t} \mathrm{ha}^{-1}$ ) in 2030 under Aus and Boro rice in the fallow lands in north-eastern Bangladesh specifically in greater Sylhet region. This can be executed by developing irrigation facilities. 
Table 2. Estimated yield loss, and relative rice yield contribution of genotype, management, environment and people in Bangladesh. Figures represent five-year annualized values that incorporate all the three rice growing seasons and all the environments across the country.

\begin{tabular}{lccccc}
\hline Period (Year) & Yield loss (\%) & \multicolumn{4}{c}{ Relative yield contribution* ${ }^{*}$ of } \\
\cline { 2 - 5 } & & Improved genotype & $\begin{array}{c}\text { Responsive } \\
\text { management }\end{array}$ & $\begin{array}{c}\text { Favourable } \\
\text { environment }\end{array}$ & $\begin{array}{c}\text { Peoples' direct } \\
\text { engagement }\end{array}$ \\
\hline $1971-1975$ & 35.48 & 8.00 & 40.00 & 22.00 & 30.00 \\
$1976-1980$ & 33.78 & 8.60 & 40.50 & 21.73 & 29.18 \\
$1981-1985$ & 31.88 & 9.25 & 41.01 & 21.45 & 28.30 \\
$1986-1990$ & 29.98 & 9.94 & 41.52 & 21.19 & 27.36 \\
$1991-1995$ & 28.08 & 10.68 & 42.04 & 20.92 & 26.36 \\
$1996-2000$ & 26.18 & 11.49 & 42.56 & 20.66 & 25.29 \\
$2001-2005$ & 24.29 & 12.35 & 43.10 & 20.40 & 24.16 \\
$2006-2010$ & 22.39 & 13.27 & 43.63 & 20.15 & 22.95 \\
$2011-2015$ & 20.67 & 14.27 & 44.18 & 19.89 & 21.66 \\
$2016-2020$ & 18.83 & 15.34 & 44.73 & 19.65 & 20.29 \\
$2021-2025$ & 16.17 & 16.49 & 45.29 & 19.40 & 18.82 \\
$2026-2030$ & 13.88 & 17.72 & 45.86 & 19.16 & 17.26 \\
$2031-2035$ & 11.92 & 19.05 & 46.43 & 18.92 & 15.60 \\
$2036-2040$ & 10.24 & 20.48 & 47.01 & 18.68 & 13.82 \\
$2041-2045$ & 8.79 & 22.02 & 47.60 & 18.45 & 11.93 \\
$2046-2050$ & 7.55 & 23.67 & 48.19 & 18.22 & 9.92 \\
\hline
\end{tabular}

* Annualized figure, estimated by the authors' using modelling technique; assumptions validated through published national data.

The area is estimated to cover $0.30 \mathrm{M}$ ha (with targeting clean rice yield $4.39 \mathrm{t} \mathrm{ha}^{-1}$ ) in 2050 (Fig. 8). About $0.13 \mathrm{M}$ ha (target clean rice yield $3.73 \mathrm{t} \mathrm{ha}^{-1}$ ) and $0.31 \mathrm{M}$ ha (target clean rice yield $4.50 \mathrm{t} \mathrm{ha}^{-1}$ ) of a section of saline belt of Southwest and greater Jashore region has potential to be under Boro rice cultivation by 2030 and 2050, respectively, through facilitating surface water irrigation (Space 3).

Coastal char land in greater Barishal region and Noakhali district (Space 4) has been estimated to accommodate high yield potential T. Aman rice in about 0.09 and $0.20 \mathrm{M}$ ha of land by 2030 and 2050, respectively.

We have explored the Chattogram hill tracts, especially Kaptai lake areas (Space 5), having potential to grow Boro rice, but constrained by lack of irrigation facilities. In this
Space about $0.04 \mathrm{M}$ ha of fallow land has been estimated to bring under rice by 2030, and 0.07 $M$ ha in 2050 through facilitating irrigation management (Fig. 8). In addition, adaptive research to test varieties and extension programmes are also important to expand rice cultivation in fallow areas.

\section{Rice production from unexplored spaces}

Considering the estimated target area and yield (Section 'Area and productivity of rice in five unexplored spaces'), in the five unexplored spaces, the combined annual production $\left(\right.$ SpacePot $\left.{ }^{4}\right)$ is estimated from 2020 through to 2050 (Fig. 9). By complementing initiative, the country will potentially be able to produce 0.83 MT clean rice in 2030 and 1.06 MT in 2050.

\footnotetext{
${ }^{4}$ Added rice production in potential unexplored spaces (Section 'Estimation of production in the unexplored spaces')
} 
Area (M ha) — Yield (t ha-1)

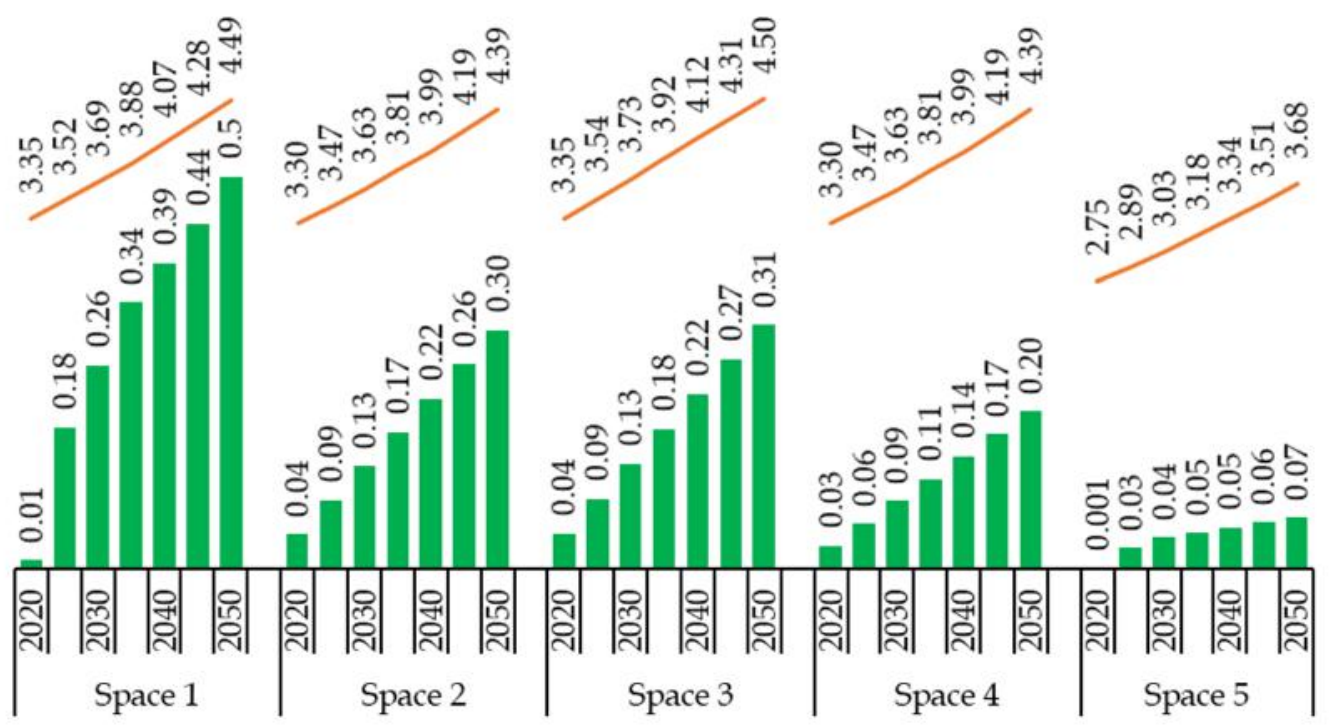

Fig. 8. Estimated area and yield of rice in five unexplored spaces of Bangladesh presented in a five-year step during 2020-2050.

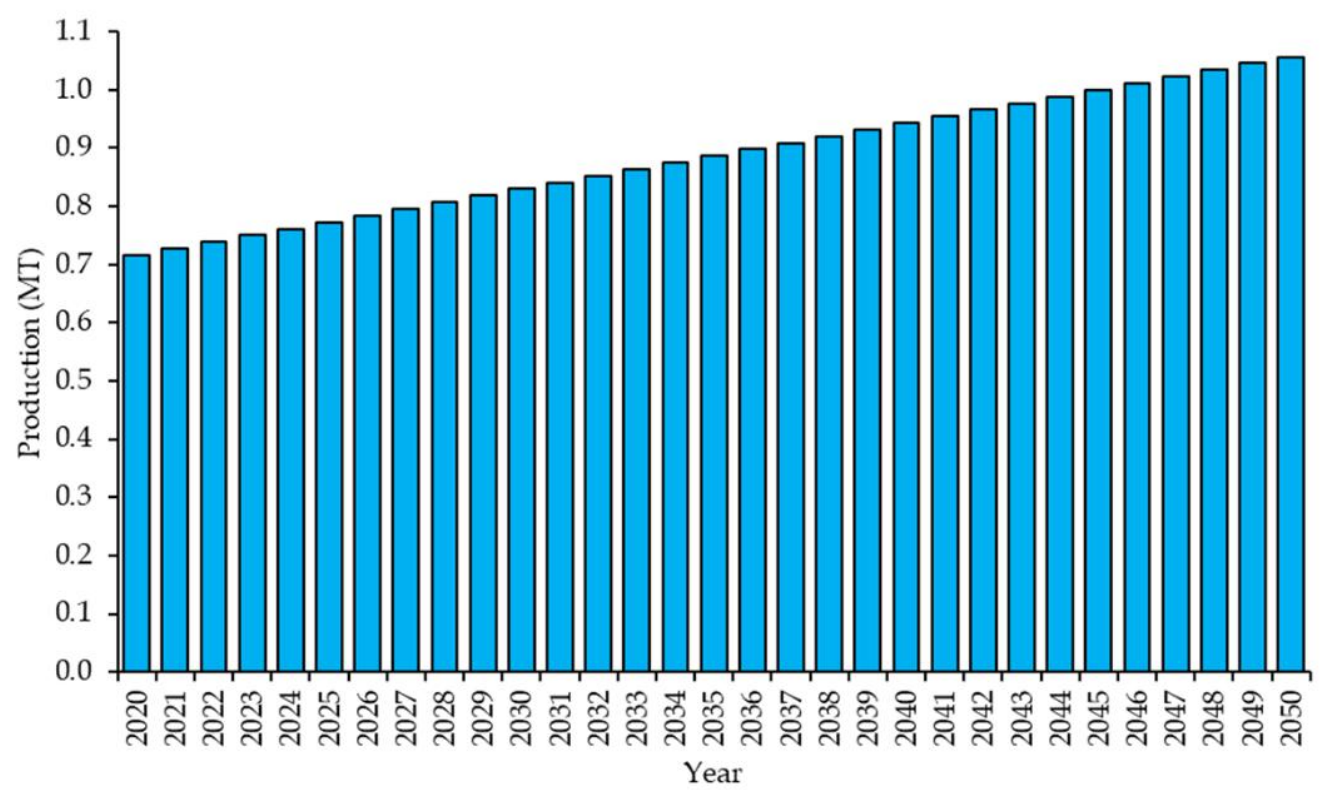

Fig. 9. Accumulated clean rice production from five unexplored spaces in Bangladesh during $2020-2050$. 


\section{Production flow: Hitting the production targets}

The flow of the future rice production in Bangladesh will stem from three pillars - GenPot (vertical dimension), SpacePot (horizontal dimension) and ManPot (cross-dimension). The future potential rice production estimates, from individual or combinations of the three pillars, have been compared with two reference targets: (i) the minimum production target or 'RefMinPro' across 2050 (35.29, 40.40, 43.80 and 47.20 MT in 2015, 2030, 2040 and 2050, respectively; red line in Figure 10, Kabir et al., 2015), and the maximum production potential or 'RefMaxPro' across 2050 set in this paper (blue line in Fig. 10). As shown in Figure 10, achievement in vertical dimension alone (i.e., GenPot) will meet the Ref-MinPro in 2050 (47.20 MT). The Ref-MaxPro will results from the combined achievements in three pillars, with which the country will be surplus of about 13.65 MT of rice by 2050. This surplus production will act as a 'pool' to overcome crop damage resulting from any externalities in production systems. A part of any such surplus will be available for (i) longer-term storing, (ii) exporting, and (iii) producing diverse rice-based products.

\section{Estimation of rice utilization flow}

Figure 11 presents annual demand for clean rice in Bangladesh for human consumption and non-human utilization from 1972 to 2050. The demand in 2020 has been 2.3 times higher compared to 1972, 2.0 times for human and 3.4 times for non-human purposes. The demand for clean rice in 2030, 2040, and 2050 has been estimated as 36.03 MT (human consumption: 26.17 MT; non-human utilization: 9.86 MT), 37.96 MT (human consumption: 27.06 MT; non-human utilization: 10.91 MT), and 40.70 MT (human consumption: $28.70 \mathrm{MT}$; non-human utilization: 12.00 MT), respectively (Fig. 11).

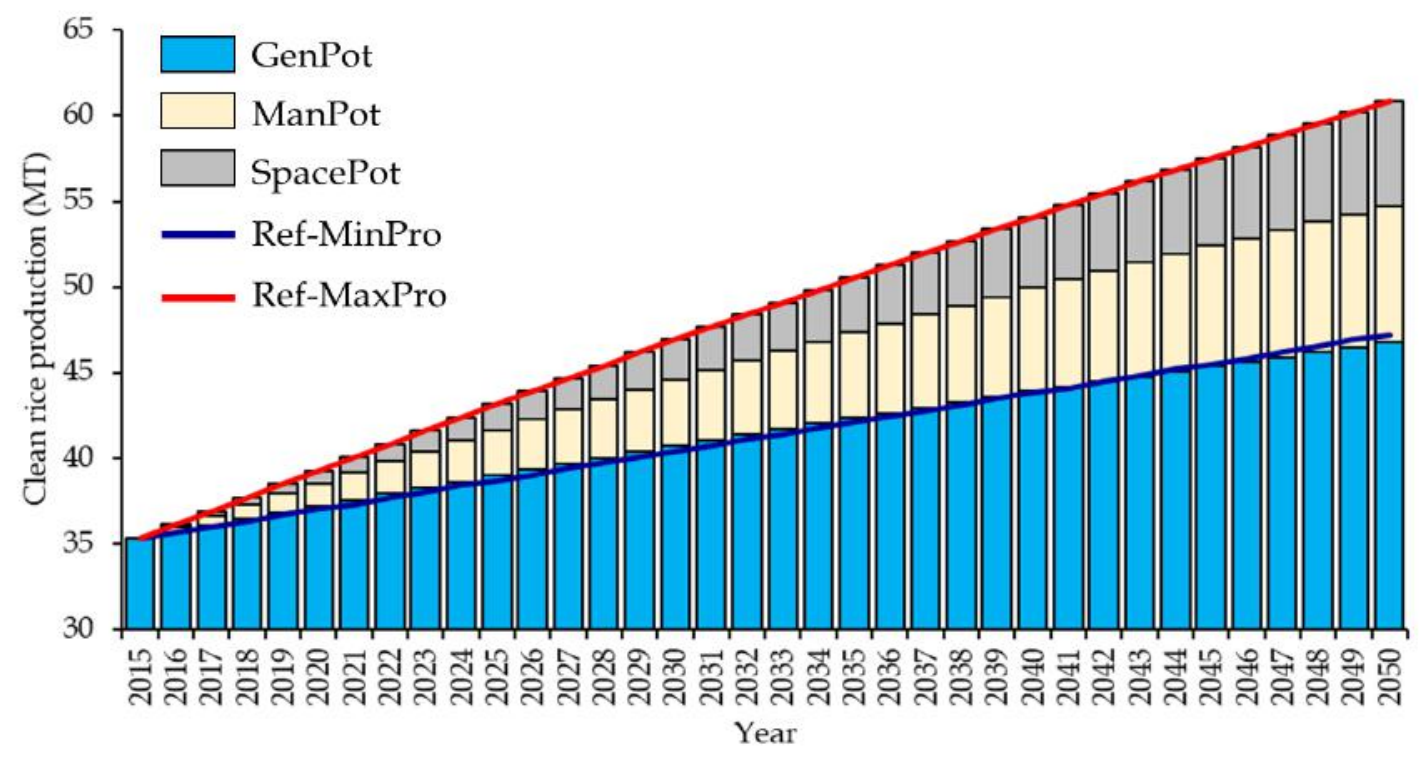

Fig. 10. Recent trend (2015-2019) and estimated future (2020-2050) rice production in Bangladesh through the three pillars of production increases - genetic potential (GenPot), management potential (ManPot) and spaces potential (SpacePot) during the period of 2020-2050. Also shown the reference minimum production (Ref-MinPro) target to achieve (solid red line) and reference maximum production (Ref-MaxPro) target (solid blue line) during the same period. 


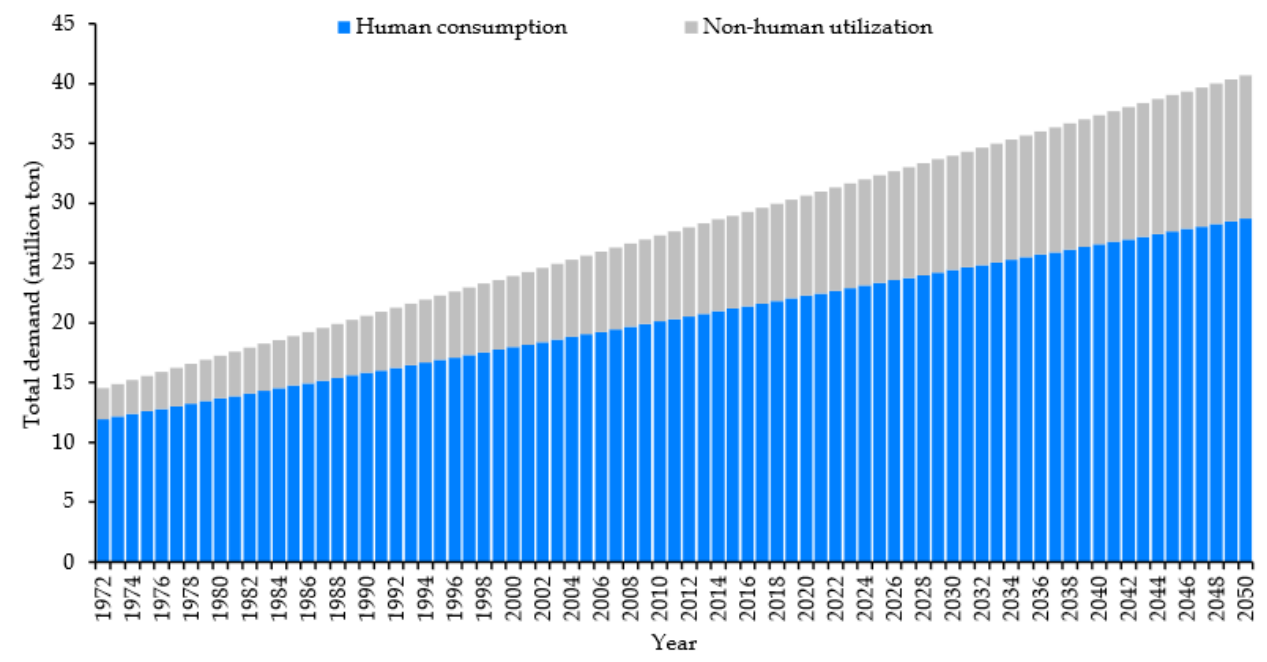

Fig. 11. Historical (1972-2020) and estimated future (2021-2050) demand of clean rice in Bangladesh under two purposes, human consumption and non-human utilization.

\section{Labour productivity}

The rice labour productivity in Bangladesh will double in 2029 considering a base productivity index of ' 1 ' in 2015 (Fig. 12a). This achievement will duly meet the SDG target 'doubling productivity' of 2030. Production will be one of the three drivers of labour productivity (Fig. 1). Based on continued success in genotype improvements under favourable and constraint environments, and adoption of modern varieties and improved management, it is unlikely that rice production of the country will negatively impact on labour productivity. The other two drivers, rice price and farm power availability, will be the determinants of future labour productivity (Fig. 1). We have estimated the required rice price and farm power for 2029 to meet the doubling labour productivity; for the year, the price, as clean rice, has set as BDT $48.40 \mathrm{~kg}^{-1}$ (equivalent rough rice price of BDT $32.43 \mathrm{~kg}^{-1}$ ), while the farm power availability as $2.71 \mathrm{~kW} \mathrm{ha}^{-1}$ (Fig. 12b). The required clean rice price can be ensured by a @3.00\% incremental increase in the base year (2015) price BDT 32.00 $\mathrm{kg}^{-1}$ (equivalent rough rice price of BDT 21.44 $\mathrm{kg}^{-1}$ ). On the other hand, the required farm power can meet by enhancing its availability @3.76\% annually. This can be achieved by public-private investment on research, development and extension, developing scale-appropriate machineries, entrepreneurship development, capacity development of service providers, and enhancing synchronized cultivation (details in Islam, 2020). Historically, the speed of mechanization, with respective to farm power availability, in Bangladesh is not far behind of India (Singh et al., 2014). The 2013 data shows the available farm power was $10.60,5.70$, $2.50,2.02,1.70,1.32,1.10$ and $0.20 \mathrm{~kW} \mathrm{ha}^{-1}$ in the Republic of Korea, China, Thailand, India, Vietnam, Cambodia, Pakistan, and Malaysia, respectively. The corresponding figure $(1.83 \mathrm{~kW}$ $\mathrm{ha}^{-1}$ ) for Bangladesh indicates the country is ahead of many comparable Asian countries (Khan and Rehman, 2019). It is expected that, 
the research, extension, and market will continue their endeavour for increasing the labour productivity to meet up the demand of 215 million people in 2050 (Kabir et al., 2015).
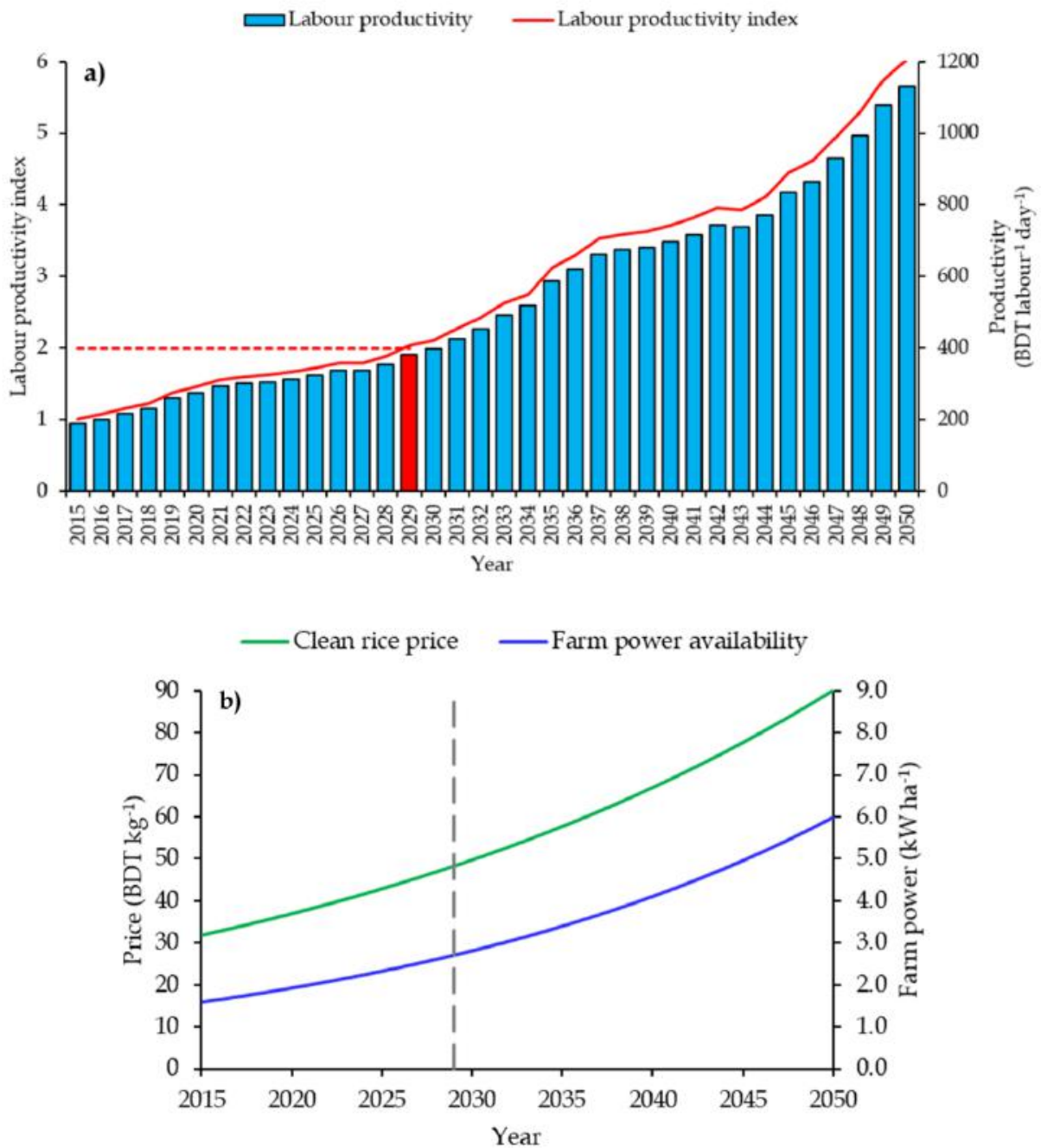

Fig. 12. Recent trend (2015-2019) and estimated future (2020-2050) rice labour productivity (BDT labour ${ }^{-1}$ day $\left.^{-1}\right)$ and productivity index (a), and clean rice price $\left(B D T \mathrm{~kg}^{-1}\right)$ and farm power availability $\left(\mathrm{kW} \mathrm{ha}^{-1}\right)(\mathrm{b})$ in Bangladesh. The red bar (a) and vertical broken line (b) indicate the time of achieving doubling rice labour productivity mark.

\section{Sensitivity to production flow and labour productivity}

Sensitivity analysis shows that under zero progress in estimated production flow in the three pillars - GenPot, SpacePot and ManPot - the country will face 18.99 and $36.00 \%$ shortfall of Ref-MinPro in 2030 and 2050, respectively (Fig. 13). This shortfall will reduce to 10.23 and $19.61 \%$ in 2030 and 2050, respectively, if $25 \%$ progress is achieved in the three pillars, and 
even $50 \%$ progress will still result in small deficit. Analysis further reveals that $75 \%$ progress in the achievement will provide 7.33 and $12.91 \%$ gain above the Ref-MinPro (Fig. 13).

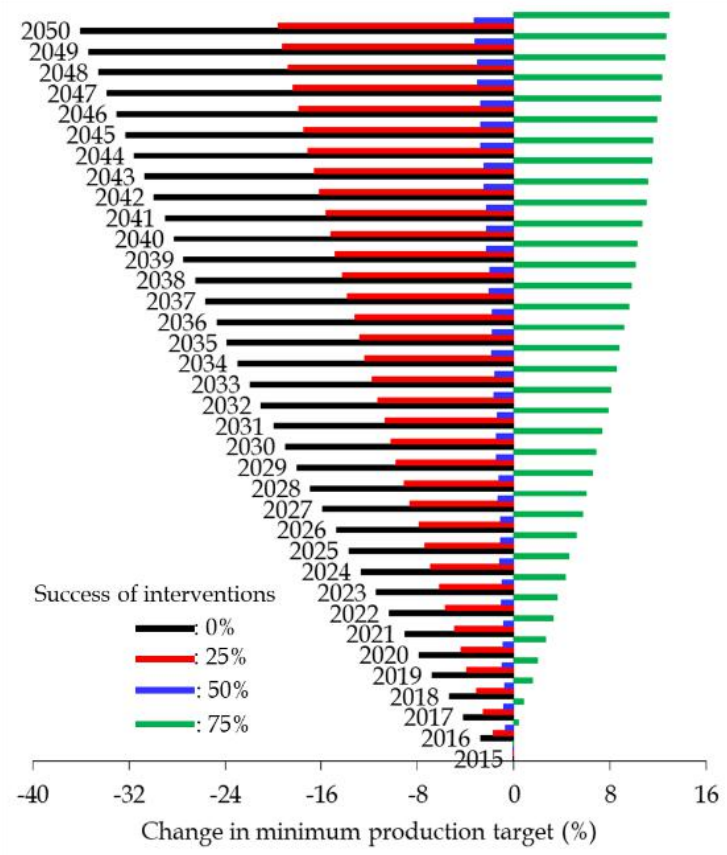

Fig. 13. Sensitivity in future rice production of Bangladesh under four scenarios of the three pillars of production increase - genetic potential (GenPot), management potential (ManPot) and spaces potential (SpacePot) during the period of 2015-2050.

On labour productivity, zero progress in the estimated production flow will result in 17.28 and $30.15 \%$ shortfall in set-target (RefMinPro) in 2030 and 2050, respectively (Fig. 14); this shortfall will narrow down to 9.36 and $16.49 \%$ in 2030 and 2050, respectively, if $25 \%$ progress is achieved across the three pillars. The analysis indicates $50 \%$ progress in the estimated production flow will still result in small shortfall in labour productivity, which, however, will turn into 6.51 and $10.61 \%$ gain above the set-target (Ref-MinPro) through 75\% progress in the achievement.
The results suggest that continued interventions in the three pillars of production flow would need to be planned and executed through research and extension to materialize at least $75 \%$ of the estimated production flow which will lead the country to a satisfactory production level to 'feed the future' through sustaining rice-food security.

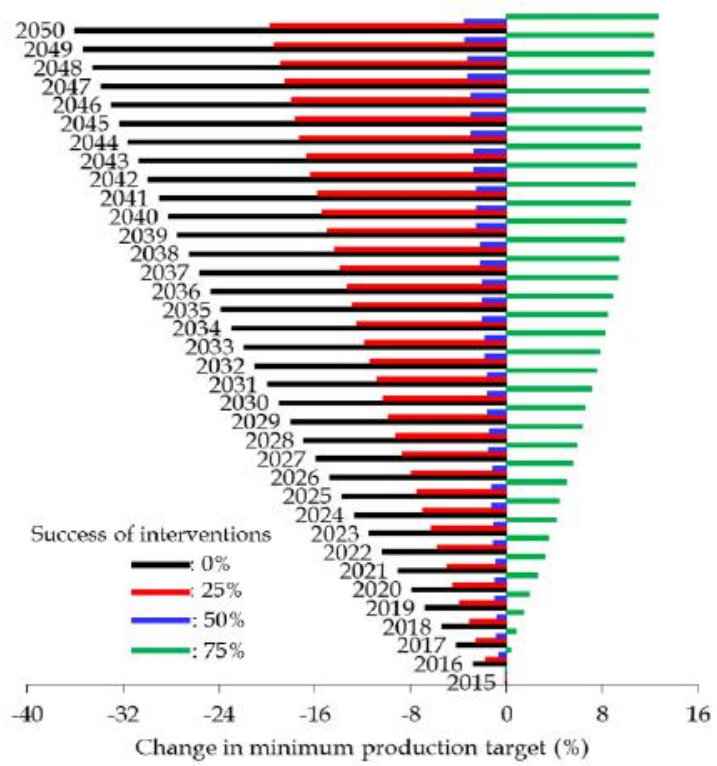

Fig. 14. Sensitivity in future rice labour productivity of Bangladesh under four scenarios of the three pillars of production increase - genetic potential (GenPot), management potential (ManPot) and spaces potential (SpacePot) during the period of 2015-2050.

\section{Speeding up Adoption-cycle of Promising Rice Varieties}

\section{Generic rice variety adoption model}

Delay in adoption of promising rice varieties in Bangladesh is a barrier to harvest the full potential of those varieties before deteriorate their genetic potential and/or rapid national production gain. It takes, on average, $16 \pm 3$ years to reach adoption peak of the most successfully adopted rice varieties, or in other words 'megavarieties', in Bangladesh (Kabir et al., 2015). A generic rice variety adoption (GRVA) model 
was developed to study the behaviour of the adoption curve with the change in the time requires to reach adoption peak (LAP). The model estimated the generic LAP of 16 years (LAP16) based on adoption pattern of nine rice varieties (Fig. 15). The model further identified a lag period of three years after which a variety adoption kicks-off exponentially; we term this period as 'diffusion period' (DP) of rice variety adoption. In experimentation with the GRVA model, we curtailed this LAP16 by 3 (LAP13) and 6 (LAP10) years and noted that the earliness in LAP is achieved by 'the area coverage of the concerned variety at the end of $\mathrm{DP}^{\prime}$; we term it as diffusion intensity (DI) having a unit of percentage. Thus, DI is the major driver for the LAP. In other words, to achieve a target LAP, one needs to ensure the right DI.

\section{Accelerated diffusion for newly released rice varieties}

In order to ensure the right DI for curtailing LAP, we investigated into ways and means and synthesize those into an accelerated diffusion for the newly released rice varieties (AD4NRV) model. The blueprint of AD4NRV model is presented in Figure 16.

According to the model, the concerned institute will produce seed during the variety-releasing year. We term the seed as 'Base seed'. The volume of the base seed will depend on the target area to be set according to breeders' confidence and institutional strength, agro-ecological suitability, farmers' and consumers' preference, and any such related factors. The model will generate information in a yearly time-step over a period of three-years. This three-years

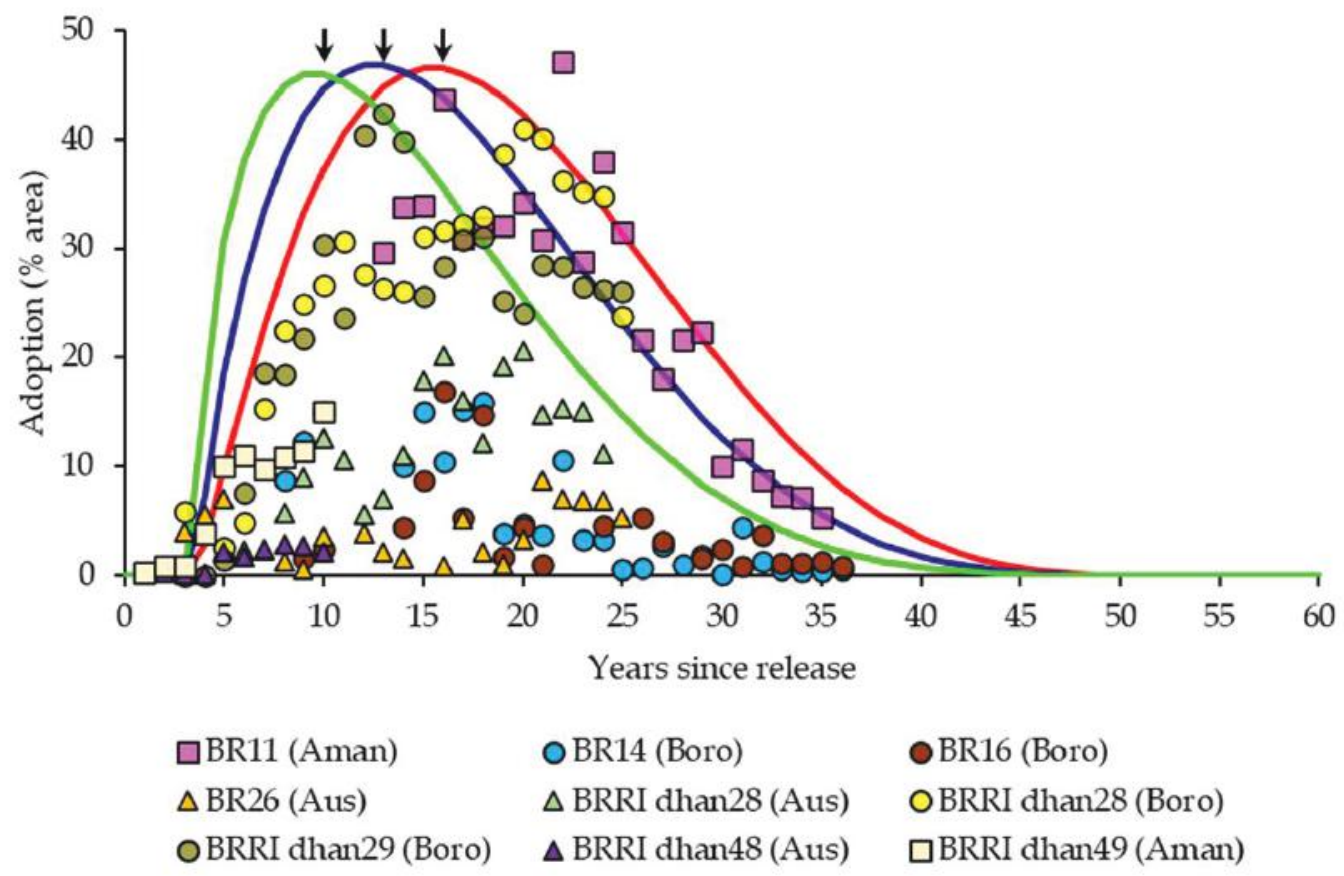

Fig. 15. Generic rice variety adoption (GRVA) model of Bangladesh (Red line). Blue and green lines indicate the shift in the length of adoption peak (LAP) that from the model by three and six years. Arrows denote for adoption peaks. The symbols show measured adoption (\% by area) of nine rice varieties since released. In legend, parentheses used with varieties indicate the growing seasons; 'Aman' represents the T. Aman season. 


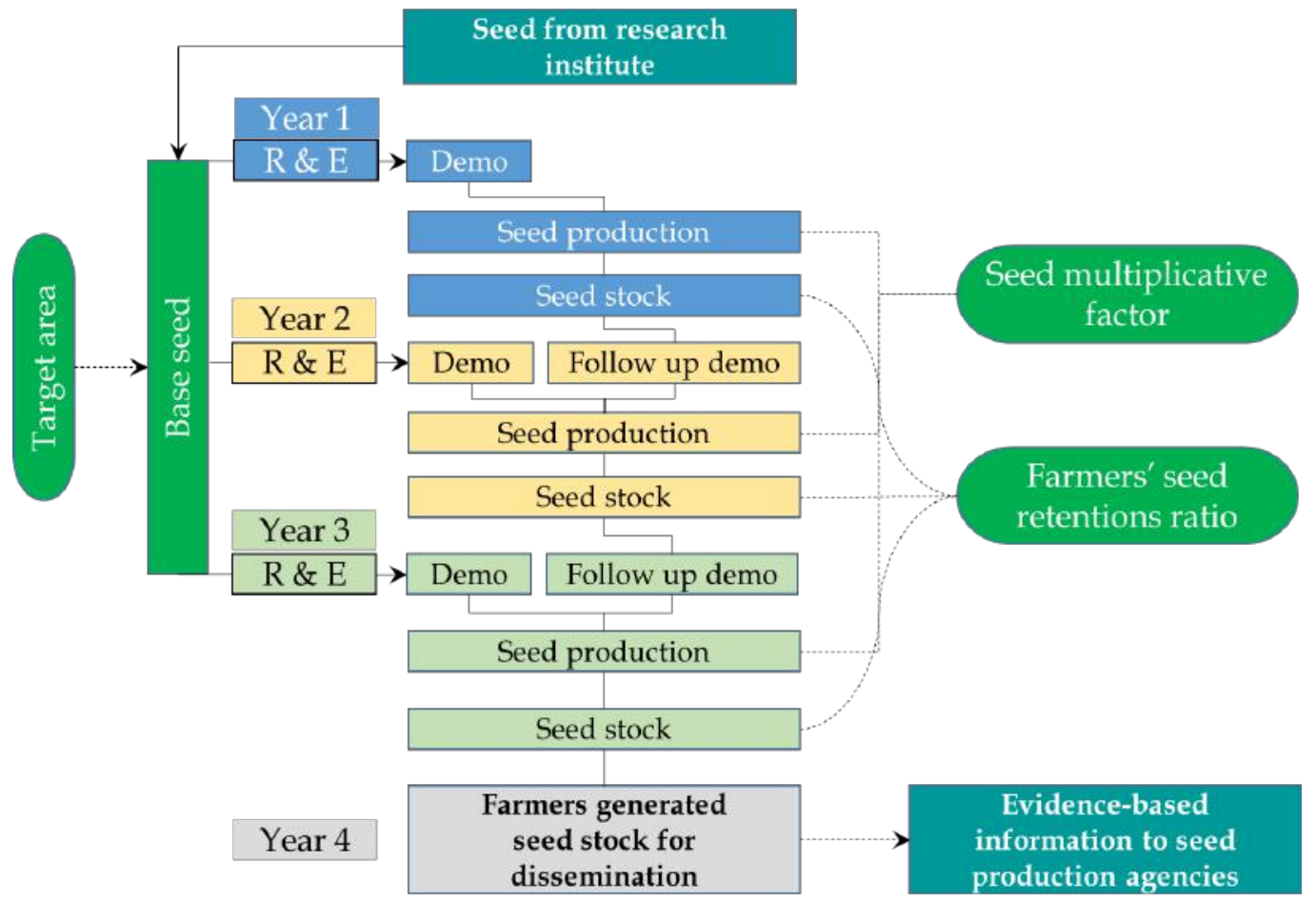

Fig. 16. Blueprint of accelerated diffusion for newly released rice varieties (AD4NRV) model. Rectangles are state variables or time period or execution bodies, while the ovals are auxiliary variables. Solid arrows and lines show material flow, and broken arrows and lines indicate information flow in the model. Blue, gold and light green rectangles represent the first, second, and third year's seed diffusion cycle. The ' $R \&$ $\mathrm{E}^{\prime}$ denotes for research and extension.

correspond to DP as observed in AD4NRV model. The seed diffusion will be carried out through two channels - demonstration (termed as 'demo') and follow up demo. The demos will be directly conducted by research and/or extension institutes (R \& E), while the follow up demos will be independently carried out by the farmers with required assistance and supervision from R \& E. All the seed diffusion activities will be carried out in farmers' fields. The demos, using the base seed, will be conducted in three years, while the follow up demos, using farmers' retained seed, will be carried out in year 2 and 3. Each farmer will use $5 \mathrm{~kg}$ seed 'bigha'-1 (1 'bigha' = 33 decimal $)$ in demo and/or follow up demos. The model assumes seed multiplicative rate of $80 \%$ sown seed, and farmers will retain $20 \%$ of produced seed. In the end of three years, the system will generate the diffusion intensity (DI) of the concerned variety. In addition, the output of the AD4NRV model will provide evidence-based information to public and private entities for commercial seed production.

\section{Application of AD4NRV model to determine DI under three LAPs}

The AD4NRV model was applied to estimate 16 diffusion outcomes aiming three scenarios of the time required to reach adoption peak LAP16, LAP13, and LAP10. We used four-levels of two determinants (auxiliary variables): 
amount of base seed available from research institute $(500,600,700$ and $800 \mathrm{~kg})$ and farmers seed retention $(20,25,30$ and $35 \%$ of produced seeds). BRRI dhan29, a mega-variety, was used a test variety for this analysis which received a maximum adoption of $42 \%$ by area during Boro season.

Results reveal that to achieve the diffusion intensity (DI) of $2.89 \%$ required for LAP16, it would require at least $500 \mathrm{~kg}$ of base seed with $20 \%$ retention involving 27,300 farmers (Fig. 17). For LAP13, achieving DI of $7.31 \%$, at least $700 \mathrm{~kg}$ of base seed with $25 \%$ retention will be needed which will involve 58,940 farmers. Little less than $600 \mathrm{~kg}$ base seed with 35\% retention will ensure materializing the required DI (16.37\%); for those 97,560 farmers would need to participate in demonstrations (Fig. 17). The results reveal that farmers' increased seed retention percentages, compared to base seed availability, will be more effective to curtail the LAP. This increased seed retention should ensure quality control in storage. Further interventions will include research-seed productionextension linkages, and large-scale training of farmers on quality seed production, processing and storage.

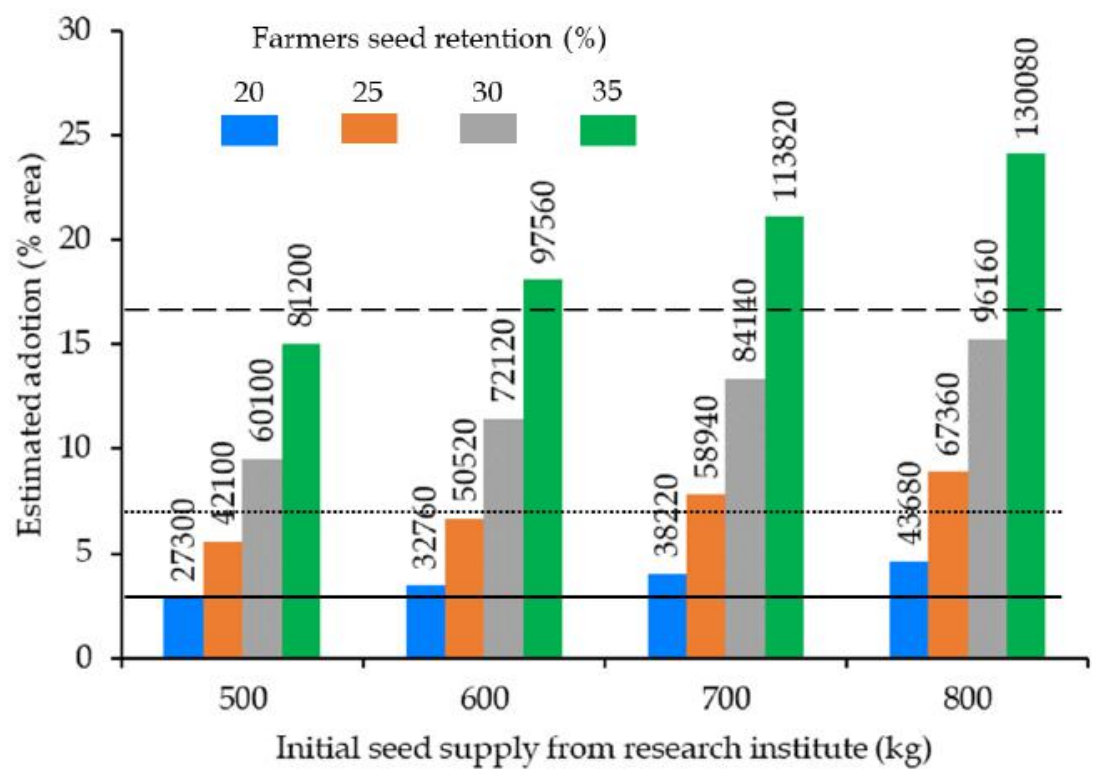

Fig. 17. AD4NRV model estimated 16 diffusion outcomes for a 'mega-variety', ${ }^{*}$ resulting from a combination of four-levels of two auxiliary variables: amount of base seed ${ }^{* *}$ available from research institute (500, 600, 700, and $800 \mathrm{~kg}$ ) and farmers seed retention $(20,25,30$ and 35\% of produced seeds). BRRI dhan29 was a test variety for this analysis which has the maximum adoption of $42 \%$ by area during Boro season. The solid, dotted and broken lines represent the required diffusion target (\%), estimated from GRVA model at the end of three years of release. Each numeric value shown on top of a bar indicates the number of demonstration needed for achieving the estimated diffusion outcome.

* A variety is designated as a 'mega-variety' which, within its adoption cycle, receives significant area coverage (perceived as at least $25 \%$ ) in a growing season.

** The seed to be used for demonstration, produced and supplied by variety releasing institute, during the releasing year. 


\section{Rice potential to ensure nutritional security}

In Bangladesh, rice has enormously contributed to the food security. Rice farming will likely be attracted in future if the crop can be valued beyond its traditional use of a 'calorie provider'. Varieties that are high in quality, rich in nutrition, and capable of producing value adding product would be lucrative and preferable to stakeholders. Such non-traditional utilization of rice has least been studied in Bangladesh. In this study, we have developed a profile of officially released rice varieties developed by BRRI, as data available, under three broad attributes quality, nutrition, and product diversity.

Among the tested varieties, nine were identified as rich in aroma (Fig. 18a and 18b), of which BRRI dhan34 has field adoption of $3.69 \%$ in T. Aman season, and BRRI dhan50 has $1.78 \%$ in Boro season. BRRI dhan 50 is also graded as premium quality rice (PQR). There are four other varieties recognized as PQR; among those, BRRI dhan 63 cover $1.07 \%$ of Boro rice area during 2019-20.

GER (Gama amino butyric acid enriched rice) has been recognized only in BRRI dhan31, IER (Iron enriched rice) in BRRI dhan84, and FSVA (Fat soluble Vitamin-A enriched rice) in BRRI dhan29; the latter variety has wide adoption (25.65\%). Three varieties (BRRI dhan71, BRRI dhan77, BRRI dhan83) were found rich in QAER (Quality amino acid enriched rice), and three (BR16, BRRI dhan46, BRRI dhan69) in LGR (Low glycemic indexed rice); current adoption rate of these varieties is low $(<1 \%)$ other than BR16 (1.20\%). It may be noted that diabetic affected people would have preference for LGR rich varieties. Eight varieties (BR5, BRRI dhan37, 84, 87, 88, 90, 94 and 99) are antioxidant enriched (AER), but they are not adopted widely by the farmers. Five varieties (BRRI dhan75, BRRI dhan76,
BRRI dhan77, BRRI dhan86, BRRI dhan87) possess QERB (Quality enriched rice bran), but their adoption is not fully scaled yet. The six (BRRI dhan70, BRRI dhan71, BRRI dhan75, BRRI dhan76, BRRI dhan77, BRRI dhan79) OER (Oryzanol enriched rice) are relatively newer and their adoption is yet to be fully explored in the field. Of the 7 WSV varieties (BR16, BRRI dhan28, BRRI dhan29, BRRI dhan36, BRRI dhan43, BRRI dhan48, BRRI dhan58), field adoption of all but BRRI dhan43 is high. Eight varieties (BRRI dhan42, BRRI dhan43, BRRI dhan62, BRRI dhan64, BRRI dhan72, BRRI dhan74, BRRI dhan84 and BRRI dhan100) have been identified as rich in zinc (ZER) but their adoption is poor. Of the ten identified protein rich (PRO) varieties, adoption is not high except BRRI dhan34; to be noted that this variety is also rich in aroma. The number of phosphorus and calcium rich varieties are relatively high (15 and 28, respectively). A few but not all of those varieties have good field adoption.

BRRI studies have identified product diversity in many varieties. For example, 25 varieties are suitable for energy-dense rice biscuits, 18 for flattened rice, 11 for popped rice, nine for puffed rice, 25 for rice biscuits, 25 for rice cake, 25 for rice dry cake and three for rice noodles (Fig. 18a and 18b). With few exceptions, varieties that possess inherent quality, nutrition and specific product diversity are not used for those purposes.

Rice production systems: The challenges and hopes

\section{The broad challenges}

Rice production environment of Bangladesh has been facing multidimensional challenges, as discussed briefly in our previous study (Kabir et al., 2015), which included population pressure and resource constraints. 

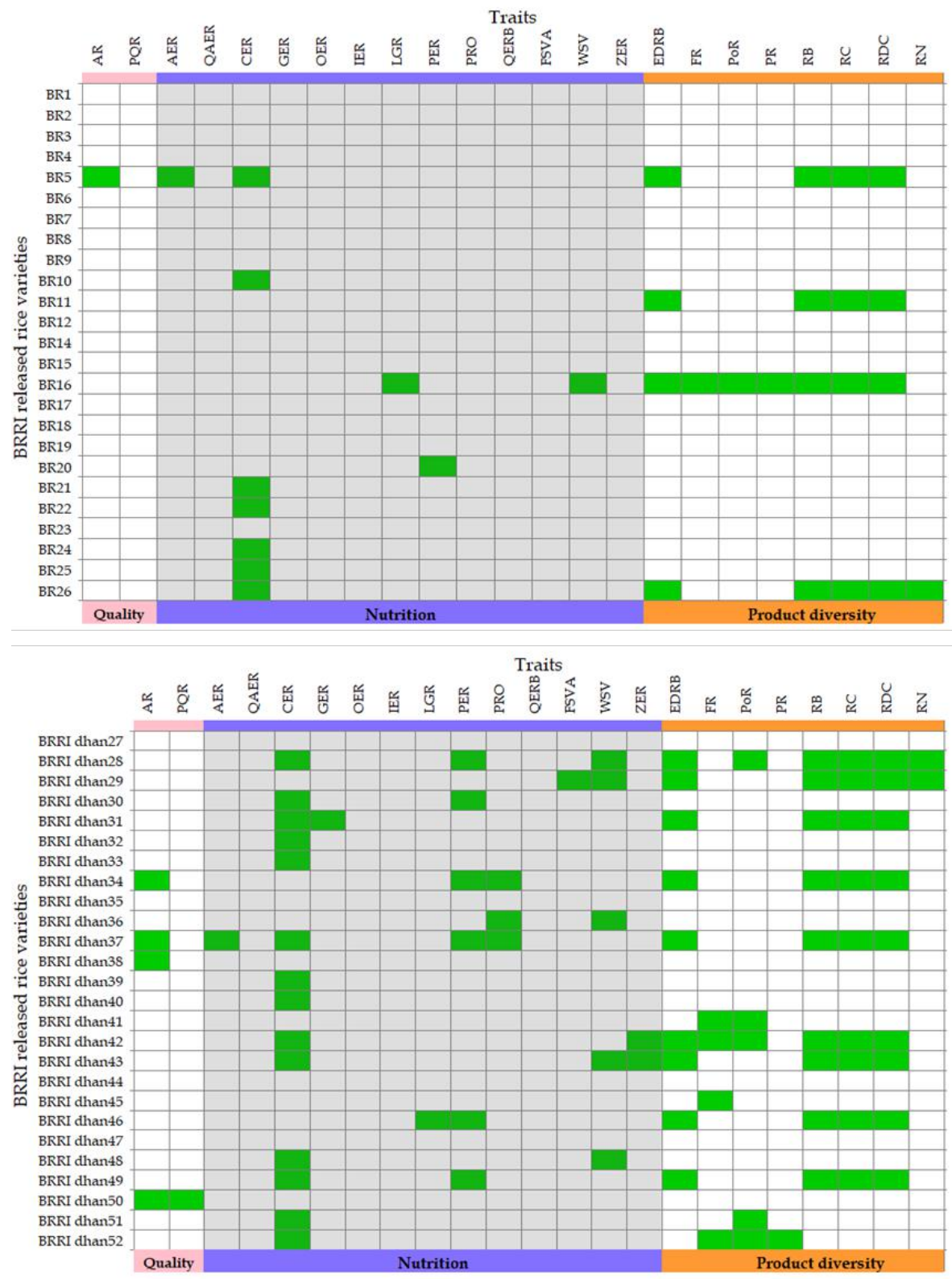

Fig. 18a. Quality, nutrition and product diversity characteristics of BRRI released rice varieties from BR1 to BRRI dhan52. AR, aromatic rice; PQR, Premium quality rice; AER, Antioxidant enriched rice; QAER, Quality amino acid enriched rice; CER, Calcium enriched rice; GER, Gama amino butyric acid enriched rice; OER, Oryzanol enriched rice; IER, Iron enriched rice; LGR, Low glycemic indexed rice; PER, Phosphorus enriched rice; PRO, Protein enriched rice; QERB, Quality enriched rice bran; FSVA, Fat soluble Vitamin-A enriched rice; WSV, Water soluble vitamin enriched rice; ZER, Zinc enriched rice; EDRB, Energy dense rice biscuit; FR, Flattened rice; PoR, Popped rice; PR, Puffed rice; RB, Rice biscuit; RC, Rice cake; RDC, Rice dry cake; RN, Rice noodles. 


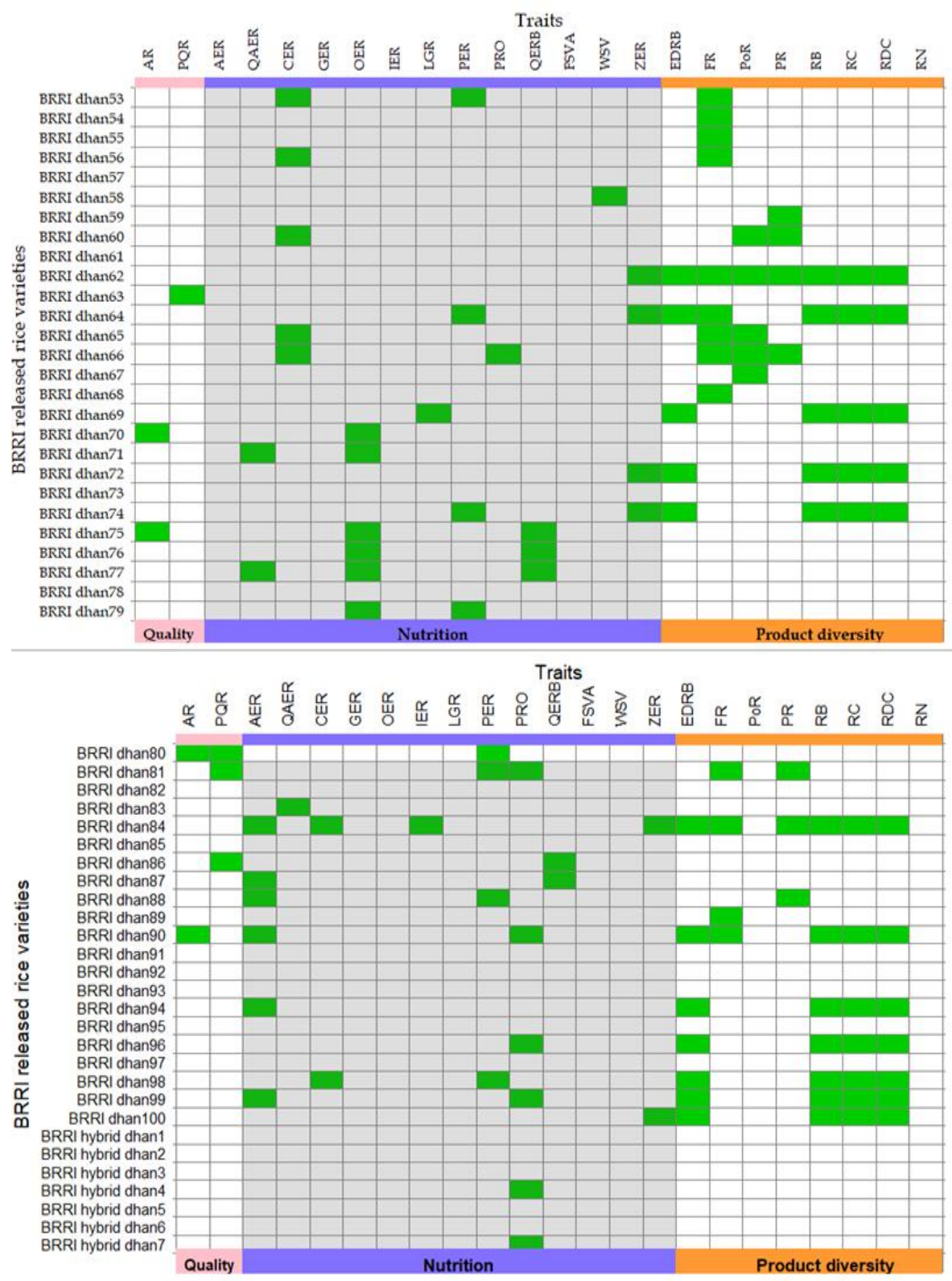

Fig. 18b. Quality, nutrition and product diversity characteristics of BRRI released rice varieties from BRRI dhan53 to BRRI hybrid dhan7. AR, aromatic rice; PQR, Premium quality rice; AER, Antioxidant enriched rice; QAER, Quality amino acid enriched rice; CER, Calcium enriched rice; GER, Gama amino butyric acid enriched rice; OER, Oryzanol enriched rice; IER, Iron enriched rice; LGR, Low glycemic indexed rice; PER, Phosphorus enriched rice; PRO, Protein enriched rice; QERB, Quality enriched rice bran; FSVA, Fat soluble Vitamin-A enriched rice; WSV, Water soluble vitamin enriched rice; ZER, Zinc enriched rice; EDRB, Energy dense rice biscuit; FR, Flattened rice; PoR, Popped rice; PR, Puffed rice; RB, Rice biscuit; RC, Rice cake; RDC, Rice dry cake; RN, Rice noodles. 
Newer challenges are driving the country towards a changed reality day by day and drawing attention for enhancing efficiency, quality, and safety through mitigating risks and other impediments.

The volume of rice production in Bangladesh is dictated by requirements for human consumption and non-human utilization. Increasing population has been demanding more rice to produce year by year. On the demand side, quality has been a rising issue that incorporates nutrition and food safety (Fig. 19). Meeting SDG, which the government is keen to achieve, is also added to the demand profile.

The rice production of Bangladesh has been constrained by limitation in resources and vulnerability in climate. The scope of utilization of natural resources, such as land and water, has narrowing both in terms of quantity and quality. Population pressure also exerting negative effect on availability of natural resources. Availability of labour in agricultural activities, including rice, has also been an issue in the last three decades. Bangladesh is one of the hot spots to climate vulnerability and is highly exposed to extreme weather events. Every year the country faces several extreme weather events has already been fighting to combat environmental risk and their impacts (WB, 2013).

Market risk frequently creates uncertainty in the rice production systems in Bangladesh. The price volatility has been a frequent threat to sustained rice cultivation. On the other side, the scope and profitability of many non-rice crops are increasing day-by-day. It has become an urgency to guarantee farmers' profitability for maintaining regularity in rice cultivation.

Bangladesh still experiencing low rice productivity due not been able to applying appropriate management options in adequacy and on time. Studies identified knowledge gap as one of the key factors for inadequately addressing crop management requirements.

Bangladesh rice sector is affected by various uncertain indirect crises, financial turmoil, political upheaval, and externalities. For example, in recent times Rohingya crisis, COVID-19 pandemic, and negative income shock are threatening the progress of the rice sector. Other challenges include subsistence type farming, small and uneconomical farm size, aging of farmers, low attraction of youth in agriculture, low agricultural diversification, and low profitability of rice farming.

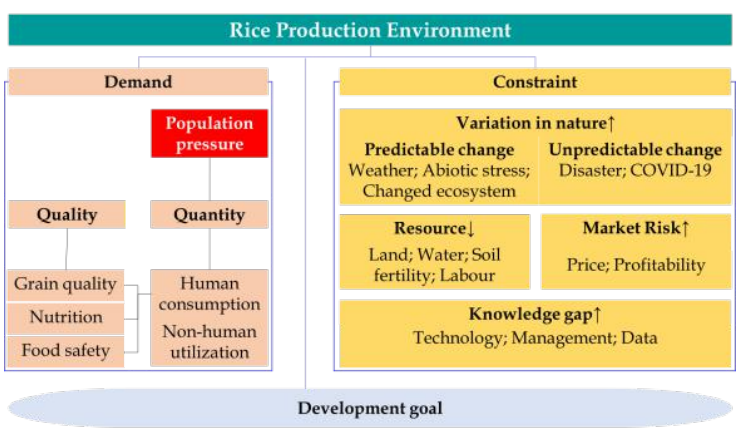

Fig. 19. A sketch of current rice production environment in Bangladesh showing demands and constraints.

\section{The hopes}

\section{Yield progress and availability of rice area}

The progress in yield, expressed as clean rice, in Bangladesh has been steady. The estimated clean rice yield has been found increasing linearly (Fig. 20) according to Holt-Winters seasonal method (Holt, 1957; Winters, 1960), which giving a strong indication that genetic potential of varieties is likely to increase. This relationship projected the yield at $95 \%$ confidence interval for 2030 as in the range of $3.06-4.53 \mathrm{tha}^{-1}$ and for 2050 as $3.00-6.56 \mathrm{t} \mathrm{ha}^{-1}$; the figures of GenPot values what we set in this study sit within the ranges, and also supported by Salam et al. (2019a). 


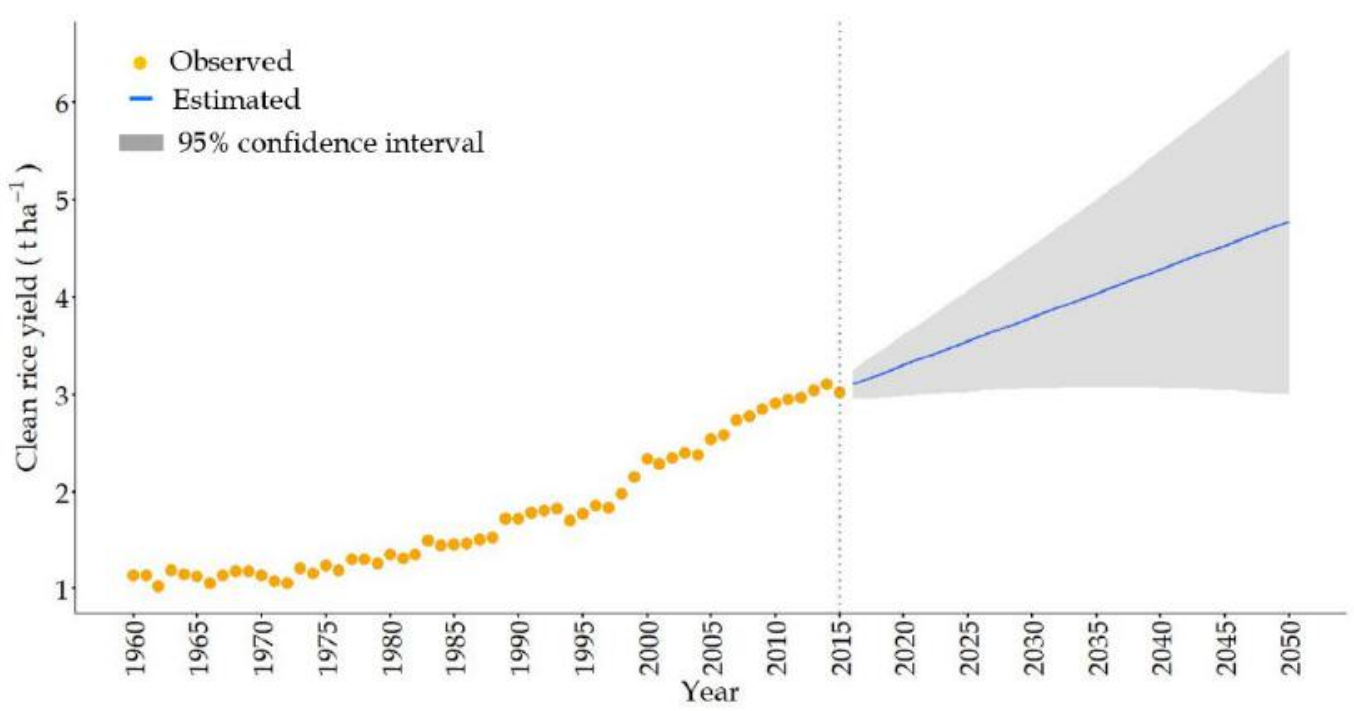

Fig. 20. Historical trend (1960 - 2015) and estimation of future (2016 - 2050) clean rice yield in Bangladesh.

Crop production increase is classically addressed either through vertical dimension i.e., yield, or horizontal dimension i.e., cultivation area. Bangladesh has bright prospect of utilizing both the dimensions for increasing rice production estimated for the period 2020 - 2050. We have shown our analyzed results above on how the country will be capitalizing genetic improvements for continued rice yield advantage. Bangladesh has three main rice growing seasons - Aus, Aman (principally transplant Aman (T. Aman)) and Boro. Our estimation shows the area under Aus, the early monsoon rice, will be heading around $1.45-1.50 \mathrm{M}$ ha in 2030, $1.50-$ $1.60 \mathrm{M}$ ha in 2040 and 1.60 to $1.70 \mathrm{M}$ ha in 2050 from 1.25 to $1.30 \mathrm{M}$ ha in 2020 . Together with the increasing yield prospect and steady improvements in crop management, the production of clean rice in Aus season in 2030, 2040 and 2050 has been estimated in the range of 4.82 4.99 MT, 6.07 - 6.47 MT and 7.62 to 8.10 MT, respectively. Similarly, rice production, through both vertical and horizontal dimensions, has conservatively estimated in the range of 16.48 16.77 MT, 18.00 - 18.53 MT and 17.09 - 20.34 MT in Aman season, and in the range of 21.76 -
21.99 MT, 22.91 - 23.65 MT and 22.49 - 25.28 MT in Boro season during 2030, 2040 and 2050, respectively. Taken all together, Bangladesh would be able to produce $43.06-43.74 \mathrm{MT}$ of clean rice in 2030 from $12.00-12.20 \mathrm{M}$ ha of gross rice area, $46.97-48.66 \mathrm{MT}$ of clean rice in 2040 from $11.85-12.27 \mathrm{M}$ ha of gross rice area and 47.20 - 53.72 MT of clean rice in 2050 from $10.78-12.35 \mathrm{M}$ ha of gross rice area. Year-byyear estimated area, yield and production of clean rice in three seasons have been presented in Appendix 1. It is to be noted that the stakeholders to meet the season-wise rice production area in the estimated ranges to ensure the production estimates. Those estimated target area and production figures will ensure to maintain future rice security of the country; any increase in target area and production over the estimates will further strengthen the rice reserve in the national food basket.

\section{Resisting the effect of climate change}

The evidence relating climate change and rice productivity in Bangladesh at macro-level is limited. In this study, we attempted to find a re- 
lationship between seasonal potential evapotranspiration and yield of Boro rice in specific locations, and anomalies in annual temperature and rice nationally.

\section{Relationship between potential evapotranspiration and rice yield}

The relationship between evapotranspiration and Boro rice yield was assessed based on historical (1981-2016) climatic parameters (e.g., maximum and minimum air temperature, relative humidity, wind speed, and bright sunshine hours) induced changes in $\mathrm{ET}_{0}$. During the period of 1981 to 2016, the linear decrease in $\mathrm{ET}_{0}$ @ $-0.0164 \mathrm{~mm}$ day $^{-1}$ had been significant $(\mathrm{Y}=$ 36.709 - 0.0164*Year, $\mathrm{R}^{2}=0.45 ; \mathrm{N}=36, \mathrm{P}<0.001$ ), indicating climatic change had taken place in the districts (Fig. 21). The decreased ET $_{0}$ could be explained by the combined effect of decreasing solar radiation (derived from bright sunshine hours) and wind speed and increasing mean air temperature and relative humidity of the study regions. On the other hand, clean rice yield had increased linearly and significantly ( $\mathrm{Y}$ $=-116.586+0.0599 *$ Year, $\mathrm{R}^{2}=0.95 ; \mathrm{N}=36$; $\mathrm{P}<0.001)$. Between the two variables, the correlation was significantly negative $(\mathrm{r}=-0.658 ; \mathrm{N}=$ 36; $\mathrm{P}<0.001)$.

\section{Relationship between temperature and rice yield}

During the period of 1961 to 2016, the linear increase in temperature anomaly @ $0.012{ }^{\circ} \mathrm{C}$ had been significant $\left(\mathrm{Y}=-23.23+0.0118^{*}\right.$ Year, $\mathrm{R}^{2}=$ $0.37 ; \mathrm{N}=56, \mathrm{P}<0.001$ ), indicating temperature variability had taken place in Bangladesh (Fig. 22). On the other hand, clean rice yield had increased linearly and significantly $(\mathrm{Y}=-78.107$ $+0.0396^{*}$ Year, $\mathrm{R}^{2}=0.92 ; \mathrm{N}=36 ; \mathrm{P}<0.001$ ). Between the two variables, the correlation was significantly positive $(\mathrm{r}=0.613 ; \mathrm{N}=36$; $\mathrm{P}<0.001$ ). In the scenario of overall Bangladesh, the historical (1961-2016) temperature anomaly was positively related to clean rice yield in Bangladesh (Fig. 22).

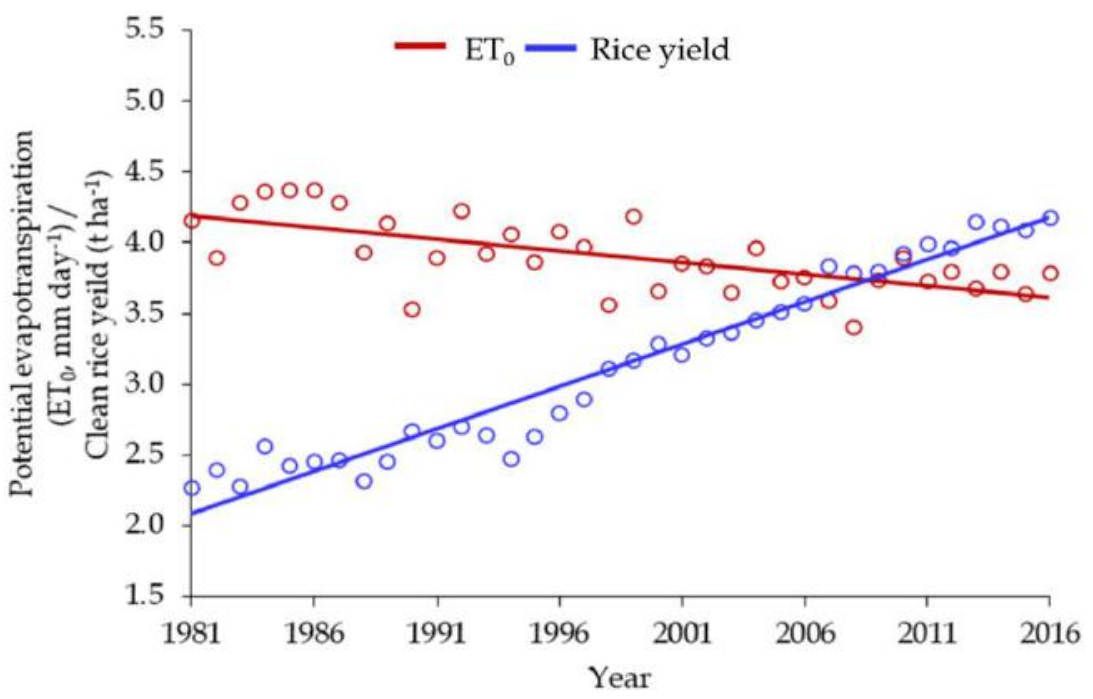

Fig. 21. Trend in potential evapotranspiration $\left(\mathrm{ET}_{0}\right)$ and clean rice yield during Boro season of 1981-2016. Data of both variables are averages for four administrative districts of Bangladesh - Faridpur, Khulna, Mymensingh and Rajshahi. 


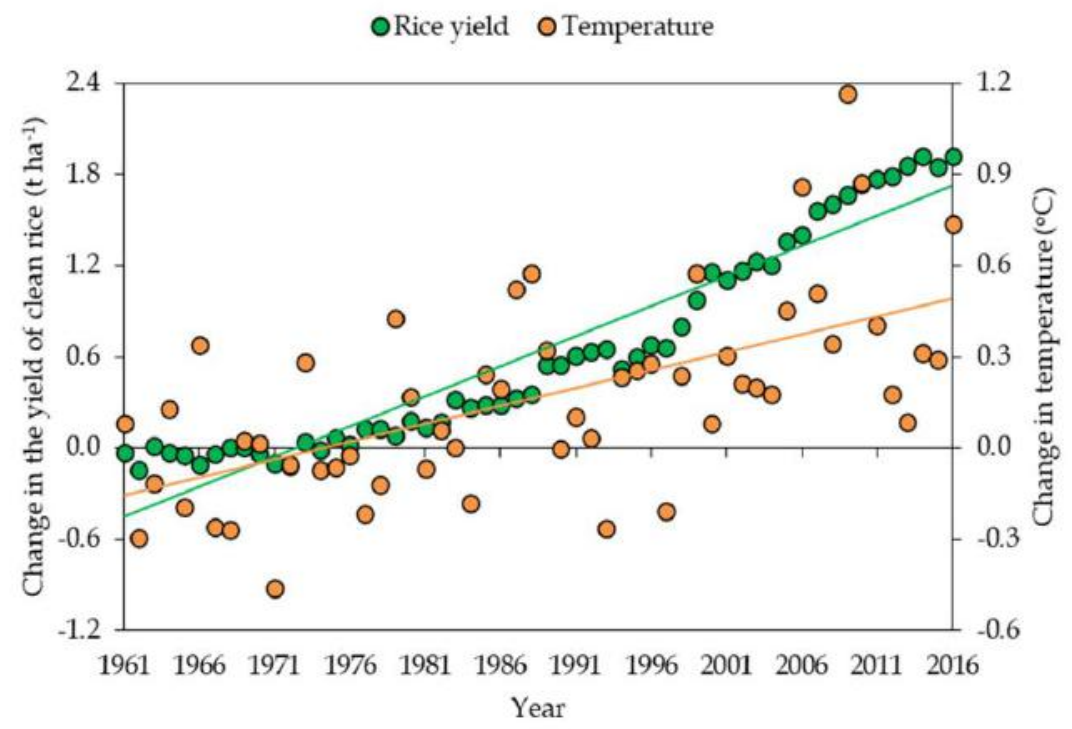

Fig. 22. Relationship between the variability in yearly anomalies of temperature and clean rice yield in Bangladesh during the period of 1961-2016.

\section{Rice Sustainability}

A conceptual framework for sustainable rice production is presented in Figure 23. The framework has four dimensions. The Dimension-1 (Economic sustainability) consists of three sub-indicators - farm output, net farm income, and economic resilience.
The status of soil degradation, water availability, fertilizers and pesticide management and biodiversity-supportive practices are the sub-indicators of Dimension-2 (environmental sustainability). Three sub-indicators represent Dimension-3 (social sustainability) - the off-

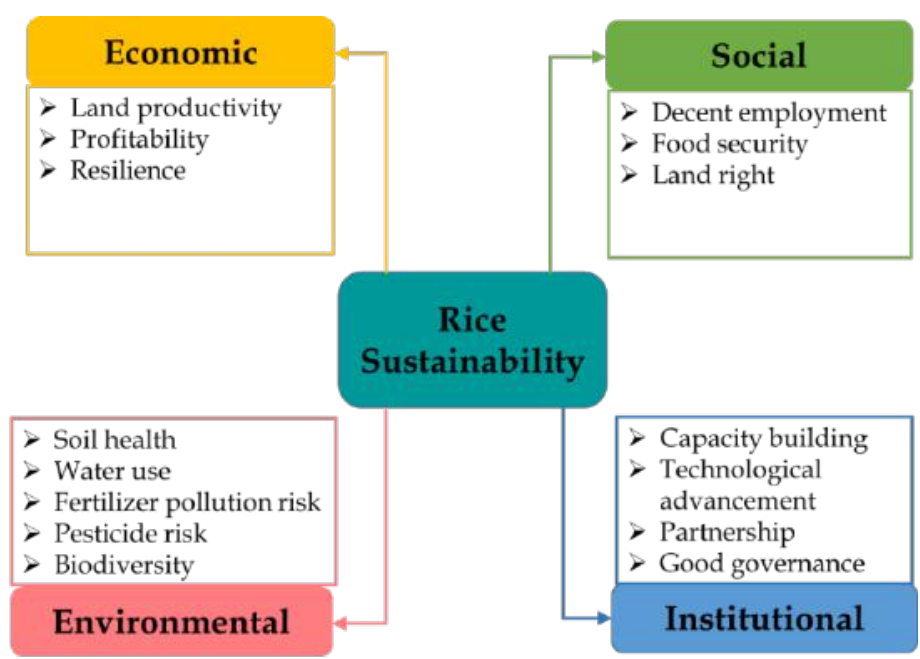

Fig. 23. A conceptual framework for sustainable rice production in Bangladesh. 
farm employment opportunity, scale of food insecurity and malnutrition experience, and tenurial rights to land. Finally, the capacity building, technological enhancement, partnership development, and good governance are grouped in Dimension-4 (institutional sustainability) as sub-indicators. The sub-indicators of the sustainability dimensions were measured using published and unpublished data from literature, secondary sources, experiments, and field surveys.

\section{Economic dimension}

\section{Land productivity}

Land and labour productivity are presented in Figure 24. The per hectare productivity of land under Aus, T. Aman and Boro rice was higher by $7.3 \%, 17.2 \%$ and $5.5 \%$, respectively in 2020 compared to SDGs base year (2016). Besides, the rate of increase of labour productivity per work-day of Aus, T. Aman and Boro rice was higher by 3-5\% in 2020 compared to 2016 (Fig. 24).

\section{Profitability and risk}

Gross income or margin (per hectare) of Aus, T. Aman, and Boro rice was found increased by $7.1,4.8$ and $10.2 \%$ in 2020 from the base year

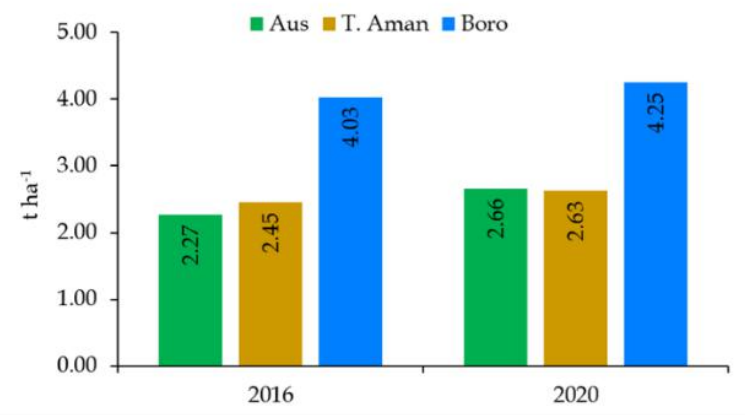

a. Production per unit of land
(Fig. 25a). Increased farm income resulted from decreased production costs. This cost reduction occurred due to increased adoption of farm machineries and receiving better rough rice prices. Figure 25b shows that the semi-mechanized and mechanized cultivation reduced per hectare cost of rice production by BDT 23,203 and BDT 42,664, respectively.

However, rice farming in Aus, T. Aman and Boro season has been highly risky (i.e., probability of having negative net income is very high) under the current market and environmental conditions due to high seasonal variation in yield and price. Nevertheless, the probability of having a negative net income of rough rice decreased to zero under the extrapolated yield and price in 2030, indicating that rice cultivation irrespective of seasons will be economically sustainable subject to meeting the targeted Ref-MinPro, and ensuring farmers' access to projected price (Kabir et al., 2020). In addition, improved profit would be achieved through development of farm-to-market linkages and increase resource use efficiency in the area of irrigation, fertilizer management and labour.

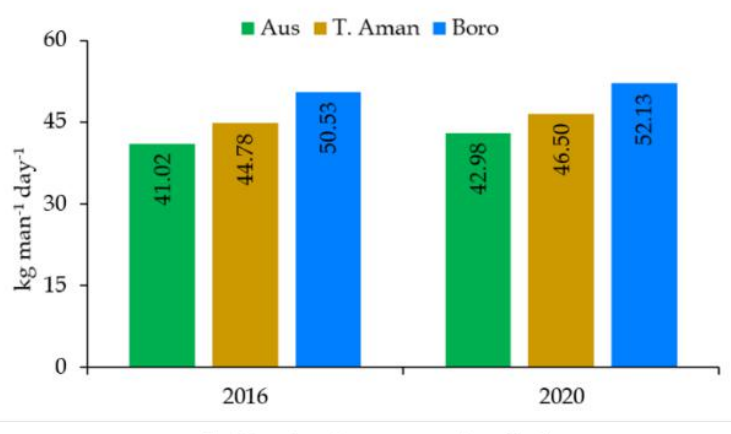

b. Production per unit of labour

Fig. 24. Productivity of land and labour in Aus, T. Aman and Boro season in Bangladesh. Authors' calculation based on DAE, 2020 and field survey, 2020 data. 


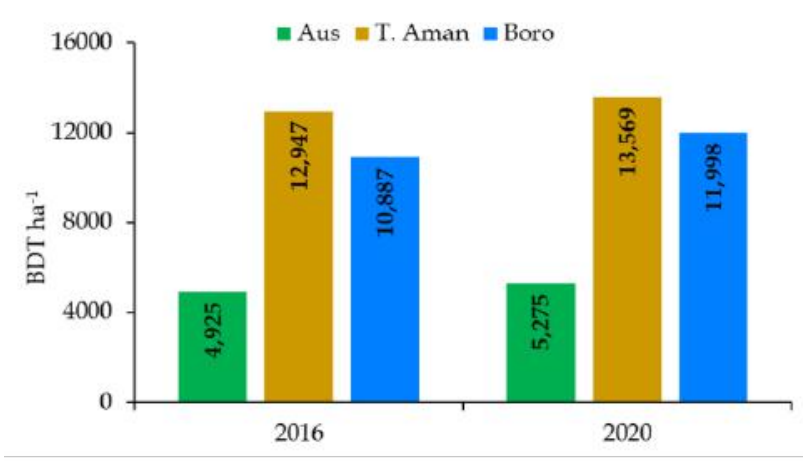

a. Rice farmers gross income

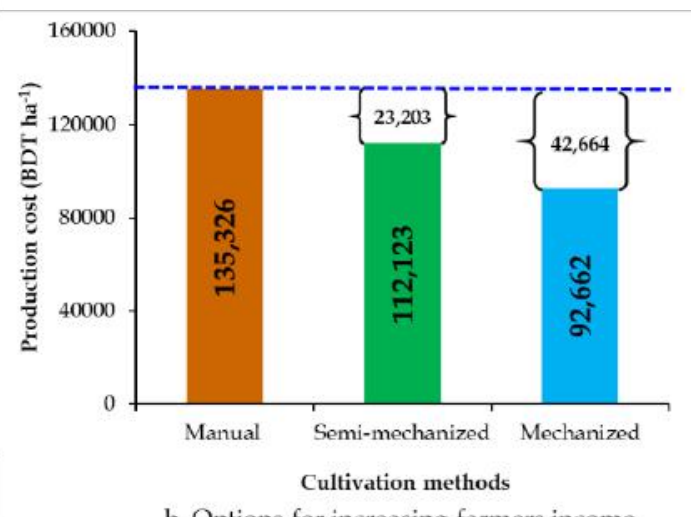

b. Options for increasing farmers income

Fig. 25. Gross income from rice cultivation and options for further increasing farmers' income in Bangladesh. Authors' calculation based on field survey data.

\section{Resilience}

The abiotic stresses, including salinity, submergence, drought and biotic agents (e.g., insects and diseases) are potential production risk factors for natural weather dependent rice production in Bangladesh. Those stresses play a vital role in the seasonal variation in rice productivity. Therefore, increased adoption of stresstolerant rice cultivars may notably alleviate the production risk. Figure 26 shows that the adoption of salinity, submergence and drought-tolerant rice cultivars were $35 \%, 26 \%$ and $12 \%$, respectively, which increased rice production by

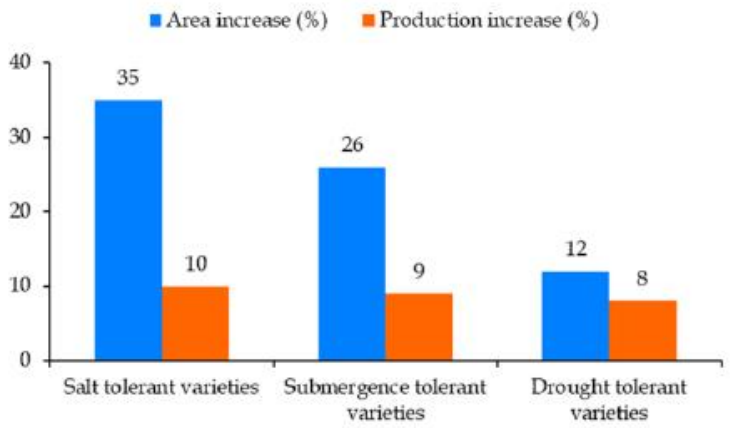

Fig. 26. Area coverage of the stress tolerant rice varieties and their contribution to the national food basket. Prepared by authors based on data from DAE.
10,9 , and $8 \%$ for respective stress-tolerant areas. This success has achieved through applying climate smart technology and practices such as ecology suited seed production, short duration variety, mechanization, and knowledge sharing and training.

\section{Environmental dimension}

\section{Soil health}

The results of a long-term experiment (33 years) confirmed that the negative net carbon balance in the fields adversely affected, consequently deteriorated soil health due only to chemical fertilizer dependent nutrient management for rice crops in Bangladesh. As a result, soil of about $40 \%$ of the net cropped area of the country is under health risk (Haque et al., 2019). The incorporation of (i) $20 \mathrm{~cm}$ of rice straw into the soils of the rice-rice cropping patterns, (ii) Sesbania (S. rostrata) cultivation during the fallow period and incorporation into the soil, and (iii) increased application of organic fertilizers (such as, kitchen waste) and farmyard manure in the crop fields may reduce soil health risk (Details in Haque et al. 2020). 


\section{Water requirement for irrigated rice}

Figure 27 presents the water requirement for producing a kilogram of rough rice both in alternate wetting and drying (AWD) method and farmers' practice (FP). The water consumption of rice crops in the dry season (Boro) depends on soil texture, variety, and seasonal variation in the temperature and rainfall between the years. The average water requirement of irrigated Boro rice per kilogram vary in the range between 807 - 1,887 liters depending on the locations; this variation occurs due to variation in

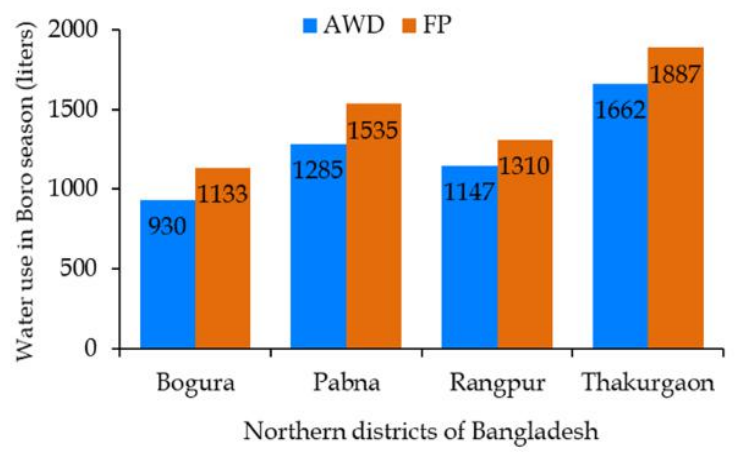

a. Water use in Boro rice cultivation, 2016-17 ble for current yield loss in the country, and human and soil health risk. Improvement of farmers' (i) knowledge about recommended fertilizer and pesticide management for rice crops and (ii) awareness about harmful consequences of improper fertilizer and pesticides management on human and soil health through providing training to farmers, and demonstration across the country may substantially reduce the yield gap and health risk for both the soil and human.

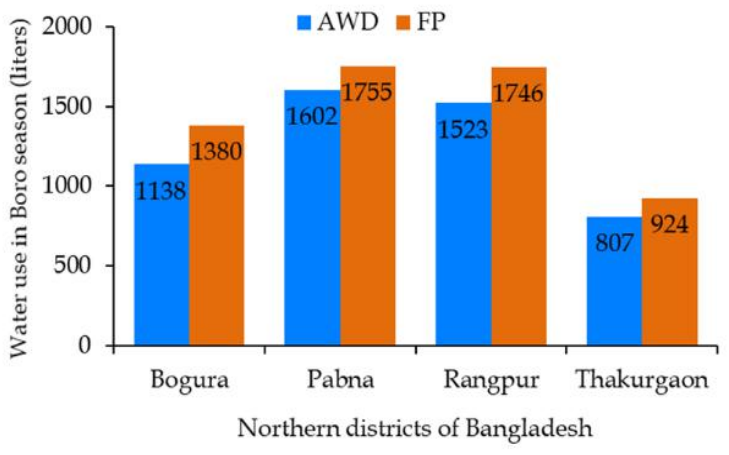

b. Water use in Boro rice cultivation, 2017-18

Fig. 27. Water requirement for producing a kilogram of rough rice. AWD and FP denote for alternate wetting and drying, and farmers' practice, respectively. Source: Adopted from BRRI (2019).

soil types, transplanting time and growth duration of the rice cultivars. However, the water consumption of the irrigated Boro rice might decrease under increased adoption of watersaving technologies.

\section{Chemical fertilizer and pesticide risk}

There has been significant gap between farmers' practices and scientific recommendations of fertilizer and pesticide management for the rice crops; this is because of inadequate knowledge of farmers about the recommended practices, and awareness about the harmful effect of applied practices on soil and human health (Miah et al., 2019; Ali et al., 2020). This gap is responsi-

\section{Biodiversity}

The decreased biodiversity of rice cultivars globally is an adverse consequence of the development of plant breeding techniques and extension programme for the adoption of higher yield potential modern cultivars to meet up the increased demand of rice grain for the growing population. Besides, biodiversity in the fauna in the rice fields also decreased substantially in the globe due to the increased adoption of chemical methods for controlling harmful arthropods and pathogens in rice crops. However, continuing cultivation of some higher yield potential and special traits cultivars in particular aro- 
matic rice in some areas and increased extension programme for adoption of biological and mechanical controlling methods of pest may improve ecological balance through increasing biodiversity. Especially, the biodiversity-supportive practices such as perching, eco-agriculture (Ali et al., 2019), and restricting the application of pesticides within 30 days of transplanting, need to be implemented in rice fields to conserve biodiversity in Bangladesh. Furthermore, maintaining rice genebank and improving yield of traditional varieties will contribute to biodiversity conservation.

\section{Social dimension}

\section{Decent employment}

Agriculture, in particular, rice farming, generates employment of $40.60 \%$ of the total labour force in the country (BER, 2019). Gender inequality still remains in the wages and earnings of agricultural labourers (Fig. 28). We should minimize gender gap in agriculture through effective policy intervention. The employment opportunity in agriculture sector might be increased further in the future due to the increased intensity of cropping in the country. Besides, the development of entrepreneurship on producing, marketing, maintenance and custom hire-based rental service of farm machineries as well as operating the farm machineries may increase the employment opportunity in the country. Moreover, a large number of people are currently employed in the value-adding sector of rice and employment opportunities in the sector will further increase in future as well.

\section{Food security}

The rice self-sufficiency ratio (RSSR) has been around $68 \%$ immediately after independence. Since then, it started increasing slowly (Fig. 29). During 1999, the RSSR sharply jumped to over $92 \%$. Towards the beginning of the current decade, Bangladesh crossed the self-sufficiency line $(100 \%)$. The dataset of the Food Planning and Monitoring Unit (FPMU) of the Ministry of Food, Government of Bangladesh (http:/ /fpm u.gov.bd/fpmu-database/0103.htm, accessed

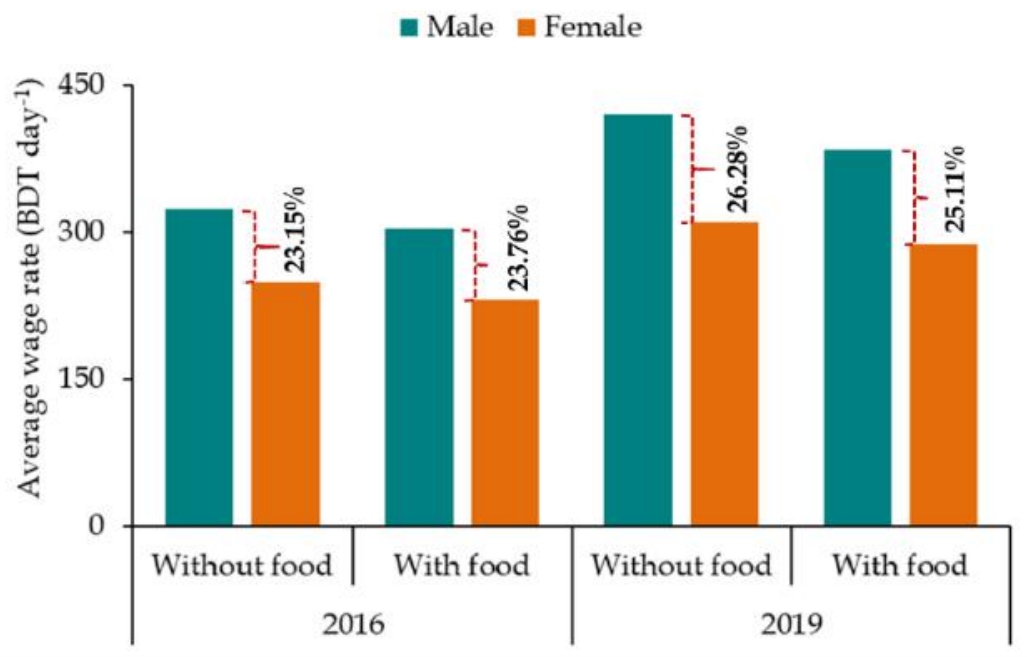

Fig. 28. Wage of male and female agricultural labourers in Bangladesh under two packages: food supplied ('with food') and no food supplied ('without food') by landlords. Also shown the wage gap between two genders. Source: Prepared by authors based on data from BBS (2020). 
on 17 November 2020) showed continued positive balance of foodgrain since 2007-08, a similar timing and trend estimated in our study. It is then evident from the figure that the country has remarkably transformed herself from so called 'bottomless basket' to 'full of food basket'. Although Bangladesh is in a strong position of maintaining self-sufficiency in rice, yearto-year variability still exists. Besides availability, there are other components of food security, which this study did not cover. Efforts to be made to highlight all the additional components (such as affordability, nutrition and stability) to comprehensively address food security of Bangladesh.

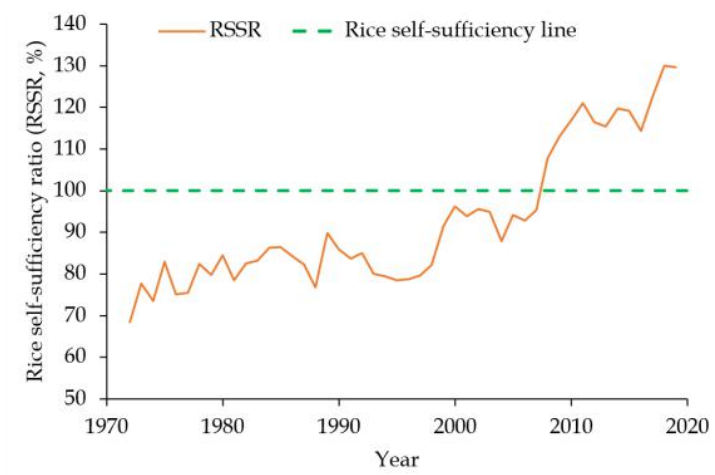

Fig. 29. Rice self-sufficiency ratio in Bangladesh during 1972 to 2019.

\section{Land right}

The current system of land tenure is based on the Land Reform Act of 1950, which abolished the British colonial landlord system. In Bangladesh, three types of tenurial arrangements are found, such as owner, owner-cum-tenant, and pure tenant operators. At present, about 56.92, 38.55 , and $4.53 \%$ of the total farm holdings are managed by owner (who cultivate their own land), owner-cum-tenant, and tenant operators, respectively. The historical trends (1960-2019) show that the owner operators have been decreasing significantly, whereas the owner-cumtenants have been increasing sharply (Fig. 30).
Productivity is closely linked to the land tenurial arrangements. Rice productivity of tenant operated farms found lower than owner-operated farms due to insecure land rights and less contribution of property owners in production cost (Islam, 2017). However, the contractual arrangements of the tenancy have been classified into two groups, for example, crop-share and fixed-rent tenancy. Surprisingly, the productivity and efficiency are higher on fixed-rent tenancy than on the crop-share tenancy (Nasrin and Uddin, 2011; Islam and Fukui, 2018). Therefore, development law for land tenurial arrangement for ensuring the right for operating the land for a specific period and rental fees per year may secure the right to the land of tenant farmers, consequently, rice productivity would increase.

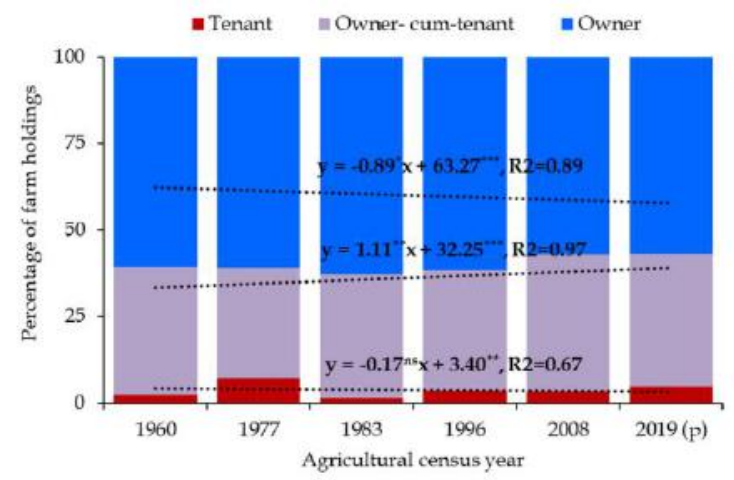

Fig. 30. Historical land tenurial arrangement in Bangladesh. Note: 'p' for provisional, ' ${ }^{\star \prime}$ ' for $10 \%$ level of significance, ‘**' for $5 \%$ level of significance, ' $* * *$ for $1 \%$ level of significance, and 'ns' for not significant. Prepared by authors based on data from different issues of Agricultural Census, Bangladesh.

\section{Institutional capacity}

The skilled manpower is a cornerstone for developing higher yield potential and stress-tolerant rice cultivars, component technologies, and disseminating the technologies to the end-users. Therefore, institutional capacity needs to be increased by increasing the skills of its manpower. Thus, the arrangement of short term 
and long-term training in the country and overseas for improving the skills of manpower of the institutes is a must. Besides, development of national and international partnerships is very important to minimize the gap between scientists' achievement and farmers' output. On top of that, adequate investment would be needed to develop enhanced research facilities and manpower. Moreover, good governance will ensure transparency, accountability, participation, and inclusion to all for achieving the development agenda 2030 and beyond.

\section{Overcoming market inequity and price insta- bility}

Figure 31 shows that farmers' share of consumer price decreased to $41 \%$ in 2019 from 65\% in 2000, indicating that the influence of producers in the rice market has been decreasing over time. The cost-benefit analysis shows that, while the rice growers pay higher cost of production, the value-adding stakeholders reap the maximum benefit. This indicates that there have been notable discrepancies in the allocation of consumers' price share between the stakeholders. This inequity might be alleviated by setting the maximum consumer price share limit by $55 \%, 25 \%, 7 \%$, and $13 \%$ for producers, millers, paddy traders and rice traders, respectively. This will be ensured through strengthening the value chain with strong farm-to-market linkage, rural infrastructure, and information to improve the market system.

An ensured access to remunerative and stable market price is a necessity for sustainable rice production and productivity, since, the rice market is inherently unstable, and the growers often inflict unexpected income losses. Thus, a Commission faor Agricultural Costs and Prices (CACP) is proposed to form through restructuring the Department of Agricultural Marketing (DAM) as an attached office of the Ministry of Agriculture to (i) alleviate the existing scrupulous market deals between the value-added stakeholders, and (ii) ensure a fair price to the producers. The CACP will be mandated to recommend grain type-wise minimum support prices (MSPs) of rough rice to incentivize farmers for increasing productivity and overall grain production in the country. The CACP will determine the grain type-wise MSP for harvesting (wet rough rice) and post-harvesting (dry rough rice) period by considering (i) demand and supply; (ii) cost of production; (iii) price trends in domestic and international markets;

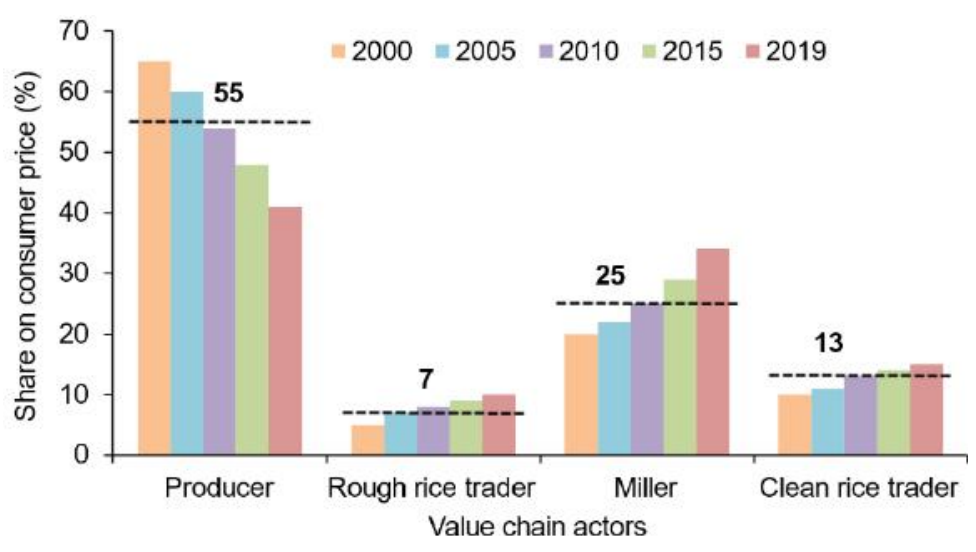

Fig. 31. Change in the share of rice price during 2000 - 2019 by the value chain actors accumulated into consumer's price. The numbers above broken lines indicate the lower thresholds for respective value chain actors. 
(iv) inter-crop price parity; (v) terms of trade between agriculture and non-agriculture; (vi) a minimum of 20 percent as the margin over the cost of production; and (vii) likely implications of MSP on consumers of that product. The grain type-wise minimum support price is a guaranteed price of rough rice at the local market during harvesting and post-harvest period to protect farmers from unexpected losses due to price falls. In other words, MSP is determined to set a floor below which the market prices cannot fall. The government will declare the grain type-wise MSP for wet and dry rough rice based on the recommendation of CACP before the planting season of crops so that the growers could make decisions for the allocation of land considering the potential intensive of the crops based on the support price. The government will purchase the rough rice in case the market price falls below the announced minimum price either because of higher production or because of scruples deal of value-adding stakeholders.

Besides, a triangular procurement model might be developed for farmers' ensuring access to MSP and shifting the government rough rice procurement benefit to real farmers, including small and marginal from the market intermediaries (Fig. 32). The CACP and local administrative unit will function as a decision-making unit and an implementation unit, respectively in the procurement model. PPC will be established at union-level where procurement activities will be carried out.

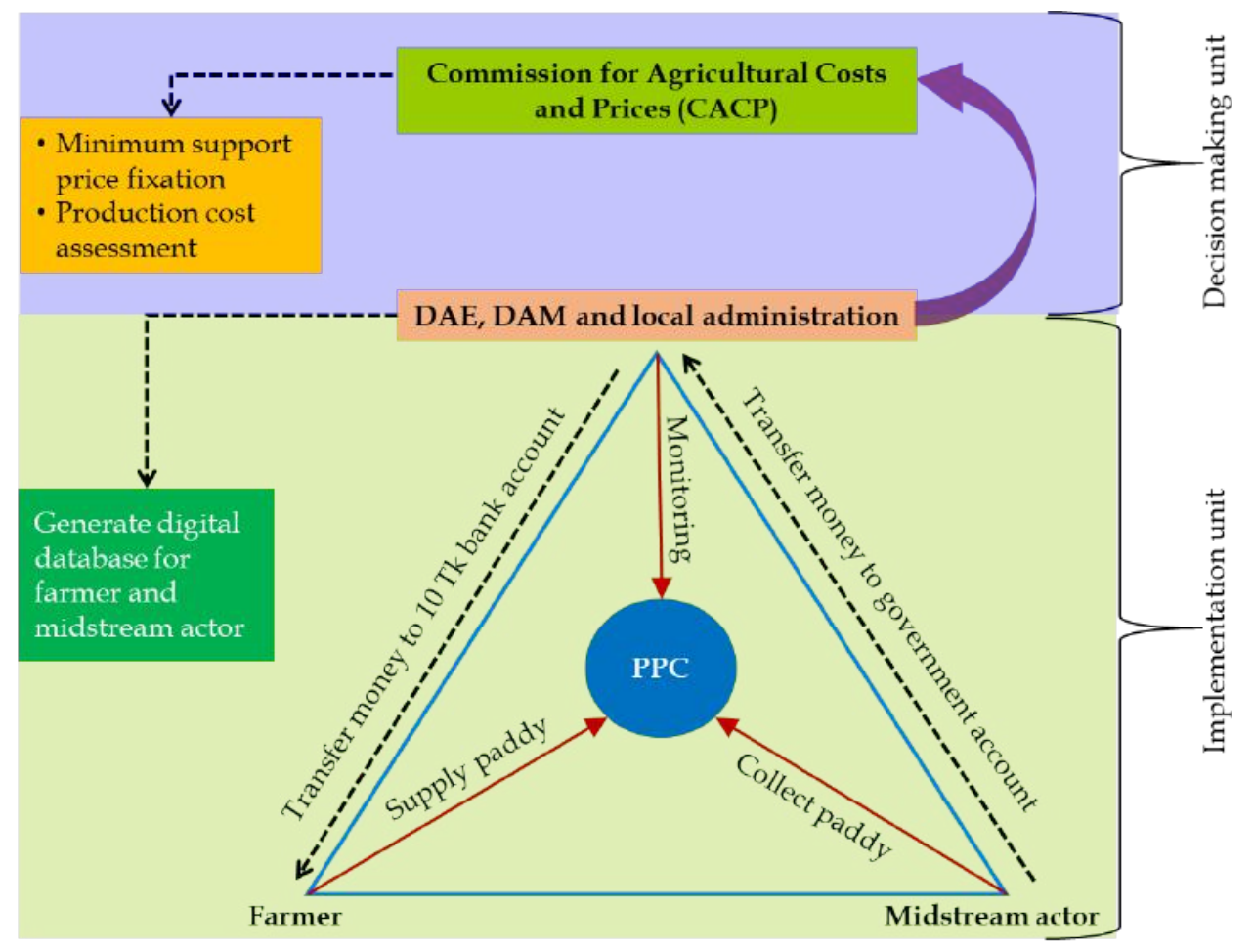

Fig. 32. A proposed concept of triangular rice procurement system for Bangladesh. DAE, DAM and PPC denotes for Department of Agricultural Extension, Department of Agricultural Marketing, and Public Procurement Center, respectively. The initial concept was presented by the lead author in the International Rice Congress 2018 (IRC2018) held in Singapore during 14 - 18 October 2018. 
Firstly, the decision-making unit e.g., the CACP will prepare a district-wise database on basic information, including farm size and mobile number of farmers and value-adding stakeholders; the database will be updated before each cropping season. The Department of Agricultural Extension (DAE) and local administration will assist the commission to develop the database. As discussed, the government will declare the floor price of rough rice for the local market in the harvesting season as suggested by the CACP.

Secondly, the CACP will broadcast the grain type-wise MSPs at harvesting (wet rough rice) and post-harvesting (dry rough rice) period and the list of local level procurement centers in mass media. Besides, they will pass the information to enlisted producers and valueadding stakeholders, including traders and millers. The producers, traders and millers will assemble at PPC for marketing the rough rice at the government declared grain type-wise MSPs at harvesting and post-harvesting season. Besides, the government will procure rough rice from the procurement location at MSP. It may be noted that the government has to develop infrastructural facilities for drying the rough rice that was procured from a local level procurement place.

Finally, the traders and millers will transfer the grain type-wise MSP of the rough rice at harvesting and post-harvesting period to the government account through online/mobile banking with farmers' information, including name, mobile number and bank details. The money will be automatically transferred to the respective farmers' bank account from the government account. The bank will send a text message to farmers' mobile number as confirmation of depositing the money to their account. Similarly, the value of the government procured rough rice from the local procurement center will also be directly paid to the respective farmers account for ensuring accountability. An inter-ministerial monitoring team and the CACP personnel will regularly monitor the rice market.

\section{Key interventions}

In order to materialize the DRP framework, 22 key interventions have been proposed across the three wings (Table 3). The state-of-art methods and tools will be employed for varietal development, capacity building of scientists, extension agents, farmers, influencers and value chain actors will be undertaken, and public private partnership will be developed, nurtured and maintained in research and development (R\&D) across the wings. Special efforts will be made to increase input use efficiency in the area of irrigation, fertilizer management and labour, while digital technologies will be used for breeding automation, data collection and processing, market information, robotics and technology inventory. We plan to develop synthesized research delivery system and find out adequate investment in research and development across the three wings. Rice management will gain efficiency and profitability through precision agriculture using high tech solutions in the fields of soil, water and pest-disease control together with deploying routine surveillance systems and designing early warning system (EWS); both surveillance and EWS will also contribute to strengthen market system for farmers and consumers. Mechanization will be extended by providing incentive and support to the farmers, and by inventing and/or adapting for scale-appropriate machineries for transplanting, harvesting and post-harvest operation.

Incentives will also encourage farmers to adopt new and smart management technologies such as one-in-all multi-nutrient essential 
Table 3. A list of key interventions to implement the proposed DRP framework.

\begin{tabular}{|c|c|c|c|c|c|c|c|c|}
\hline \multirow[b]{2}{*}{$\begin{array}{l}\text { Sl. } \\
\text { no. }\end{array}$} & \multirow[b]{2}{*}{ Key intervention } & \multicolumn{4}{|c|}{ Wing-1 } & \multirow{2}{*}{ 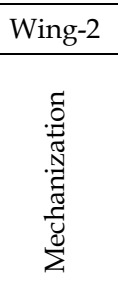 } & \multicolumn{2}{|c|}{ Wing-3 } \\
\hline & & 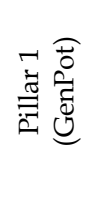 & 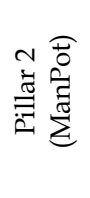 & 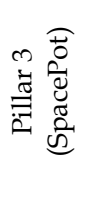 & 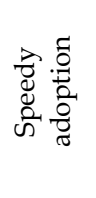 & & 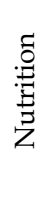 & 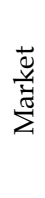 \\
\hline 1 & $\begin{array}{l}\text { Varietal development using state-of-art } \\
\text { methods and tools }\end{array}$ & & & & & & & \\
\hline 2 & $\begin{array}{l}\text { Agro-ecology / zone specific / growth } \\
\text { stage-based technology design }\end{array}$ & & & & & & & \\
\hline 3 & Synthesized research delivery system & & & & & & & \\
\hline 4 & Irrigation infrastructure development & & & & & & & \\
\hline 5 & Increase input use efficiency & & & & & & & \\
\hline 6 & $\begin{array}{l}\text { Precision agriculture using high tech so- } \\
\text { lutions }\end{array}$ & & & & & & & \\
\hline 7 & $\begin{array}{l}\text { Early warning system based } \\
\text { agro-advisory }\end{array}$ & & & & & & & \\
\hline 8 & $\begin{array}{l}\text { Buffer input stock zone for stress man- } \\
\text { agement }\end{array}$ & & & & & & & \\
\hline 9 & $\begin{array}{l}\text { Improvement of the rice-based } \\
\text { system productivity }\end{array}$ & & & & & & & \\
\hline 10 & $\begin{array}{l}\text { Farmer-based speedy seed multiplication } \\
\text { and dissemination system }\end{array}$ & & & & & & & \\
\hline 11 & $\begin{array}{l}\text { Scale-appropriate mechanization for } \\
\text { transplanting, harvesting and post-har- } \\
\text { vest operation }\end{array}$ & & & & & & & \\
\hline 12 & Use of digital technologies & & & & & & & \\
\hline 13 & $\begin{array}{l}\text { Incentive and support to farmers to } \\
\text { adopt new technologies }\end{array}$ & & & & & & & \\
\hline 14 & Monitoring and surveillance & & & & & & & \\
\hline 15 & $\begin{array}{l}\text { Public private partnership in research } \\
\text { and development }\end{array}$ & & & & & & & \\
\hline 16 & $\begin{array}{l}\text { Establishment of commission for } \\
\text { agricultural cost and price }\end{array}$ & & & & & & & \\
\hline 17 & Farm-to-market linkage & & & & & & & \\
\hline 18 & $\begin{array}{l}\text { Adequate investment in research and de- } \\
\text { velopment }\end{array}$ & & & & & & & \\
\hline 19 & Capacity development & & & & & & & \\
\hline 20 & Agro-processing and value addition & & & & & & & \\
\hline 21 & $\begin{array}{l}\text { Long-term storage facility } \\
\text { development for enhanced profit }\end{array}$ & & & & & & & \\
\hline 22 & Commercialization of rice farming & & & & & & & \\
\hline
\end{tabular}

Note: 'DRP' represents doubling rice productivity, 'GenPot' denotes for enhancing genetic potential, 'ManPot' for reducing yield loss, 'SpacePot' for exploring the unexplored spaces. Market is represented for 'fair price' in the DRP framework. The filled colour indicates the targeted interventions in the respective wings

fertilizer package for rice. To make the technologies attractive and adoptable to farmers agroecology and/or zone-specific and/or growth stage-based technology will be designed. Newer spaces for rice will be ensured by developing irrigation infrastructure, and stress will 
be managed by creating buffer input stock zone. Variety adoption will be speeded up by creating farmer-based speedy seed multiplication and dissemination system. A congenial rice market environment will be developed through the establishment of 'commission for agricultural cost and price', farm-to-market linkage, facilitating agro-processing and value addition, and commercialization of rice farming. The latter two interventions will also benefit nutritional improvement efforts. This paper also proposes activities to improve rice-system productivity in Bangladesh.

\section{CONCLUSION}

Potentially, rice production in Bangladesh can be increased to $46.90,54.09$ and 60.85 MT by the year 2030, 2040 and 2050, respectively, from the 2015 baseline of 35.29 MT through the combined successful contribution of three pillars of DRP framework - yield improvements by enhanced genetic potential (Pillar 1, GenPot), reduction in existing yield loss (Pillar 2, ManPot) and production increase by exploring unexplored spaces for rice (Pillar 3, SpacePot). Pillar 1 and 2 will enhance production by increasing productivity, while Pillar 3 will add extra rice to the production by expanding area. The country will be a $6.50 \mathrm{MT}, 10.29 \mathrm{MT}$ and 13.65 MT surplus in rice production, respectively, in 2030, 2040 and 2050 if we could implement the DRP framework successfully. Besides, labour productivity will double by 2029, meeting the SDG goal, through scale-appropriate mechanization backed up by estimated fair price. By realizing research and extension initiated needful 'diffusion intensity', i.e., the area coverage of the concerned variety at the end of three-year diffusion period, will curtail the 'length of adoption peak' of rice varieties resulting speedy achievement in production target. To achieve the rice production targets, efficiency, resilience and sustainability around the three pillars of DRP framework to be ensured. Thus, policy supports are needed for ensuring implementation of highlighted nine points: (i) strengthening demand-driven research on variety development for constraint environments, and nutrition enrichment, (ii) developing and disseminating field-adoptable management across the 17 rice growth stages, (iii) increasing mechanization on transplanting and harvesting operations, (iv) designing special extension approach for successful intensifying rice cropping in the five unexplored spaces, (v) implementing farmerbased intensive speedy seed multiplication and dissemination system, (vi) establishing input buffer stock terminals to mitigate externalities, (vii) establishing commission for agricultural costs and prices, (viii) exploring options for accommodating surplus production such as longterm storage and exporting, (ix) publicizing and market development for rice-based products through public-private partnership.

\section{ACKNOWLEDGEMENTS}

We acknowledge a number of scientists of the Bangladesh Rice Research Institute (BRRI) for participating discussion at various stages of preparation of the manuscript. The authors are especially grateful to Dr Humnath Bhandari, the Country Representative of the International Rice Research Institute (IRRI), Bangladesh, for his intensive review and constructive suggestions on improvement of the manuscript.

\section{AUTHORS' CONTRIBUTIONS}

MSK, MUS, MARS, and MAAM generated idea; MSK and AKMSI coordinated the project; MUS, MARS, and MAAM developed methodology; MSK, MUS, MARS, and MAAM provided scientific insights; MUS, MARS, MAAM, MCR, MBH, HBS, AC, MN, KMI, MSH, MKAB, BK, MSR, MMH, MTK, MPA, SMHAR, PLB, ESMHR, and NMFR gathered data; MUS, MARS, MAAM, and MCR carried out analysis and synthesis; MUS, MARS, MAAM, and MCR 
did the writings for all versions of the manuscript; MSK, BN, MJK, MSR, MPA, and SMHAR performed critical review and editing; All authors read and approved the final manuscript.

\section{DECLARATION OF INTERESTS}

A version of the paper was published in a book "Doubling Rice Productivity in Bangladesh" in 2020 by the Bangladesh Rice Research Institute (BRRI), Gazipur 1701, Bangladesh to commemorate BRRI's 50 th anniversary. The Bangladesh Rice Journal has prior knowledge of the book publication and does not see any conflict of interest.

\section{REFERENCES}

Abrecht, D, H Cox, M D'Antuono and J Fisher. 2008. How important is season specific or soil specific wheat agronomy in southern Australia? In: Dr Murray Unkovich (Ed.), 14 $4^{\text {th }}$ Australian Agronomy Conference, 21 September 2008. Adelaide, South Australia: Australian Society of Agronomy.

Adelman, I. 1984. Beyond export-led growth. World Development, 12(9): 937-949.

Ahmmed, S. 2017. Country Paper: Bangladesh. $5^{\text {th }}$ Regional Forum on Sustainable Agricultural Mechanization in Asia and the Pacific 12-14 December 2017, Kathmandu, Nepal.

Alam, M J, S Kaneko and M M Rahman. 2015. The decreasing trend of agricultural land in Bangladesh: Myth and Facts. The Jahangirnagar Economic Review, 26: 8596.

Alam, M M. 2019. Study to find out extent and constraints of use of farm machineries developed by national institutes of Bangladesh to accelerate mechanization Final Report. Krishi Gobeshona Foundation (KGF), BARC Complex, Farmgate, Dhaka-1215, Bangladesh.

Ali, M P, B Nessa, M T Khatun, M U Salam and M S Kabir. 2020. A way forward to combat insect pest in rice. In: Doubling rice productivity in Bangladesh, MS Kabir, M U Salam, A K M S Islam, M A R Sarkar and M A A Mamun (Eds.). Bangladesh Rice Research Institute, Gazipur-1701, Bangladesh, 259-292.

Ali, M P, M M M Kabir, S S Haque, X Qin, S Nasrin, D Landis, B Holmquist and N Ahmed. 2020. Farmer's behavior in pesticide use: Insights study from smallholder and intensive agricultural farms in Bangladesh. Science of the Total Environment, 141160.
Ali, M P, M N Bari, S S Haque, M M M Kabir, S Afrin, F Nowrin, M S Islam and D A Landis. 2019. Establishing next-generation pest control services in rice fields: Eco-agriculture. Scientific Reports, 9(1): 1-9.

Allen, R G, L S Pereira, D Raes and M Smith. 1998. Crop evapotranspiration-Guidelines for computing crop water requirements. FAO Irrigation and drainage paper 56, FAO, Rome, 300(9): D05109.

Anderson, W K, M A Hamza, D L Sharma, M F D Antuono, F C Hoyle, N Hill, B J Shackley, M Amjad and C Zaicou-Kunesch. 2005. The role of management in yield improvement of the wheat crop - a review with special emphasis on Western Australia. Australian Journal of Agricultural Research, 56: 1137-1149.

AOAC (Association of Official Agricultural Chemists). 1995. Official procedure of mineral estimations (Zn, $\mathrm{Fe}$ and $\mathrm{Ca}$,) of association of official agricultural chemists.

Banerjee, A, N Dasgupta and B De. 2005. In vitro study of antioxidant activity of Syzygium cumini fruit. Food Chemistry, 90: 727-733.

Bari, M N, M F Rabbi, M Hasan and M P Ali. 2012. Assessment of yield losses of some modern rice varieties due to rice hispa infestation in different rice seasons of Bangladesh. Bangladesh Journal of Entomology, 22 (1): 47-59.

BBS (Bangladesh Bureau of Statistics). 2018. 45 years agriculture statistics of major crops (Aus, Aman, Boro, Jute, Potato and Wheat). Bangladesh Bureau of Statistics (BBS), Statistics and Informatics Division, Ministry of Planning, Government of the People's Republic of Bangladesh, Dhaka, Bangladesh.

BBS (Bangladesh Bureau of Statistics). 2020. Yearbook of Agricultural Statistics-2019. Bangladesh Bureau of Statistics (BBS), Statistics and Informatics Division, Ministry of Planning, Government of the People's Republic of Bangladesh, Dhaka, Bangladesh.

BER (Bangladesh Economic Review). 2019. Bangladesh Economic Review. Finance Division, Ministry of Finance, Government of the People's Republic of Bangladesh, Dhaka, Bangladesh.

Bhuiyan, M K A, A K M S Islam, M A R Sarkar, M A A Mamun, M U Salam and M S Kabir. 2020a. Agronomic management and interventions to increase rice yield in Bangladesh. Bangladesh Rice Journal, 24(2): 135-156.

Bhuiyan, M K A, M U Salam and M S Kabir. 2020b. Integrated weed management strategies for sustainable rice production in Bangladesh. Bangladesh Rice Journal, 24(2): 157-183.

Bhuiyan, M K A, S S Kakon, A A Begum, S K Paul, R R Saha, M A K Mian, M M Islam and M S Hossain. 2018. Weed management in Bangladesh: Present status and future needs. In $6^{\text {th }}$ conference of weed science society 
of Bangladesh. 12 May, Bangladesh Rice Research Institute, Gazipur.

Bhuiyan, M K A. 2016. Effect of resource conservation technologies and weed management on nutrient use efficiency, growth and yield of rice. Unpublished $\mathrm{PhD}$ thesis, Department of Agronomy, Bangladesh Agricultural University, Mymensingh-2202, Bangladesh.

Brolley, M. 2015. Rice security is food security for much of the world. Rice Today. International Rice Research Institute (IRRI), DAPO Box 7777, Metro Manila, Philippines. PP. 30-32.

BRRI (Bangladesh Rice Research Institute). 2019. Technological interventions for improving water use efficiency in the northwest region of Bangladesh. Annual report of Bangladesh Rice Research Institute 2018-19, Bangladesh Rice Research Institute (BRRI), Gazipur1701, Bangladesh.

Chen, Y and C Lu. 2018. A comparative analysis on food security in Bangladesh, India and Myanmar. Sustainability, 10(2): 405. DOI: 10.3390/su10020405.

Clapp, J. 2017. Food self-sufficiency: Making sense of it, and when it makes sense. Food Policy, 66: 88-96.

Conway, G R. 1987. The properties of agroecosystems. Agricultural Systems, 24: 95-117.

Custodio, M C, R P Cuevas, J Ynion, A G Laborte, M L Velasco and M Demont. 2019. Rice quality: How is it defined by consumers, industry, food scientists, and geneticists? Trends in Food Science and Technology, 92: 122-137.

DAE (Department of Agricultural Extension). 2020. Weekly crop production report. Department of Agricultural Extension, Ministry of Agriculture, Government of the People's Republic of Bangladesh, Dhaka, Bangladesh.

Gali, J, C Tate and M O'Sullivan. 2000. Structural Analysis of Agriculture: A Methodological Perspective. Report no. 411-2016-25726.

Gunawan, S, S R Vali and Y Ju. 2006. Purification and identification of rice bran oil fatty acid steryl and wax esters. JAOCS, 83(5).

Haffner, S M, M P Stern, H P Hazuda, J A Pugh and J K Patterson. 1986. Hyperinsulinemia in a population at high risk for non-insulin dependent diabetes mellitus. The New England Journal of Medicine, 315: 220-224.

Haque, M M, J C Biswas, M R Islam, A Islam and MS Kabir. 2019. Effect of long-term chemical and organic fertilization on rice productivity, nutrient use-efficiency, and balance under a rice-fallow-rice system. Journal of Plant Nutrition, 42(20): 2901-2914.

Haque, M M, M R Islam, M S Rahman, M A R Sarkar, M A A Mamun, M U Salam and M S Kabir. 2020. Soil health as influenced by fertilizer management in rice based cropping system. Bangladesh Rice Journal, 24(2): 121-134.
Hasan, M N, M S Hossain, M R Islam, M A Bari, D Karim and M Z Rahman. 2013. Trends in the availability of agricultural land in Bangladesh. Soil Resource Development Institute (SRDI), Ministry of Agriculture, Bangladesh, Dhaka.

Holt, C E. 1957. Forecasting seasonal and trends by exponentially weighted averages (O.N.R. Memorandum no. 52). Carnegie Institute of Technology, Pittsburgh USA. https://doi.org/10.1016/j.ijforecast.2003.09. 015

Hossain, M B, M Maniruzzaman, A K MS Islam, M U Salam and M S Kabir. 2020. Management and utilization strategy of water resources for rice production. In: Doubling rice productivity in Bangladesh, MS Kabir, M U Salam, A K M S Islam, M A R Sarkar and M A A Mamun (Eds.). Bangladesh Rice Research Institute, Gazipur-1701, Bangladesh, 317-342.

ILO (International Labour Organization). 2020. ILOSTAT database [Population and labour force]. Available from https://ilostat.ilo.org/data/.

Islam, A K M S. 2020. Mechanized cultivation increases labour efficiency. Bangladesh Rice Journal, 24(2): 49-68.

Islam, M A and S Fukui. 2018. The influence of share tenancy contracts on the cost efficiency of rice production during the Bangladeshi wet season. Economics Bulletin, 38(4): 2431-2443.

Islam, M A. 2017. An economic study on the efficiency and welfare impact of modern rice production in Bangladesh. PhD Dissertation, Graduate of School of Agriculture, Kyoto University, Japan. DOI: 10.14989/ doctor.k20716.

Islam, A K M S. 2018. Status of rice farming mechanization in Bangladesh. Journal of Bioscience and Agriculture Research, 17(01): 1386-1395.

Kabir, M J, M A R Sarkar, M C Rahman, N M F Rahman, M A A Mamun, A Chowdhury, M U Salam and MS Kabir. 2020. Risk of rice cultivation under current and future environment and market. In: Doubling rice productivity in Bangladesh, MS Kabir, M U Salam, A K MS Islam, M A R Sarkar and M A A Mamun (Eds.). Bangladesh Rice Research Institute, Gazipur-1701, Bangladesh, 419-434.

Kabir, M S, M U Salam, A Chowdhury, N M F Rahman, K M Iftekharuddaula, M S Rahman, M H Rashid, S S Dipti, A Islam, M A Latif and A S Islam. 2015. Rice vision for Bangladesh: 2050 and beyond. Bangladesh Rice Journal, 19(2): 1-18.

Khan, M U and T Rehman. 2019. Early trends, current status and future prospects of farm mechanization in Asia. Agricultural Engineering International: CIGR Journal, 21(3): 76-87.

Khatun, M T, B Nessa, M U Salam and M S Kabir. 2020. Strategy for rice disease management in Bangladesh. In: Doubling rice productivity in Bangladesh, MS Kabir, M U Salam, A K M S Islam, M A R Sarkar and M 
A A Mamun (Eds.). Bangladesh Rice Research Institute, Gazipur-1701, Bangladesh, 293-316.

Lynam, J K and R W Herdt. 1989. Sense and sustainability: Sustainability as an objective in international agricultural research. Agricultural Economics, 3: 381-398.

Ma and Zuazaga. 1942. Micro-Kjeldahl Determination of Nitrogen. A New Indicator and An Improved Rapid Method. Industrial and Engineering Chemistry Analytical Edition, 14(3): 280-282.

Maniruzzaman, M, J C Biswas, M B Hossain, M M Haque, U A Naher and N Kalra. 2018. Extreme temperature events and rice production in Bangladesh. Environment and Natural Resources Research, 8(4): 62-74.

Miah, M A M, M A R Sarkar, M S Islam, M J Alam, M H A Rashid, D Boyd, R W Bell, M E Haque, M A Satter, M W Rahman, H Jahan and J Hutchinson. 2019. Assessment of gaps in current fertilizer use by farmers and scientific recommendations in selected areas of Bangladesh: A Baseline Study. Krishi Gobeshona Foundation, BARC, Farmgate, Dhaka.

Miah, M D, R Hasan and H Uddin. 2020. Agricultural development and the rural economy: The case of Bangladesh. In: Bangladesh's Economic and Social Progress, M Barai (Eds.). Palgrave Macmillan, Singapore. https://doi.org/10.1007/978-981-15-1683-2_8.

MOA (Ministry of Agriculture). 2016. Agricultural mechanization road map 2021, 2031, 2041. Ministry of Agriculture, Government of the People's Republic of Bangladesh, Dhaka, Bangladesh.

Mottaleb, K A and T J Krupnik. 2015. Uptake of scale-appropriate agricultural machinery in Bangladesh: Policy insights from historical and census survey analyses. Cereal Systems initiative for South Asia Mechanization and Irrigation (CSISA-MI) project, Dhaka, Bangladesh: CIMMYT.

Nasrin, M and M T Uddin. 2011. Land tenure system and agricultural productivity in a selected area of Bangladesh. Progressive Agriculture, 22(1-2): 181-192.

Oktay, M, I Culcin and O I Kufrevioglu. 2003. Determination of in vitro antioxidant activity of fennel (Foeniculum vulgare) seed extracts. LWT - Food Science and Technology, 36: 263-271.

Psyrogiannis, A, V Kyriazopoulou, A Symeonidis, M Leotsinidis and A G Vagenakis. 2003. Relative iron 'overload' in offspring of patients with type 2 diabetes mellitus: a new component in the conundrum of insulin resistance syndrome. Hormones, 2(3): 161-168.

PwC (PricewaterhouseCoopers). 2017. The World in 2050 The long view: How will the global economic order change by 2050? February 2017. https://www.pwc.c om/gx/en/world-2050/assets/pwc-world-in-2050summary-report-feb-2017.pdf (Accessed on 09 August 2020).
Qiu, Y, Q Liu and T Beta. 2010. Antioxidant properties of commercial wild rice and analysis of soluble and insoluble phenolic acids. Food Chemistry, 121: 140-147.

Rabbi, S M H A, P L Biswas, E S M H Rashid, N M F Rahman, K M Iftekharuddaula, M S Rahman, M A R Sarkar, M A A Mamun, M U Salam and M S Kabir. 2020. Increasing rice yield through targeting genetic potentials by rice types. Bangladesh Rice Journal, 24(2): 69-84.

Rahman, M S, M M Haque, M J Kabir, A K M S Islam, M A R Sarkar, M A A Mamun, M U Salam and MS Kabir. 2020. Enhancing rice productivity in the unfavorable ecosystems of Bangladesh. Bangladesh Rice Journal, 24(2): 85-104.

Ran, Y, H Chen, D Ruan, H Liu, S Wang, X Tang and W Wu. 2018. Identification of factors affecting rice yield gap in southwest China: An experimental study. PloS One, 13(11): e0206479. DOI: https://doi.org/10.13 71/journal.pone.0206479.

Salam, M U, R K Khangura, A J Diggle and M J Barbetti. 2003. Blackleg Sporacle: A model for predicting onset of pseudothecia maturity and seasonal ascospore showers in relation to blackleg of canola. Phytopathology, 93(9): 1073-1081.

Salam, M U, M A Kader, M A J Mridha, A K M R Amin, N A Khandaker, A K Das, M H Rashid and M S Kabir. 2016. Agronomic vision and roadmap for Bangladesh Agriculture through to 2050 . In proceedings of $15^{\text {th }}$ conference of Bangladesh Society of Agronomy, Bangladesh Agricultural University, Mymensingh.

Salam, M U, B K Mahalder, H Bhandari, M S Kabir, M A R Sarkar, B Nessa and M A Ali. 2019a. Policy directions toward increasing rice productivity - Lessons from Bangladesh. In: Advances in Rice Research for Abiotic Stress Tolerance. Elsevier Inc. Pages 895-913. DOI: https://doi.org/10.1016/B978-0-12-814332-2.0 0044-7.

Salam, M U, T J Krupnik, C Montes, B Nessa, M T Khatun, M P Ali, S Shahrin, S Ishtiaque, M A Mannan, S M Q Hassan, M Aziz and M S Uddin. 2019b. Potential impact of climate change on crop insect pests and diseases in Bangladesh: Future scenarios and strategies for climate services. In: Climate change and Bangladesh Agriculture: Adaptation and mitigation strategies. Krishi Gobeshona Foundation, Dhaka, Bangladesh, 105-134.

Sen, P K. 1968. Estimates of the regression coefficient based on Kendall's tau. Journal of the American Statistical Association, 63(324): 1379-1389.

Shahjahan, A K M. 1994. Practical approaches to rice blast disease management in tropical monsoon ecosystems, with special reference to Bangladesh, Rice blast disease. CAB International, Wallingford. UK, 465488 . 
Shozib, H B, M A Siddiquee, N M F Rahman, M A A Mamun, M A R Sarkar, S M H A Rabbi, M U Salam and MS Kabir. 2020. Grain quality research of rice for ensuring nutritional food security. Bangladesh Rice Journal, 24(2): 105-120.

Shozib, H B, S A S Mahmud and M A Siddiquee. 2018a. Energy dense rice biscuit formulation to improve malnutrition status of urban street children in Bangladesh. Journal of Food Nutrition and Health, 1(1): 16-19.

Shozib, H B, S A S Mahmud, R B Amin, M N Hossain, J K Biswas, J Timsina, M A Ali and M A Siddiquee. 2018b. Nutraceutically enriched rice-based food to mitigate malnutrition in Bangladesh. EC Nutrition, 13(5): 24049.

Siddiquee, M A, S Jahan, Y Kabir and H B Shozib. 2017. BRRI dhan31 generate elevated level of bioactive component, $\gamma$-aminobutyric acid (GABA) at pre-germinated brown rice condition. International Journal of Scientific Research (IJSR), 6 (7): 511-513.

Singh, R B, T Woodhead and M K Papademetriou. 2002. Strategies to sustain and enhance Asia-Pacific rice production. Proceedings of the $20^{\text {th }}$ session of the International Rice Commission, Bangkok, Thailand.

Singh, S, R S Singh and S P Singh. 2014. Farm power availability on Indian farms. Agricultural Engineering Today, 38(4): 44-52.

Srisaipet, A, S Daungnate and J Nukua. 2013. The adsorption coefficient $(\mathrm{k})$ for determination of total lipid and gamma oryzanol content in rice bran varieties from the northern of Thailand. Journal of Medical and Bioengineering, 2(3).

Tang, G, Q Jian, G G Dolnikowski, R M Russell and M A Grusak. 2009. Golden rice is an effective source of vitamin A. The American Journal of Clinical Nutrition, 89: 1776-1783.

The Daily Prothom Alo. 2015. Jomi komleo chal utpadon bereche tin goon (Rice production has increased by three times in spite of decreased land). http://prothom-alo.com/bangladesh/article/658390.

Turkmen, N, Y S Velioglu, F Sari and G Polat. 2007. Effect of extraction conditions on measured total polyphenol contents and antioxidant and antibacterial activities of black tea. Molecules, 12: 484-496.

Van Loon, J, L Woltering, T J Krupnik, F Baudron, M Boa and B Govaerts. 2020. Scaling agricultural mechanization services in smallholder farming systems: Case studies from sub-Saharan Africa, South Asia, and Latin America. Agricultural Systems, 180: 102792.

WB (World Bank). 2007. World development report 2008: Agriculture for development. World Bank publication, Washington, DC. Available at: http://hdl.handle.net/10986/5990 (accessed on January 07, 2021).

WB (World Bank). 2013. Turn down the heat: Climate extremes, regional impacts, and the case for resilience. Postdam Institute for Climate Impacts Research and
Climate Analysis, World Bank, Washington, DC, USA.

Winters, P R. 1960. Forecasting sales by exponentially weighted moving averages. Management Science, 6: 324-342. https:/ / doi.org/10.1287/mnsc.6.3.324

Yoshida, S D, D A Forno, J Cock and K Gomez. 1976. Laboratory Manual for Physiological Studies of Rice. International Rice Research Institute (IRRI), Philippines, 17-18. 
Appendix 1. Estimated area, production and yield targets of rice in Bangladesh by rice growing season during 2020 to 2050.

\begin{tabular}{|c|c|c|c|c|c|c|c|c|c|c|c|}
\hline \multirow{2}{*}{ Year } & \multicolumn{4}{|c|}{ Area (M ha) } & \multicolumn{4}{|c|}{ Production (MT) } & \multicolumn{3}{|c|}{ Yield $\left(\mathrm{t} \mathrm{ha}^{-1}\right)$} \\
\hline & Aus & $\operatorname{man}$ & Boro & Total & Aus & Aman & Boro & Total & us & $\operatorname{man}$ & Boro \\
\hline 2020 & $1.25-1.30$ & $.85-5.90$ & $70-4.75$ & $.80-11.95$ & $26-3.39$ & $1.94-15.07$ & $19.65-19.86$ & $7.85-38.31$ & 2.60 & 2.55 & 4.18 \\
\hline 2021 & $7-1.32$ & $85-5.90$ & $1-4.76$ & $82-11.98$ & $0-3.53$ & $5.10-15.24$ & $19.86-20.07$ & $8.36-38.84$ & 2.68 & 2.58 & 4.22 \\
\hline 2022 & $1.29-1.34$ & $84-5.90$ & $1-4.76$ & $.84-12.00$ & $55-3.68$ & $.25-15.41$ & $0.07-20.28$ & $8.87-39.37$ & 2.75 & 2.61 & 4.26 \\
\hline 2023 & $1.31-1.36$ & $5.84-5.90$ & $4.72-4.77$ & $1.86-12.03$ & $3.69-3.84$ & $15.41-15.58$ & $20.28-20.49$ & $39.38-39.91$ & 2.82 & .64 & 4.30 \\
\hline 2024 & $3-1.38$ & $83-5.90$ & $2-4.77$ & $.88-12.05$ & $85-3.99$ & $.56-15.75$ & $20.49-20.71$ & $9.90-40.45$ & 2.89 & .67 & 4.34 \\
\hline 2025 & $5-1.40$ & $5.83-5.90$ & $3-4.78$ & $90-12.08$ & $00-4.15$ & $15.72-15.92$ & $20.70-20.92$ & $40.42-40.99$ & 2.96 & 2.70 & 4.38 \\
\hline 2026 & $1.37-1.42$ & $5.82-5.90$ & $4.73-4.78$ & $.92-12.10$ & $4.16-4.31$ & $15.87-16.09$ & $20.91-21.13$ & $40.94-41.53$ & 3.04 & 2.73 & 4.42 \\
\hline 2027 & $39-1.44$ & $5.82-5.90$ & $.74-4.79$ & $.94-12.13$ & $.32-4.48$ & $16.02-16.26$ & $21.12-21.34$ & $41.47-42.08$ & 3.11 & 2.76 & 4.46 \\
\hline 2028 & $1.41-1.46$ & $5.81-5.90$ & $74-4.79$ & $1.96-12.15$ & $4.48-4.64$ & $16.18-16.43$ & $21.33-21.56$ & $42.00-42.63$ & 3.18 & 2.78 & 4.50 \\
\hline 2029 & $1.43-$ & $5.81-5.90$ & $4.75-4.80$ & 1108 & $4.65-4.81$ & $.33-16.60$ & 21.77 & 42 53-4 & 3.25 & 2.81 & 4.54 \\
\hline 2030 & $1.45-1.50$ & $5.80-5.90$ & $4.75-4.80$ & $2.00-12.20$ & $4.82-4.99$ & $16.48-16.77$ & $21.76-21.99$ & $43.06-43.74$ & 3.32 & 2.84 & 4.58 \\
\hline 2031 & $1.45-1.51$ & $5.80-5.90$ & $4.74-4.80$ & $11.99-12.21$ & $4.94-5.13$ & $16.64-16.94$ & $21.88-22.16$ & $43.46-44.22$ & 3.40 & 2.87 & 4.62 \\
\hline 2032 & & 0 & & & & & & & 47 & & 4.66 \\
\hline 2033 & $1.46-1.53$ & $5.79-5.91$ & $4.71-4.79$ & $11.96-12.22$ & $5.18-5.41$ & $16.94-17.29$ & $22.12-22.49$ & $44.24-45.19$ & 3.54 & 2.93 & 4.70 \\
\hline 2034 & $1.47-1.54$ & $5.78-5.91$ & $4.69-4.78$ & $11.94-12.22$ & $5.30-5.55$ & $17.10-17.47$ & $22.23-22.66$ & $44.63-45.68$ & 3.61 & 2.96 & 4.74 \\
\hline 2035 & 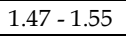 & -5.91 & & & & 64 & 22.83 & $\begin{array}{ll}70.00 \\
\end{array}$ & 68 & & 78 \\
\hline 2036 & $1.48-1.55$ & $5.77-5.91$ & $4.66-4.77$ & $11.91-12.24$ & $5.55-5.84$ & $17.40-17.82$ & $22.46-22.99$ & $45.42-46.65$ & 3.76 & 3.01 & 4.82 \\
\hline 2037 & $1.48-1.56$ & $5.77-5.91$ & $4.65-4.77$ & $11.90-12.24$ & $5.67-5.99$ & $17.56-18.00$ & $22.58-23.16$ & $45.80-47.14$ & 3.83 & 3.04 & 4.86 \\
\hline 2038 & $1.49-1.57$ & $5.76-5.91$ & $4.63-4.76$ & $11.88-12.25$ & $5.80-6.13$ & $17.71-18.17$ & $22.69-23.32$ & $46.19-47.63$ & 3.90 & 3.07 & 4.90 \\
\hline 2039 & $1.49-1.58$ & $5.76-5.92$ & $4.62-4.76$ & $11.87-12.25$ & $5.92-6.28$ & $17.86-18.35$ & $22.80-23.49$ & $46.58-48.12$ & 3.97 & 3.10 & 4.94 \\
\hline 2040 & $1.50-1.60$ & $5.75-5.92$ & $4.60-4.75$ & $11.85-12.27$ & $6.07-6.47$ & $18.00-18.53$ & $22.91-23.65$ & $46.97-48.66$ & 4.04 & 3.13 & 4.98 \\
\hline 2041 & $1.51-1.61$ & $5.68-5.92$ & $4.56-4.75$ & $11.75-12.28$ & $6.21-6.62$ & $17.95-18.71$ & $22.88-23.82$ & $47.04-49.15$ & 4.12 & 3.16 & 5.02 \\
\hline 2042 & $1.52-1.62$ & $5.61-5.93$ & $4.52-4.74$ & $65-12.28$ & $6.36-6.78$ & $17.89-18.89$ & $22.85-23.98$ & $47.10-49.65$ & 4.19 & 3.19 & 5.06 \\
\hline 2043 & $1.53-1.63$ & $5.55-5.93$ & $4.47-4.74$ & $11.55-12.29$ & $6.51-6.93$ & $17.84-19.07$ & $22.82-24.15$ & $47.16-50.15$ & 4.26 & 3.22 & 5.10 \\
\hline 2044 & $1.54-1.64$ & $5.48-5.93$ & $4.43-4.73$ & $11.45-12.30$ & $6.66-7.09$ & $17.78-19.25$ & $22.78-24.31$ & $47.21-50.65$ & 4.33 & 3.25 & 5.14 \\
\hline 2045 & $1.55-1.65$ & $5.41-5.93$ & $4.39-4.73$ & $11.34-12.30$ & $6.81-7.25$ & $17.71-19.43$ & $22.74-24.47$ & $47.26-51.15$ & 4.40 & 3.27 & 5.18 \\
\hline 2046 & $1.55-1.65$ & $5.34-5.94$ & $4.35-4.72$ & $11.24-12.31$ & $6.96-7.41$ & $17.64-19.61$ & $22.69-24.64$ & $47.29-51.65$ & 4.48 & 3.30 & 5.22 \\
\hline 2047 & $1.56-1.66$ & $5.27-5.94$ & $4.31-4.72$ & $11.14-12.32$ & $7.11-7.57$ & $17.57-19.79$ & $22.65-24.80$ & $47.33-52.15$ & 4.55 & 3.33 & 5.26 \\
\hline 2048 & $1.57-1.67$ & $5.20-5.94$ & $4.26-4.71$ & $11.04-12.32$ & $7.27-7.73$ & $17.49-19.97$ & $22.60-24.96$ & $47.35-52.66$ & 4.62 & 3.36 & 5.30 \\
\hline 2049 & $1.58-1.68$ & $5.14-5.94$ & $4.22-4.71$ & $10.94-12.33$ & $7.42-7.89$ & $17.41-20.15$ & $22.54-25.12$ & $47.37-53.16$ & 4.69 & 3.39 & 5.34 \\
\hline 2050 & $1.60-1.70$ & $5.00-5.95$ & $4.18-4.70$ & $10.78-12.35$ & $7.62-8.10$ & $17.09-20.34$ & $22.49-25.28$ & $47.20-53.72$ & 4.76 & 3.42 & 5.38 \\
\hline
\end{tabular}


48 Kabir et al. 